Portland State University

PDXScholar

$1-1-2010$

\title{
Exploring School Engagement as a Protective Factor for Youth At Risk of Joining Gangs
}

Lorraine M. Escribano

Portland State University

Follow this and additional works at: https://pdxscholar.library.pdx.edu/open_access_etds Let us know how access to this document benefits you.

\section{Recommended Citation}

Escribano, Lorraine M., "Exploring School Engagement as a Protective Factor for Youth At Risk of Joining Gangs" (2010). Dissertations and Theses. Paper 441.

https://doi.org/10.15760/etd.441

This Dissertation is brought to you for free and open access. It has been accepted for inclusion in Dissertations and Theses by an authorized administrator of PDXScholar. Please contact us if we can make this document more accessible: pdxscholar@pdx.edu. 
Exploring School Engagement as a Protective Factor for Youth At Risk of Joining Gangs

by

Lorraine M. Escribano

A dissertation submitted in partial fulfillment of the requirements for the degree of

Doctor of Philosophy

in

Applied Psychology

\author{
Dissertation Committee: \\ Ellen Skinner, Chair \\ Thomas Kindermann \\ Robert Roeser \\ Dae Kim \\ Dilafruz Williams
}

Portland State University

(C)2010 
ABSTRACT

Research on gangs has traditionally focused on identifying the risk factors associated with youth gang membership in multiple developmental domains with limited attention on examining the protective factors that may buffer youth from joining gangs (Howell \& Egley, 2005). Educational and psychological research have found robust evidence that school engagement protects youth from a host of risky activities and negative outcomes (e.g., substance use, dropping out of school) and may hold promise in also protecting youth from gang involvement. Therefore, the purpose of the present study is three-fold: (1) to identify students who are at risk for gangs; (2) to investigate whether school engagement can be a protective factor for youth at risk for joining gangs; and (3) to examine whether a well-supported model of motivational development can account for the dynamics that may facilitate or undermine school engagement as a protective factor for gang involvement.

Data $(N=342)$ from an ethnically/racially diverse and socio-economic homogeneous sample were analyzed. Students reported on their levels of (1) engagement versus disaffection from school activities, (2) belongingness, competence, and autonomy, (3) school climate and teacher support, and (4) attraction to and participation in diverse extracurricular activities. In addition, an innovative method for measuring student attraction to gangs was tested.

Preliminary evidence indicated that Gang Attraction Profile was a distinct student profile that was structurally different and not redundant with traditional methods of self-reported gang membership. The Gang Attraction profile was sensitive in 
distinguishing youth of differing levels of gang attraction and gang involvement. Results also indicated that school environments that are experienced as supportive and caring promoted student engagement and achievement. Evidence was found that belongingness to the school played an important role in buffering youth from being attracted to and involved in gangs. Specifically, a student's self-perception of belongingness was related to higher levels of school engagement and teacher support, and lower levels of gang attraction and gang involvement. These results not only highlighted the importance of school belongingness in buffering youth from negative outcomes such as gang involvement and gang attraction, but also revealed a different motivational process that may lead to gang involvement than previously expected. Implications for the design of prevention and intervention programs are discussed as well as directions for future research. 


\section{ACKNOWLEDGEMENTS}

I would like to thank Drs. Thomas Kindermann, Robert Roeser, Dae Kim, and Dilafruz Williams for all their support and feedback throughout this project. I would also like to offer my gratitude and profound appreciation to my mentor and dissertation chair, Dr. Ellen Skinner, for her enthusiastic support, guidance, and patience throughout my graduate career and dissertation project.

In terms of the research project, I would like to thank Lane Middle School, the Learning Gardens Laboratory and, more specifically, the principal, vice principle, teachers, and students for their generous participation and for opening their doors to our research team. In addition, I would like to express my gratitude to my research colleagues and lab friends who have made this journey so fun and enjoyable throughout these years. Thank you, Una, Jen, Mika, and Cynthia for being there in all the road blocks and good times!

On a personal level, I would like to thank my good friend, Gemuchi, who has been there from the very beginning offering her outrageous humor, support, and feedback in my most challenging times. And, lastly, I would like to thank my husband, Ben, who has been my rock since the day I've met him. 


\section{TABLE OF CONTENTS}

\section{$\underline{\text { CHAPTERS }}$}

Abstract...................................................................

Acknowledgements...........................................................

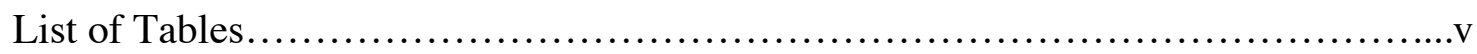

List of Figures......................................................... viii

1. Introduction. .........................................................

2. A Review of the Literature............................................5

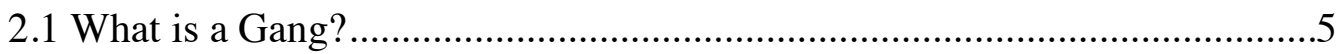

2.2 Overview of Developmental Theories of Gang Membership............... 7

2.3 A Framework for Understanding the Attraction and Motivation of Youth to Join a Gang ..................................................20

2.4 School Engagement as a Protective Factor for Gang Membership..........28

2.5 Self-System Model of Motivational Development........................35

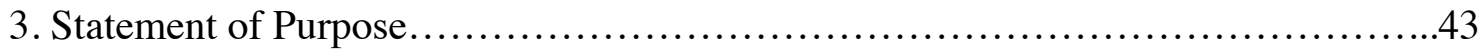

3.1. Research Questions and Hypotheses...............................44

4. Research Design and Methods.............................................53

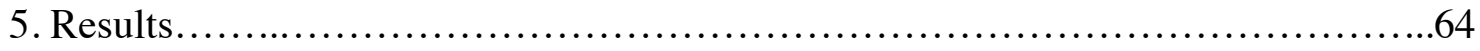

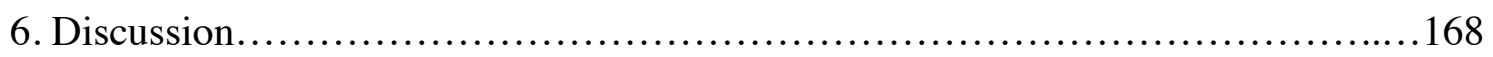

6.1 Strengths and Limitations..........................................184

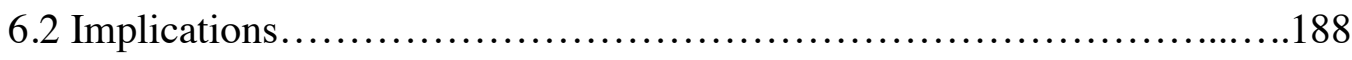

References............................................................202 
List of Tables

Table 2.1 Synthesis of Risk Factors for Gang Membership........................10

Table 2.2 Additional Risk Factors for Gang Membership...........................18

Table 4.1 Index of Items by Study Constructs.................................62

Table 5.1 Summary of Means, Standard Deviations, and Internal Consistencies for each

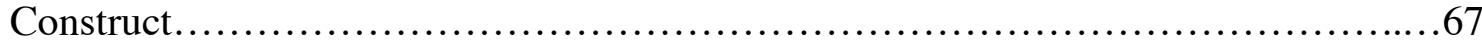

Table 5.2 Intra-Construct Correlations among Indicators of School Support............69

Table 5.3 Intra-Construct Correlations among the Self System Processes..............69

Table 5.4 Correlation between Engagement and Disaffection.....................69

Table 5.5 Group Classification for Levels of Gang Involvement by Gender...........71

Table 5.6 Group Classification for Levels of Gang Involvement by Grade.............71

Table 5.7 Pairwise Comparison between Grades in levels of Gang Involvement.......73

Table 5.8 Group Classification for Levels of Gang Attraction by Gender..................74

Table 5.9 Group Classification for Levels of Gang Attraction by Grade...................75

Table 5.10 Pairwise Comparison between Grades in levels of Gang Attraction........76

Table 5.11 Cross Tabulation of Student Profiles of Risk................................78

Table 5.12 Cross Tabulation of Levels of Gang Involvement across Ethnicity.........79

Table 5.13 Pairwise Comparison between Latino and White ethnic groups in levels of

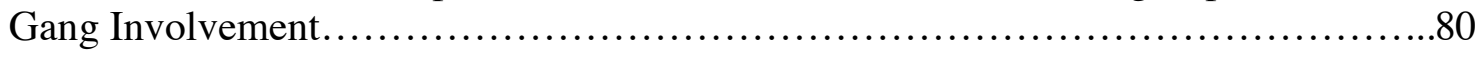

Table 5.14 Cross Tabulation of Personal Attraction to Gangs across Ethnicity.........81

Table 5.15 Pairwise Comparison between Ethnic groups in levels of Gang Attraction............................................................. 81

Table 5.16 Cross Tabulation of Levels of Gang Involvement across Immigrant Status.... 
Table 5.17 Pairwise Comparison between Immigrant versus US born students in

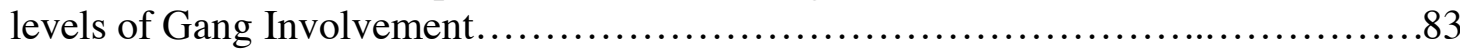

Table 5.18 Cross Tabulation of Personal Attraction to Gangs across Immigrant

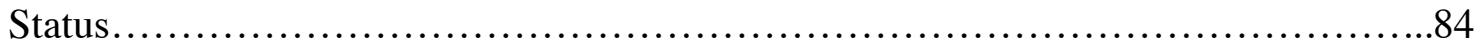

Table 5.19 Cross Tabulation of Ethnicity and Immigrant Status.....................84

Table 5.20 Cross Tabulation of Levels of Gang Involvement across English, Spanish,

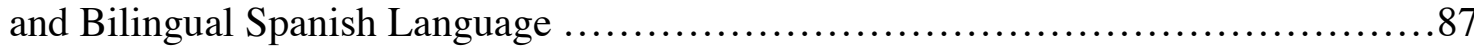

Table 5.21 Pairwise Comparison between English, Spanish, and Bilingual Spanish Language and Levels of Gang Involvement......................................88

Table 5.22 Cross Tabulation across English, Spanish, and Bilingual Spanish Language and Levels of Gang Attraction................................................. 89

Table 5.23 Pairwise Comparison across English, Spanish, and Bilingual Spanish Language and Levels of Gang Attraction..................................... 90

Table 5.24 Cross Tabulation across English, Asian, and Bilingual Asian Language Language and Levels of Gang Attraction......................................91

Table 5.25 Pairwise Comparison across English, Asian, and Bilingual Asian Language and Levels of Gang Attraction................................................

Table 5.26 Cross Tabulation of English, Russian/Ukrainian, and Bilingual Russian/Ukrainian Levels of Gang Attraction across Language....................92

Table 5.27 Cross Tabulation of Levels of Gang Involvement across English, Spanish, and Bilingual Spanish Language.

Table 5.28 Pairwise Comparison between English, Spanish, and Bilingual Spanish Language and Immigrant Status............................................ 94

Table 5.29 Cross Tabulation of Levels of Gang Involvement across English, Asian, and Bilingual Asian Language.

Table 5.30 Pairwise Comparison between English, Asian, and Bilingual Asian Language and Immigrant Status........................................... 96

Table 5.31Descriptive Statistics for Gender Differences in Study Constructs .........97

Table 5.32 Descriptive Statistics of Constructs across Grades .................................99 
Table 5.33 Correlations between Engagement, Disaffection, Gang-Involvement, Gang Attraction, and Achievement........................................100

Table 5.34 Regression Analyses for Engagement and Disaffection as Predictors of Achievement......................................................... 105

Table 5.35 Correlations between the Motivational Supports, Gang Involvement, Gang Attraction, and Achievement..............................................107

Table 5.36 Correlations between the Self-Systems, Engagement, and Disaffection...114

Table 5.37 Multiple Regression Analyses for the Self-System Processes as Predictors of Engagement and Disaffection.............................................116

Table 5.38 Correlations between School Climate, Teacher Support, Engagement, and Disaffection............................................................117

Table 5.39 Multiple Regression Analyses for the School Climate and Teacher Support

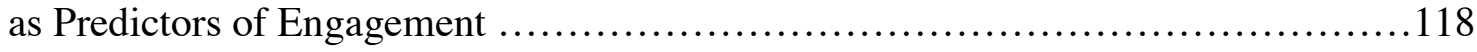

Table 5.40 Multiple Regression Analyses for the School Climate and Teacher Support as Predictors of Disaffection..............................................119

Table 5.41 Correlations between Overall School Support, Self-System Processes, Engagement, and Disaffection.............................................. 121

Table 5.42 Correlations between the Motivational Supports, Gang Involvement, Gang Attraction, and Achievement................................................132

Table 5.43 Means and Standard Deviations of Study Constructs across Levels of Gang Involvement and Gang Attraction..........................................150

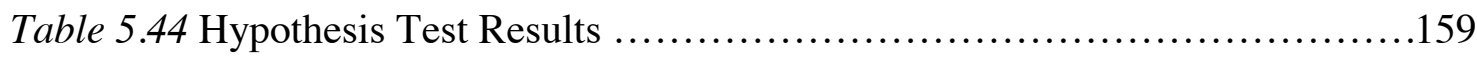

Table 6.1 Attraction to Gangs as a Pathway to Gang Involvement...................193 
List of Figures

Figure 1. Conceptualization of the microsystems in the life of a youth using the bioecological model.

Figure 2. A motivational model of gang involvement (GI) and achievement derived from the self-system model of motivational development.

Figure 3. Detail of Self-System Model Motivational Development in the School Microsystem.

Figure 4. Mediational model for overall school support as mediator between relatedness and engagement.

Figure 5. Mediational model for overall school support as mediator between competence and engagement.

Figure 6. Mediational model for autonomy as partial mediator between autonomy and engagement.

Figure 7. Mediational model for aggregate SSPs as mediator between overall school support and engagement.................................................. 126

Figure 8. Results of regression and multinomial regression analyses for GI (GI relative

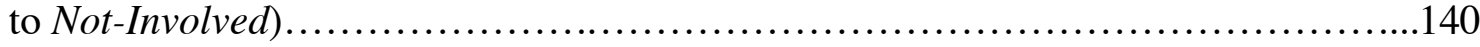

Figure 9. Results of regression and multinomial regression analyses for GI (GI relative

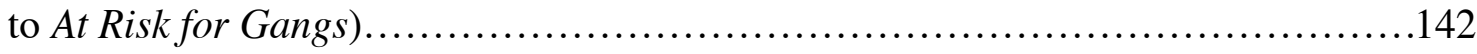

Figure 10. Results of regression and multinomial regression analyses for GA........144

Figure 11. Results of regression and multinomial regression analyses for Achievement.

Figure 12. Alternative Motivational Model for Gang Involvement for Students who are Gang-Involved relative to Not-Involved in Gangs

Figure 13. Alternative Motivational Model for Gang Involvement for Students who are Attracted to Gangs versus Not Attracted to Gangs... 


\section{CHAPTER I}

Introduction 1

\section{Introduction}

In the past 20 years, research on gangs, gang members, and gang-related problems has been substantial. Our growing understanding of the nature, causes, and consequences of gang membership (GM) has facilitated a burgeoning interest in identifying the risk factors for GM and in designing prevention and intervention programs that may potentially curb the gang problem and keep youth out of gangs. Today, we know a great deal about what increases the vulnerability of a youth to join a gang (for a review see Howell \& Egley, 2005). The accumulation of risk factors across developmental domains differentiates youth who are involved in gangs from those who are not (Hill, Howell, Hawkins, \& Battin-Pearson, 1999; Thornberry, Krohn, Lizotte, Smith, \& Tobin, 2003; Thornberry, Lizotte, Krohn, Smith, \& Porter, 2003). For example, a middle school student who lives in an impoverished high crime neighborhood while simultaneously experiencing low levels of parental and school attachment is at an increased risk of associating with antisocial peers and internalizing antisocial values, which in turn may increase their risk of joining a gang. Although this area of research is imperative in increasing our understanding of what may underlie the reasons for youth to join gangs and design prevention and intervention programs that are evidence-based, little improvement has been documented (Gottfredson \& Gottfredson, 2001) and the proliferation of gangs across cities in the United States continues to increase (Miller, 2001).

The repercussions of GM affect not only the youth who are gang-involved and their immediate families, but they are also experienced at a school-, community- and 
Introduction 2

societal-level. Among the individual-level consequences, prolonged gang-involvement seriously affects the socio-emotional development of youth and limits access to prosocial networks and conventional pursuits (Thornberry, Krohn, Lizotte, Smith, Tobin, 2003; Thornberry, Huizinga, Loeber, 2004). Gang members are dropping out of school, committing crimes, and engaging in delinquent behaviors at rates far higher than the rest of the population (Belitz \& Valdez, 1994; Vigil 1988; Alfaniarromo, 2001).

At the school-level, gangs play a significant role in increasing the threat of violence and victimization. The presence of gangs is correlated with criminal activity (e.g., drug trafficking, possession of weapons) and the use of self-protective measures by the schools (e.g., security guards, metal detectors, locker checks, etc.) that is indicative of an atmosphere of perceived danger in the school environment (Howell \& Lynch, 2000). At the community- level, the impact of gang activity can range from intimidation, vandalism, and lethal violence, to a decrease in financial investment for community development (Howell, 2006). And, finally, the costs of gangs and gangrelated crime and violence to society are enormous. It is estimated that each assaultrelated gunshot injury costs the public approximately $\$ 1$ million and a single adolescent delinquent career of about 10 years can approximately cost taxpayers between $\$ 1.7$ to \$2.3 million (Howell, 2006).

Despite the large body of research that identifies the risk factors across developmental domains for GM from longitudinal prospective empirical studies (see Howell \& Egley, 2005, for review), less is known about the protective factors that may buffer youth from joining gangs. While many gang members come from impoverished, economically and socially depressed neighborhoods, not all youth from these 
neighborhoods join or are attracted to gangs. Spergel (1992) asserts that current gang literature fails to identify the psychological differences between gang and non ganginvolved youth who come from the same social milieu (cited in Parks, 1995). Therefore, although contextual factors may place youth at risk for GM, other youth are resilient in the face of similar circumstances, and the social and personal factors which might serve to buffer such youth deserve inquiry. Hence, the purpose of the present study is to contribute to the empirical task of identifying protective factors that may make youth resilient to joining gangs. This study is a direct response to Howell and Egley's (2005) statement on the importance of such inquiry given the large body of research showing that problem behaviors are more likely to occur when the accumulation of risk factors outweigh the protective factors in major developmental domains.

In what follows, Chapter II provides an overview of the current state of the gang literature and presents the emerging theories that conceptualize gang membership using a developmental systems approach. In addition, a framework is presented that attempts to explain the underlying reasons youth may join gangs. Special attention is given to schools as contexts of preventive intervention strategies and reviews research on school engagement. Chapter III presents an overview of the study and an explanation of the study conceptual models, the research questions, and hypotheses. Chapter IV presents the research design, methodology, and measures used in the study. And, lastly, Chapter $\mathrm{V}$ and VI contain the results and the discussion sections along with the implications from the present study. 
Literature Review 4

\section{CHAPTER II}

\section{A Review of the Literature}

This chapter is organized in the following sections. The first section offers an overview on the current state of the gang literature. This overview includes (1) a brief description of the differences between a gang and a group; and (2) a review of the emerging theories that conceptualize gang membership (GM) from a developmental systems perspective. The second section proposes a conceptual framework that attempts to explain the attraction and motivation of youth to join gangs. This framework makes the argument that the unmet psychological needs for protection, support, and belongingness may set the stage for youth to join gangs, especially in high risk environments. The third section explores the school microsystem as a setting of potential prevention and intervention efforts for youth at risk for gang involvement and reviews literature on school engagement. A motivational model is presented in the fourth section that brings attention to the interplay between the contextual factors and the youth that helps explain how the school may satisfy or undermine the fulfillment of primary psychological needs. And, lastly, guided by the Self-System Model of Motivational Development, school engagement is explored as a protective factor for youth at risk for GM.

\section{What is a Gang?}

Numerous studies have explored GM and what is considered a gang. Much of the literature acknowledges, however, an underlying disagreement among scholars in the conceptualization and operationalization of the term gang membership (Lopez \& 
O’Donnell, 2003; Yoder, Whitbeck \& Hoyt, 2003; Dukes \& Stein, 2003). Researchers have relied on self-reports of gang membership in order to differentiate those individuals who are in a gang from others who may just be associating with a group of peers, and criticisms of the validity of the construct have raised the issue of possible self-report biases (Bjerregaard, 2002).

Bjerregaard (2002) investigated the relationship between a person's selfidentification as a gang member and his/her actual involvement in a street gang. According to Bjerregaard's study, an organized gang had the following characteristics: substantial number of members $(51+)$, a gang name and the usage of nicknames for its members, a distinguished gang leader, regular meetings, a specific dress style, turforientation, and easy access to weapons. Results supported the notion that individuals who claimed membership in an organized gang were more likely to be involved in delinquent behaviors. In fact, individuals who self-reported being gang members were more likely to participate in delinquency relative to those individuals who did not identify themselves as members of an organized gang. Therefore, self-identification as a member of a gang seems to be a valid indicator of GM.

\section{What is the Difference between a Gang and a Group?}

Miller (1991) has identified six universal elements present in all gangs: structured organization, acknowledged leader, territorial orientation, continual association, mission-oriented, and involvement in delinquent and illegal behaviors (cited in Parks, 1995). In addition, in recent years the structure of gangs and their activities have evolved and become more complex, violent, drug-related, and weapons- 
Literature Review 6

orientated (Parks, 1995). Bjerregaard (2002) asserts that the defining feature of a street gang from other forms of organizations or groups is the organized involvement in criminal activity. Specifically, Huff (1992) identifies four factors that distinguish gangs from other forms of adolescent groups: (1) routine involvement in illegal activities; (2) a deliberate intention to engage in these illegal actions; (3) the deliberate claiming of a particular geographical location (turf); and (4) a distinguished leader (cited in Parks, 1995). Thus, the difference between a gang and a group of peers lies in the groups' level of criminal involvement and, most importantly, the intentionality and organized effort toward engaging in criminal behavior.

\section{Overview of Emerging Developmental Theories of Gang Membership}

The literatures of sociology and criminology have traditionally provided the foreground in understanding the etiology of gangs and GM. These theoretical frameworks have offered insightful and valuable descriptions and explanations of the nature, causes, and consequences of GM. For example, social disorganization theory focuses on the relationship between neighborhood structure, social control, and crime. According to social disorganization theory, a social institution is a group of people who come together for a common goal. When social institutions (e.g., families, schools, faith-based institutions) are strong and active, they serve as informal social controls of problem behavior of youth (Carlie, 2002). However, when social institutions are weak, non-existent, or neglected (social disorganization), informal controls are not present for youth showing signs of problem behaviors and formal controls (e.g. police, juvenile justice system) are required to act as agents of socialization (Carlie, 2002). Curry and 
Spergel (1992) asset that gangs are most commonly located in socially disorganized neighborhoods.

Although sociological and criminological theories such as social disorganization theory have contributed to our understanding of the environmental factors that are conducive to the formation of gangs, these theories do not address the multi-systemic forces that influence a youth onto a trajectory towards GM. In order to address this problem, a small set of theories have recently emerged that place GM in a developmental systems perspective. A developmental systems framework allows the consideration of how multiple risk factors in multiple developmental domains may slowly pave a youth's pathway towards GM. It is not just one risk factor that pushes a youth into GM, but the accumulative and the additive effects of many risk factors throughout various domains in a youth's life that make GM a viable option.

\section{Interactional Theory of Delinquency}

Thornberry and Krohn (2001) proposed an interactional theory of delinquency that attempts to understand how bidirectional forces between a youth and the environment throughout juxtaposing contexts impose emerging demands on a youth atrisk for delinquency. This interactional theory has three premises: (1) the antecedents of antisocial behavior are not determined in childhood; (2) emphasis is placed on the bidirectional causality in which behavioral patterns unfold and change across the youth's life as a response to the demands of the environment; and (3) the life course trajectory of a youth is embedded within a social structure that indirectly determines or 
influences the context in which these interactions are occurring (Howell \& Egley, 2005).

Thornberry and colleagues (2003) later expanded their interactional theory to include GM and described how both distal structural variables (i.e., neighborhood- level variables) and proximal processual variables (i.e., family-structural variables) exert a cumulative indirect influence on the risk of GM through the weakening of prosocial bonds (Howell \& Egley, 2005). In other words, living in disorganized neighborhoods with concentrated poverty and violence in addition to experiencing low levels of parental and school attachment may increase the youth's risk of socializing with antisocial peers and internalizing antisocial values, which in turn may increase the risk of gang membership as an alternative means of adjustment to the youth's environment (Howell \& Egley, 2005).

\section{Developmental Model of Gang Involvement}

Using Thornberry and colleagues' (2003) theoretical model of gang membership, Howell and Egley (2005) organized the risk factors of delinquency that precede GM (see Table 2.1) and propose a gang pathway from preschool through early adolescence (13 and under). The authors expanded Thornberry and colleagues' (2003) theory by including younger age groups because their theory was only tested on adolescent boys ages 13 and older. In addition, these researchers compiled the risk factors identified in prospective quantitative longitudinal studies in gang research and organized them in five developmental domains: community and neighborhood risk 
factors, family risk factors, school risk factors, peer group risk factors, and individual risk factors.

Table 2.1

Synthesis of Risk Factors for Gang Membership (Howell \& Egley, 2005)

Community or neighborhood risk factors

Availability of or perceived access to drugs

Neighborhood youth in trouble

Community arrest rate

Feeling unsafe in the neighborhood

Low neighborhood attachment

Neighborhood residents in poverty or family poverty

Availability of firearms

Neighborhood disorganization

Neighborhood drug use

Family risk factors

Family structure

Family poverty

Family transitions

Family financial stress

Sibling antisocial behavior

Low attachment to parents or family

Child maltreatment

Low parental education level

Parent proviolent attitudes

Family management: low parental supervision, control or monitoring

Teenage fatherhood

School risk factors

Low achievement in elementary school

Negative labeling by teachers

Low academic aspirations

Low school attachment

Low attachment to teachers

Low parent college expectations for child

Low degree of commitment to school

Low math achievement test score

Identified as learning disabled

Peer group risk factors

Association with peers who engage in delinquent or other problem behaviors 


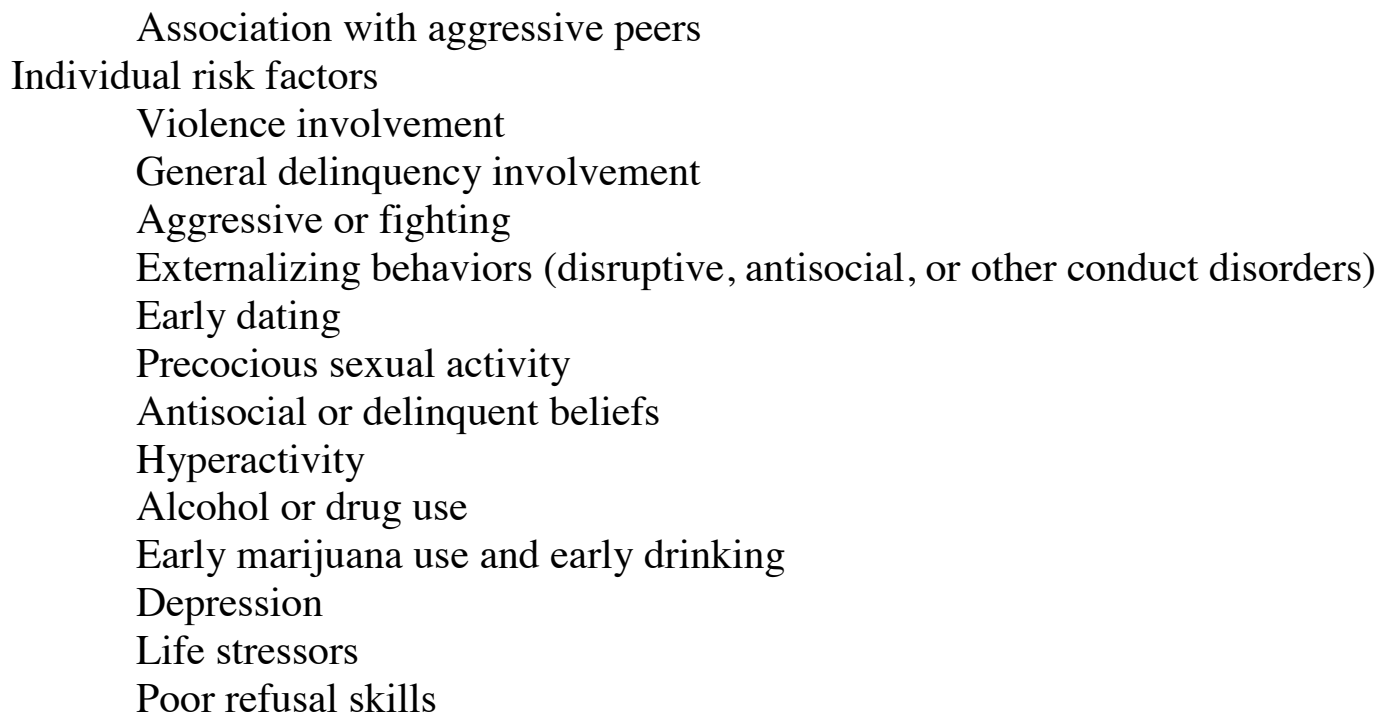

The authors argue that their developmental model incorporates the antecedents of GM from birth through adolescence, pointing out that the antecedents of gang involvement begin to manifest years prior to a youth actually joining a gang. For example, the authors posit that the highest-risk youth for GM begin a deviant developmental trajectory as early as age 3 or 4 with the emergence of conduct problems. These conduct problems are carried over to the school arena, which in turn affect school performance, resulting in elementary school failure at ages 6 to 12 . Further, these youth begin to exhibit delinquent behaviors by age 12, gang joining at ages 13-15, and serious, violent, and chronic delinquency from age 15 and onward (Howell \& Egley, 2005).

Although currently there is no empirical evidence for this hypothesized deviant trajectory, Loeber and Farrington $(1998,2001)$ found evidence of escalating problem behaviors leading to delinquency (cited in Howell \& Egley, 2005). Furthermore, Howell (2003) replicated Loeber and colleagues (1993) Pathways Model which demonstrated 
key milestones in escalating delinquent behavior. Children who begin exhibiting stubborn behavior, defiance, and disobedience in early childhood are at risk for later avoidance of authority figures, running away from home, and school truancy, which may in turn increase their risk of engaging in progressively more delinquent behaviors. An intermediate step in Loeber and colleagues' pathway model is gang involvement (cited in Howell \& Egley, 2005).

Howell and Egley's (2005) theoretical model, which focuses solely on gang joining, includes four developmental stages: preschool, school entry, childhood, and adolescence. The influences of risk factors from different developmental domains for delinquency and GM, which exert a cumulative and additive effect on the youth, may vary with age. By the time a youth enters high school, the majority of the risk factors from different domains related to GM are already in place. A description of the risk factors for GM proposed for each developmental stage follows.

Risk factors in the preschool stage. Thornberry and Krohn (2001) assert that there is a strong correlation between structural community factors and delinquency at an individual level that is mediated by family variables (cited in Howell \& Egley, 2005). Risk factors during the preschool stage include not only macrolevel factors (community level variables such as impoverished, distressed neighborhoods) but also certain family and child characteristics, which in turn influence the socialization of children. Family variables such as low parental education, single parents, parental criminality, poor family and child management, abuse and neglect, serious marital discord, and young motherhood in conjunction with child characteristics such as a difficult temperament, 
impulsivity, aggressiveness, inattentiveness, and proneness to sensation seeking impact the child's socialization, which may lead to early childhood problems such as aggressive and disruptive behavior and impede adequate socialization practices, which in turn may increase the likelihood of delinquency during childhood and GM in adolescence (Howell \& Egley, 2005).

Risk factors in the school entry stage. Howell and Egley (2005) assert that early childhood disruptive behaviors such as stubbornness, defiance, disobedience, and truancy following school entry are the result of dysfunctional families (p. 341). Children who enter school with aggressive and disruptive tendencies are more likely to be rejected by their prosocial peers, which in turn increases the likelihood of associating with similar aggressive and deviant peers, which in turn predicts delinquency in later childhood and early adolescence (Coie \& Miller-Johnson, 2001, cited in Howell \& Egley, 2005). However, it is important to note that not all disruptive children engage in delinquent behaviors or become delinquents in later adolescence. Nonetheless, there is a strong correlation between early onset of problem behaviors and later continuity of delinquency (Thornberry \& Krohn, 2001).

Risk factors in later childhood stage. According to Thornberry and Krohn (2001), very early onset of delinquency, violence, and drug use is the result of the combination and interaction of structural, individual, and parental influences (cited in Howell \& Egley, 2005), which in turn put youth at a higher risk for GM. By the time youth reach the developmental stage of later childhood, other risk factors for GM come into play. Peer rejection in the earlier years increase youth's risk of associating with 
more aggressive and antisocial peers. Research supports the notion that patterns of aggressive friendships continue through adolescence. Delinquent peer associations result in greater engagement in delinquent behaviors, which further reinforces prosocial peer rejection and increases the associations with antisocial peers. This feedback loop (i.e., aggressive tendencies $\rightarrow$ prosocial peer rejection $\rightarrow$ deviant peer association $\rightarrow$ engagement in delinquency $\rightarrow$ further increase of prosocial peer rejection $\rightarrow$ escalating increase of deviant peer associations) is an important interactional effect which further weakens prosocial bonds (Howell \& Egley, 2005).

Moreover, Thornberry and Krohn (2001) assert that poor school performance and low achievement are the result of prosocial peer rejection, child delinquency, and family problems (cited in Howell \& Egley, 2001). These factors come into play in the youth's identification and sense of belonging in the school, which can result in low feelings of connection to school. At the same time, however, it is important to keep these factors in a larger developmental systems perspective, because poor children's academic performance is a factor that is embedded within a school system in which the quality of the school, the quality of the school policies, and the quality of the relationship with the youth's teacher (in addition to family problems and individual characteristics) can all contribute to poor school performance. School policies that can negatively contribute to delinquency and GM are zero-tolerance policies, which produce high suspension, expulsion, and dropout rates (Howell \& Egley, 2005). These policies contribute not only to alienating youth from schools and teachers and further 
weakening prosocial bonds, but also increase the risk of exposing these youth to more deviant peer associations and influences on the streets (Howell \& Egley, 2005).

Risk factors in the early adolescence stage. The risk factors that predict GM in the early adolescence stage are a product of community or neighborhood problems, family problems, school problems, delinquent peer associations, and individual characteristics. Research supports the notion that future gang members not only have an accumulation of risk factors, but also that these risk factors are present in multiple developmental domains and gang joining is considered a developmental step that results from escalating delinquent involvement (Howell \& Egley, 2005).

The community or neighborhood risk factors that predict GM include availability and perceived access to drugs and firearms, neighborhood delinquent youth, feeling unsafe in the neighborhood, low neighborhood attachment, high drug use, and high community arrest rates. These risk factors are products of neighborhood disorganization where informal social controls for early youth problem behaviors are limited in the face of greater community structural deficits.

Howell and Egley (2005) divide the family-level factors into two groups: the structural variables (e.g., nonintact family) and the social process variables (i.e. family management practices). GM is indirectly associated with family structural variables because family social process variables mediate the structural variables (Howell \& Egley, 2005). That is, structural adversity variables such as single-parent households, family transitions, and/or family poverty may affect family management (i.e., parental supervision, parental monitoring) and hamper the development of strong family bonds. 
In addition, research also identified other family process variables that are associated with GM: sibling antisocial behavior, family financial stress, parents' proviolent attitudes, family conflict, child victimization, and teenage fatherhood (Howell \& Egley, 2005).

In the school context, the risk factors that compound previous developmental risk factors are poor school performance on math tests, low academic aspirations, low attachment to teachers, low parental college expectations for the child, low degree of commitment to school, negative teacher labeling (i.e., bad or disturbed), and feeling unsafe in the school (Howell \& Egley, 2005). In addition, along with increasing associations with deviant peers and/or gang members, the peer risk factor most important in this developmental stage is the adoption of delinquent beliefs, which is a significant predictor of GM (Howell \& Egley, 2005). Consequently, these beliefs may further weaken the bonds with prosocial institutions (i.e., family and school). Additionally, in the individual domain, the risk factors that may contribute to GM in the developmental stage of early adolescence are violent personal victimization, delinquency involvement, early dating, drug and alcohol use, antisocial and delinquent beliefs, and life stressors.

Additional Risk Factors for Gang Membership Not Considered by Howell and Egley

Most of the research on GM has involved identifying the personal and social factors that put youth at risk for joining gangs. According to Spergel, Chance, \& Curry (1990) and Goldstein (1991), the profile of a typical gang member is the following: males 13 to 24 years of age with an average age of 20 to 21 years, low socioeconomic 
status, and a youth of color (cited in Parks, 1995). In addition, Spergel et al. (1990) identified contributing factors in GM which include neighborhood social disorganization, failures in local institutions, racism, cultural traditions of intergenerational familial GM, crime opportunities, policy and program fragmentation in the criminal justice and social service system, and the presence of gangs in the community (cited in Parks, 1995). Calabrese and Noboa (1995) add that "researchers have traditionally viewed the root causes of GM as economic, cultural, and psychological, [however] it is not surprising to find that GM come in disproportionate numbers from single parent (mostly mother- centered) households where they experience poverty" (p. 228).

Furthermore, research also suggests that youths are attracted to gangs because of violent temperaments, low self-esteem, fragile and fragmented egos (Vigil, 1988; Spergel, 1992); a necessity to appear brave, daring, and courageous (Parks, 1995); for fraternity, friendship, emotional support, protection, belongingness, understanding, acceptance, power, economic opportunities, excitement, a normative structure and a sense of achievement that they lack at home (Calabrese \& Noboa, 1995; Houchhaus \& Sousa, 1987; and Vigil, 1988). Moreover, Hoyt (1985) found that alienation from parents was the initial cause of adolescents turning to delinquency and gang activity. Yoder, Whitbeck, and Hoyt (2003) report that homeless youth may join gangs for protection, social support, companionship, and tutelage for surviving in the streets. Table 2.2 summarizes the additional risk factors for GM not considered by Howell and Egley (2005). 
Table 2.2

\section{Additional Risk Factors for Gang Membership}

Individual risk factors

Youth of color

Age ranges between 13-24

Alienation from parents

Fragile or fragmented egos

Sense of fraternity

Violent temperaments

Protection

Unmet need to belong

Unmet need of support

Necessity to appear brave, daring, and courageous

Low self-esteem

Homelessness

Family risk factors

Single parent-headed household, usually female

Lack of male role model

Family financial strain

Unstable financial situations

Familial intergenerational GM

Community or Neighborhood risk factors

Gang presence

Racism

\section{Critique of Howell and Egley's Model}

Howell and Egley's (2005) model of gang involvement offers a developmental systems understanding of how antecedent problem behaviors in early childhood can escalate to behavioral problems in later childhood, which in turn may contribute to the risk factors for GM during adolescence. The authors offer a comprehensive organization of the risk factors identified in prospective quantitative longitudinal studies into multiple domains and propose a pathway towards gang joining across unfolding developmental stages from early childhood to adolescence. In addition, they describe 
how multiple domains in a youth's life interact to compound the influences of multiple risks factors, which suggests that there are developmental stepping stones to becoming gang involved that may appear as early as ages 3 or 4. In sum, Howell and Egley's developmental model is a valuable contribution to gang research and offers a comprehensive theoretical foundation upon which future empirical inquiries may build. Despite the strengths of their model, however, there are two limitations. First, Howell and Egley's model of gang joining offers a normative developmental trajectory towards GM, which is descriptive in nature rather than explanatory. Their model does not offer a plausible explanation for why youth may be drawn to gangs and portrays GM to an inevitable consequence of mounting risk factors in a youth's life. Their aim was only to "synthesize research-supported variables" (pg. 335) and, therefore, they do not consider findings from studies with different methodologies (i.e., qualitative studies). However, by ignoring the findings of these studies, valuable information may be lost that may add to our understanding of the motivations of youth into joining a gang.

Secondly, Howell and Egley only focused on empirically-supported risk factors to formulate the trajectory of youth into gang involvement and did not address the role of protective factors. The addition of protective factors into their model would allow for preventative strategies that focus on reducing or moderating the influence of risk factors and promoting or enhancing the protective factors in one or more domains of the lives of youth. Although there are numerous studies that suggest possible protective factors that may buffer youth from gangs (Bjerregaard \& Smith, 1993; Esbensen, Huizinga, \& 
Weiher, 1993; Hill et al., 1999; Howell, 2004; Maxson et al., 1998; Thornberry, Krohn, et al., 2003; Walker-Barnes \& Mason, 2001; Whitlock, 2002; Wyrick, 2000), there are no studies that empirically examine the role of protective factors for GM.

The current study seeks to expand the work of Howell and Egley in two ways: (1) a conceptual framework will be proposed that attempts to explain how the attraction and motivation of youth to join a gang may be a direct response to unmet psychological needs; and (2) the school microsystem will be explored as a setting of potential prevention and intervention efforts to prevent, disrupt, or lower the attraction and/or involvement of at-risk youth in gangs. A motivational model will be presented that brings attention to the contextual factors of the school setting that may facilitate or undermine the experiences of youth to meet their basic psychological needs. A key component of this model is the construct of school engagement which will be explored as a protective factor for gang involvement. This study and its framework should have clear implications for proposing intervention and prevention programs at a middle school/high school level that incorporate motivational principles in creating social contexts that promote positive youth development.

\section{A Framework for Understanding the Attraction and Motivation of Youth to Join a Gang}

Understanding why youth join gangs requires a conceptual framework that simultaneously considers the interaction of multiple distal and proximal contexts in a youth's life as well as the developmental needs of the youth as they develop within these contexts. The current framework argues that youth gang membership (GM) should 
be conceptualized within a series of interdependent contexts that starts with the primary microsystems of the family, school, and peer group and then moves up in complexity to the neighborhood and community as influential contexts. This framework was originally proposed by Bronfenbrenner (1979) who emphasized that the development of a child is nested within highly interconnected and interactive ecological systems that directly or indirectly influence his/her development. Figure 1 depicts Bronfenbrenner and Morris' (1998) bioecological model which illustrates four separate systems that influence the development of a child: the microsystem, the mesosystem, the exosystem, and the macrosystem.

Bronfenbrenner (1979) defined the multiple environmental systems as the proximal and distal living contexts of human development, which are nested within each other "like a set of Russian dolls" (p. 3). According to Bronfenbrenner and Morris (1998), the microsystem is the immediate context or setting in which the developing person engages in face-to-face interactions "with particular physical, social, and symbolic features that invite, permit, or inhibit, engagement in sustained, progressively more complex interactions with, and activity in, the immediate environment" (p. 1013). The bi-directional influences between the youth and social partners (i.e., parents, teachers and/or peers) are strongest in the microsystem and have the greatest impact on the development of the youth although the outer systems can impact the immediate environments. The interpersonal relationships, involvement in activities, and roles are 
Literature Review 21

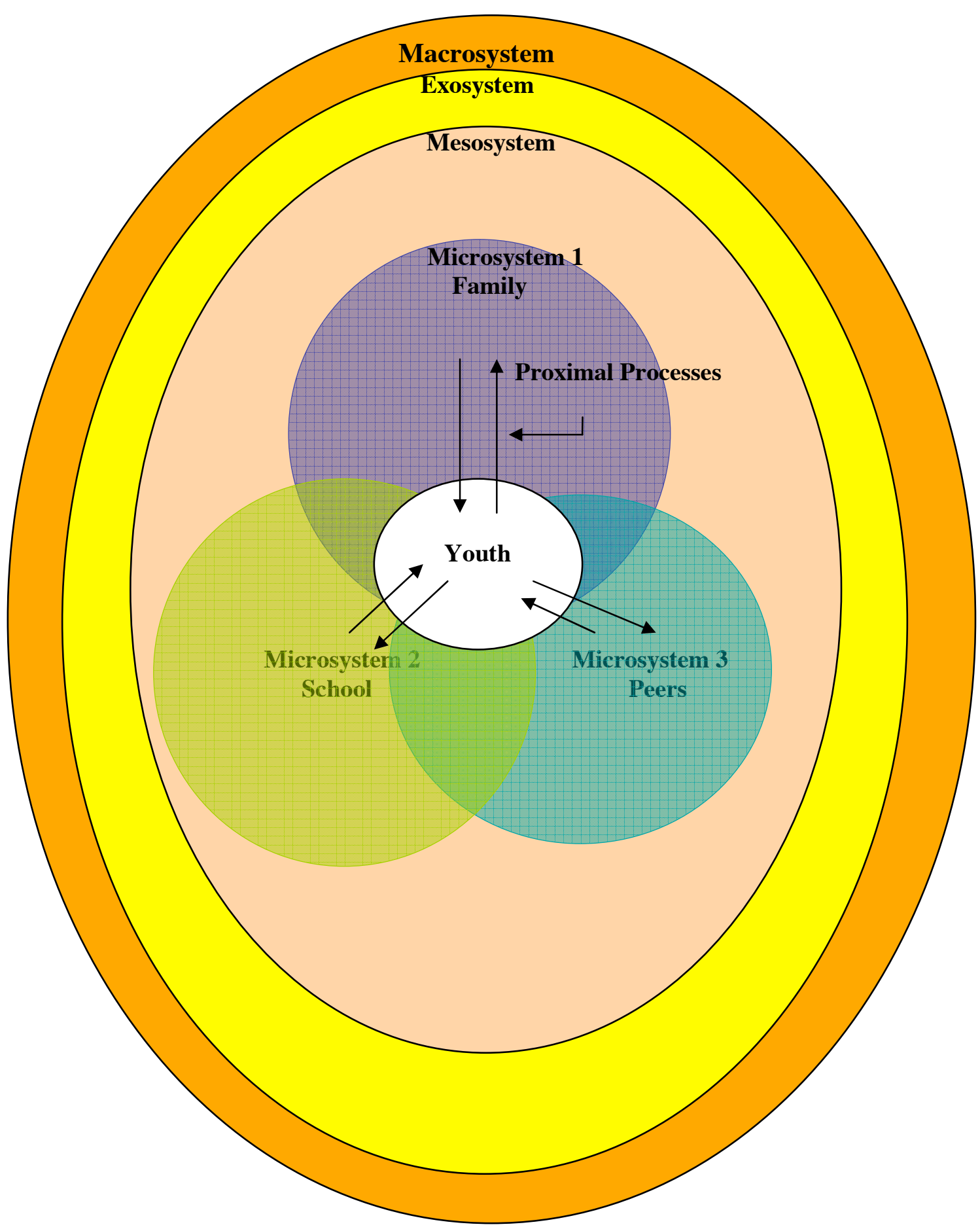

Figure 1. Conceptualization of the microsystems in the life of a youth using the bioecological model. 
the essential elements of the microsystem (Hirsto, 2001). The home environment is often the primary and most significant microsystem in a youth's life, followed by the school and the peer group microsystem.

The mesosystem comprises the overlap and interrelationships of two or more microsystems in which the developing youth is actively involved. According to Bronfenbrenner (1998), events that occur in one microsystem (i.e., the home) are carried over to other microsystems (e.g., school) thus influencing the environment in that microsystem in indirect ways. The exosystem refers to "the linkages and processes taking place between two or more settings, at least one of which does not contain the developing person" (Bronfenbrenner, 1993, p.24). However, the events that occur in this system indirectly influence and affect the immediate microsystems in which the youth is developing. For example, the neighborhood or community in which the youth is developing comprises the exosystem.

The broadest ecological system that is furthest removed from the youth's direct experience is considered the macrosystem. This system comprises the cultural values, customs, and laws of the specific geographical environment in which the youth is developing. Any changes or effects in this system have a cascading influence on the other systems (Hirsto, 2001). For example, changes in legislature or policies that directly impact the funding available for prevention/ intervention programs offering resources, education, and mentoring for youth at-risk for GM are examples of macrosystemic influences on youth's development. 
Bronfenbrenner and Morris (1998) proposed that the driving forces behind developmental change are the proximal processes, which are the reciprocal interactions between an individual and his/her immediate environment that occur over time (see Figure 1). There are four features that constitute a proximal process: (1) the individual must engage in an activity; (2) the individual must repeat the activity over extended periods of time; (3) the activity must become increasingly more complex; and (4) the activities must entail a reciprocal exchange between the interactions of the social partners (e.g., developing youth and parent). For the proposed framework, the quality of the relationships between a youth and the social partners in each microsystem in addition to their level of engagement in activities will be conceptualized as markers of important proximal processes of youth GM.

\section{Quality of the Relationship as a Marker of Proximal Processes}

The quality of the relationship between the youth and the social partners of each domain (i.e., family, school, and peer microsystems) can be conceptualized as the outcome of recurring and reciprocal interactions (i.e., proximal processes). Within the attachment theory, attachment has been defined as the enduring affectional bond between two individuals. Initially proposed by Bowlby (1969) to account for the relationship between an infant and its caregiver and later formalized by Ainsworth (1979), attachment theory has served as an important framework for the explanation of the impact of the quality of parental attachment on psychosocial and emotional development among adolescents (Allen \& Land, 1999). Attachment relationships, formed early in life between the child and the parent, are hypothesized to promote the 
development of trust, confidence, and predictability in others that individuals carry with them throughout their lifespan (Peacock, McClure, \& Agars, 2003; Wallace \& May, 2005).

Ethnographic studies have found that the need to belong, the need for protection, and the need for support are primary reasons (or risk factors) youth have joined gangs (Calabrese \& Noboa, 1995; Hochhaus \& Sousa, 1987; Vigil, 1988). These three risk factors stand out due to their psychological significance for attachment and may give us an understanding of the benefits of belonging to a gang. Although the very nature of antisocial youth gangs denotes a lifestyle with negative consequences, qualitative and quantitative studies have also identified a number of benefits that provide prospective gang members with positive psychological rewards (Calabrese \& Noboa, 1995; Houchhaus \& Sousa, 1987; and Vigil, 1988). Baumeister and Leary (1995) assert that the need to belong is a fundamental human motivation that drives individuals to seek out and form strong, stable interpersonal relationships. In order for this need to be satisfied, the individual must believe that the social partner (e.g., parent) cares about his/her welfare and exhibits behaviors of interest, liking, and/or loving. If a youth does not perceive that $\mathrm{s}$ /he is valued as a unique individual who is worthy of love and affection in his/her primary microsystem (family), this youth may seek out other individuals or groups such as a gang to satisfy this need.

Considering Vigil's (1999) assertions that the gang may act as a surrogate family to unattached youth (Baumeister \& Leary, 1995), the application of attachment theory to research in understanding the motivation and attraction of youth to join a gang 
might help illuminate the psychological needs that are being met by GM. The attachment perspective would suggest that the relationship between the gang and a potential recruit is reciprocal and magnetic, satisfying particular and specific needs of safety and protection to the potential recruit. The psychological needs for belongingness, support, and protection fulfill the basic criteria for the establishment of an attachment with a significant other or group (Ainsworth, 1991; Hazan \& Zeifman, 1994), especially in the face of perceived threat (or real sense of danger).

Within the attachment perspective there is controversy about the nature of the relationships that can be characterized as attachments (Thompson, 2005). However, it can be argued that the gang may simulate an attachment relationship under specific circumstances. For youth who live in neighborhoods with high crime and violence, the gang may satisfy immediate psychological needs such as protection that may ensure survival. As such, the benefits of belonging to a gang may be powerful incentives that may play a key role in a youth's decision-making process in joining a gang.

If youth are attracted and motivated to join a gang because of its potential immediate psychological benefits, then it would follow that the gang has a functional status for these youth that satisfies fundamental psychological needs. If this notion holds true, it may provide information that could be crucial for the conceptualization and design of successful prevention/intervention programs for youth at risk for gangs. For example, if motivational factors such as the need to belong influence youth to join gangs, then prevention/intervention programs that strive to genuinely create constructive, meaningful, and stable relationships may be more fruitful in serving these 
youth. Implicit in these programs' framework would be the consideration of the contextual factors (e.g., features that optimally enhance relationships and the classroom environment experience) that facilitate or undermine the fulfillment of fundamental psychological needs of youth at risk for gangs. A critical component that is influenced by contextual factors is the construct of engagement, which shapes the relationship between the youth and the social partner (i.e., teacher).

\section{Engagement as a Marker of Proximal Processes}

Engagement can be conceptualized as the outcome of important proximal processes. Engagement, which is closely related to attachment, is also shaped by the interrelationships and interactions with the social partners of each domain (i.e., parents, teachers, and peers). It is considered a source of development (i.e., proximal process) because the exchange between the youth and the social partners in the activities reflect the internal psychological experience of involvement, participation, enjoyment, liking, belonging, and investment which is believed to be observable through the behavior expressed by the youth and the social partners (Wellborn, Connell, Skinner, \& Kindermann, 2005). These interactions have effects that feed back to both partners that intensify and reinforce themselves over time leading to the expectations of availability of social support and the emergence of self-perceptions of competence, efficaciousness, and worthiness (Wellborn et al., 2005).

Research has found a positive relationship between engagement and academic outcomes such as grades and achievement, attendance and graduation, and academic resilience (Connell, Halpern-Fesher, Clifford, Crichlow, \& Usinger, 1995; Connell, 
Spencer, \& Aber, 1994; Finn \& Rock, 1997; Jimerson et al., 2003; Pierson \& Connell, 1992; Ryan \& Patrick, 2001; Skinner, Zimmer-Gembeck, \& Connell, 1998; Wenzel, 1994) and a negative relationship between engagement and substance abuse, delinquency, and other problem behaviors (Garcia-Reid et al., 2005; O’Farrell \& Morrison, 2003). This accumulation of evidence suggests that school engagement may also be a promising protective factor for GM. Considering that youth who are involved in gangs have higher rates of school dropout, higher rates of delinquency, and lower attachments to parents, schools, and the larger community (Arfaniarromo, 200; Belitz \& Valdez, 1994; Howell \& Egley, 2005; Vigil 1988), it follows that promoting school engagement may have a positive impact in reducing gang involvement.

\section{School Engagement as a Protective Factor for Gang Membership}

Schools in general and teachers in particular play an essential role not only in instilling the norms and values of society, but also in influencing the intellectual, social, emotional, moral, and civic development of children (Gurin, 1999). Research on schools as central contexts of human development assert that schools play an integral role in fostering (and hindering) student motivation and achievement (Roeser, Urdan, \& Stephens, 2008). Regrettably, research has documented that gang members, specifically Latino gang members, reported negative experiences at school, especially with their teachers (Calabrese \& Noboa, 1995; Tellez \& Estep, 1997). Specifically, this research found that for Latino students who did succeed in finishing school or succeeded in not dropping out of school in an earlier grade level, it was one teacher who inspired, motivated, and guided the student with patience, respect, and accountability for their 
learning (Tellez \& Estep, 1997). Furthermore, Curry and Spergel (1992) found evidence that Hispanic students were more likely to join gangs when the schools failed to meet their emotional, social, and educational needs. In particular, one qualitative study documents how one gang member never felt that he "belonged to school," and it was a “joke" and "meaningless" (Reyes, 2006). For this reason, the current investigation will explore how schools may be contexts for prevention and intervention efforts in preventing youth gang involvement.

School engagement. Academic engagement has been defined as a multifaceted construct that includes affective, cognitive, and behavioral involvement in school activities. Although defined and operationalized in a number of ways, the core construct of academic engagement refers to the quality of an individual's "connection, bonding, or involvement with the enterprise of school and, hence, with the people, activities, tasks, values, goals, rules, customs, and place that comprise it" (Wellborn et al., 2005). Specifically, the three components of engagement have been defined in the following ways. Emotional engagement is assumed to reflect an individual's ties, bonding, sense of belonging, and/or identification with the school and includes both positive and negative emotions and reactions to the social partners and activities in the school domain (e.g., teachers and schoolwork). Cognitive engagement refers to the investment, thoughtfulness, and the willingness to exert the mental effort necessary in an activity. And lastly, behavioral engagement encompasses the level of participation, task involvement, and prosocial conduct in the school activities (Furlong, Whipple, St. Jean, Simental, Soliz, \& Punthuna, 2003; Fredricks, Blumenfeld, \& Paris, 2004). 
A recent review by Fredricks et al. (2004) suggests that school engagement has the potential to prevent negative developmental outcomes such as dropping out of school and delinquency. Research focusing on the emotional or affective component of school engagement suggests that feelings such as alienation, estrangement, social isolation, social difficulties, and an emotional disconnection from school or negative feelings toward school all contribute to a youth's decisions to drop out of school. These studies suggest that increasing a student's emotional connection to his/her teachers may help reduce dropout rates (Fredericks et al., 2004).

In addition, research on the behavioral component of school engagement has suggested that low behavioral engagement is related to risky behaviors such as cutting class, skipping school, suspension, and retention and has been found to be a precursor to dropping out of school (Fredericks et al., 2004). Specifically, when compared to other students, dropouts are more likely to have poor attendance, exhibit behavioral problems, and express early signs of school failure (Barrington \& Hendricks, 1989; Cairns, Cairns, \& Neckerman, 1989; cited in Fredericks et al., 2004). School failure has been identified as a predictor of substance abuse, juvenile delinquency, and other problem behaviors (Battistich, Schaps, Watson, \& Solmon, 1996).

Contextual factors. While school engagement is conceptualized as a malleable behavioral, cognitive, and affective state within the student, there are distal and proximal contextual factors that may promote (or undermine) a student's level of sustained participation, involvement, and commitment in academic activities. This is especially true for ethnic/racial minority and low socio-economic (SES) students. While 
school success is important for all students, dropout rates are disproportionately high for ethnic minorities and low income students (National Center for Educational Statistics, 2002). Latino and African American students have dropout rates of approximately $22 \%$ and $11 \%$ compared to $5.8 \%$ for white students (U.S. Department of Education, 2008). Latino and African American students are also enrolled in the 47 largest city school districts in the nation and attend some of its poorest school districts (Eccles \& Roeser, 2003). It should be noted, however, that although race/ethnicity and SES are overlapping categories (Shernoff \&Schmidt, 2008), low SES white students are often overlooked in research (Spencer, 2006).

There is a growing body of literature that examines the effects of neighborhood and community characteristics on student engagement (Daly, Shin, Thakral, Selders, \& Vera, 2009; Garcia-Reid, Reid, \& Peterson, 2005; Schultz, 1993; Shernoff \& Schmidt, 2008; Sirin, 2005; Wooley \& Bowen, 2007). For example, students who reside in urban neighborhoods with concentrated poverty have lower school engagement and lower achievement scores (Daly et al., 2009). These disadvantaged communities have high levels of crime and violence, lack adequate resources and appropriate role models, and adult supervision that may help explain differences in academic achievement between low-achieving minority, immigrant, and low SES students and high-achieving middle class white students (Ainsworth, 2002). Community SES has been found to be negatively related to student engagement and intrinsic motivation (Shernoff \& Schmidt, 2008). In fact, Sirin's meta-analysis (2005) found that the socio-economic composition 
of schools was one of the strongest predictors of student achievement, with lower SES schools having the lowest achievement.

Neighborhood safety. Research has shown that direct and indirect exposure to community and school violence has harmful effects on urban ethnic minority youth resulting in emotional, social, and psychological difficulties (Aisenberg \& Mennen, 2000; Ceballo, Dahl, Aretakis, \& Ramirez, 2001; Garbarino, 2001; Saltzman, Pynoos, Layne, Steinberg, \& Aisenberg, 2001). Some studies suggest that perceived neighborhood safety may also negatively affect student performance and student engagement (Bowen \& Bowen, 1999; Garcia-Reid et al., 2005). Gorski and Pilotto (1993) found that children who fear for their personal safety have more concentration problems that negatively impacted their school performance.

In a study conducted by Daly and colleagues (2009), age differences were found in the influence of neighborhood safety on student engagement. The authors found that for younger students, as perception of neighborhood crime increased, their engagement in school increased. However, the opposite was found for older students; that is, as perceived neighborhood crime increased, school engagement decreased. Unfortunately, the authors did not provide information on the age ranges that comprised "younger" and “older" student groups. Nonetheless, this finding may reflect that negative neighborhood characteristics affect youth differently depending on their age. It could be that for the younger students in the study, schools may be seen as a "safe haven" and a primary source of structure, safety, and predictability that offers protection from the dangers of the neighborhood and the possible desolation of the home life (Lawrence- 
Lightfoot, 1983); whereas, for older students, such concerns may be less salient. Another interpretation could be that the observed decrease in levels of school engagement between younger and older students may reflect normative declines in achievement motivation, which wanes steadily across all school years (Wigfield, Eccles, Schiefele, Roeser \& Davis-Kean, 2006).

Social support. A number of studies indicate that the amount of social support is a critical factor in successful student outcomes (Brewster \& Bowen, 2004; Bowen \& Chapman, 1996; Daly et al., 2009; Garcia-Reid, Reid, \& Peterson, 2005; Woolley \& Bowen, 2007). Morrison et al. (2002) reported that perceptions of available support from family, teachers, and peers were also associated with higher levels of school engagement and lower problem behaviors for Latino students. Wentzel's (1999) study also found that middle school students who perceived their teachers as supportive and caring also reported higher levels of motivation to excel in school. Moreover, Brewster and Bowen's (2004) findings suggest that teachers (compared to parents) play an especially significant role in making school meaningful for students at risk for dropping out of school.

Promising new research suggests that there may be moderating factors that can buffer the negative influence of neighborhood characteristics on student engagement (Bowen \& Bowen, 1998; Bowen \& Chapman, 1996; Garcia-Reid et al. 2005). For example, neighborhood safety was found to have indirect effects on student engagement through its relationship with parental and teacher support (Garcia-Reid et al. 2005). In another study that investigated the effect of risk exposure on student engagement, it was 
found that youth who reported having supportive adults also reported higher levels of psychological and behavioral engagement (Woolley \& Bowen, 2007). However, in Daly et al.’s (2009) study, different levels of social support provided by parents, teachers, and peers did not modify the relationship between perceived neighborhood safety and school engagement.

Summary. As the above literature review demonstrates, distal and proximal contextual factors may have differential impacts on students' engagement, especially for youth who are at risk due to their socioeconomic and ethnic/racial minority status. These contextual factors may help explain why some students persist in school endeavors while others do not. The current review and conceptualization of school engagement by Fredricks et al. (2004) acknowledges that school engagement may be malleable and is influenced by environmental factors. The authors cite studies that address the link between individual needs as a mediator between contextual factors and engagement. This research provides guidance and insight on how school engagement may be influenced by contextual factors and how it may be malleable and amenable to environmental change. Therefore, a process model of motivational development will be used in the current study that brings attention to the interpersonal and social factors that facilitate (or undermine) school engagement by the fulfillment of students' basic psychological needs, which in turn influences student outcomes. For the current study, student outcomes will be learning and achievement versus gang involvement. 
Literature Review 34

\section{Self-System Model of Motivational Development}

The self-system model of motivational development is a dynamic motivational model that explains linkages between an individual's experiences of a social context, their self-system processes (a person's self-perceptions), their patterns of action, and the outcomes of their performance (e.g., grades) that is consistent with self-determination theory and other organismic models of intrinsic motivation (SSMMD; Connell, 1990; Connell \& Wellborn, 1991; Deci \& Ryan, 1985; Skinner \& Edge, 2002; Skinner \& Wellborn, 1994, 1997). According to the SSMMD, a student's engagement is the key motivational state that drives learning and school success. It is defined as an internal source of motivation that is reflected in a student's "active enthusiastic participation in academic activities in the classroom.” (Marchand \& Skinner, 2007; Skinner \& Belmont, 1993). A student's engagement is expressed in behaviors and emotions that are assumed to reflect and underlie high-quality learning (Skinner, Furrer, Marchand, \& Kindermann, 2008). Such emotions include enthusiasm, interest, and enjoyment. Behaviors associated with engagement are effort, attention, and persistence. In contrast, disaffection, which is more than the absence of engagement, reflects maladaptive motivational states that are manifested in behaviors and emotions such as lack of interest, withdrawal, boredom, anxiety, and frustration (Skinner et al., 2008). Figure 2 depicts the Self-System Model of Motivational Development.

The SSMMD is based on the assumption that a student's engagement versus disaffection is shaped and optimized when their interactions with the social context fulfill three fundamental psychological needs (Connell \& Wellborn, 1991). The need for 
relatedness or belongingness refers to an individual's need to experience themselves as belonging, loved, appreciated, and connected to important others. The need for competence or efficacy reflects an individual's need to experience oneself as efficacious and masterful in interactions with the environment. And, lastly, the need for autonomy refers to the necessity to experience oneself as the authentic source of one's own actions (Marchand \& Skinner, 2007). The three psychological needs of relatedness, competence, and autonomy organize the self-systems processes (SSPs) and have been found to be key predictors of engagement and disaffection in school (Furrer \& Skinner, 2003; Patrick, Skinner, \& Connel, 1993; Skinner, Zimmer-Gembeck, \& Connell, 1998; cited in Marchand \& Skinner, 2007).

Teacher support. The SSMMD states that social partners such as teachers play an especially important role in providing motivational supports (see Figure 2 for detail of the SSMMD in the classroom). Three motivational supports are assumed to promote engagement through the fulfillment of students' needs. A teacher's warmth and involvement, which refers to the quality of the interpersonal relationship between a student and their teacher, is assumed to fulfill a student's need of relatedness. Teachers who are involved with their students by dedicating time and resources, express affection, are attuned to students' needs, and enjoy interactions with students communicate to students that they are important and welcomed in school. Numerous studies have documented a link between students' sense of belonging in school and academic motivation and achievement (see Skinner et al., 2008). In fact, Roeser, Midgley, \& Urdan (1996) found that positive student-teacher relationships were related 
Figure 2. A motivational model of gang involvement (GI) and achievement derived from the self-system model of motivational development.

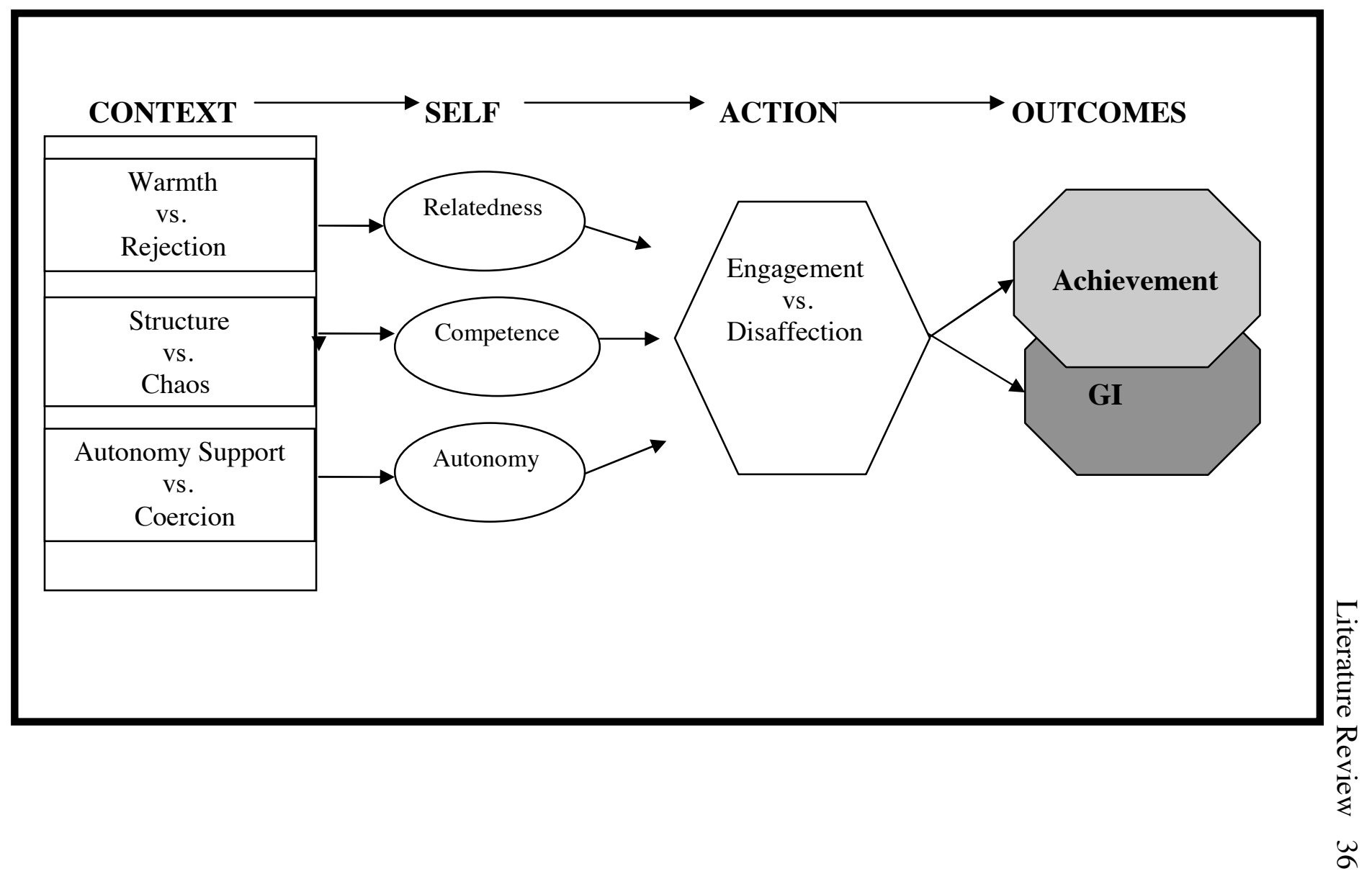


to a sense of belonging in school, which in turn predicted positive school-related affect (cited in Skinner et al., 2008).

The SSMMD holds that a teacher's provision of structure and explanations of contingency fosters competence in students. Structure refers to the amount of information available in the context that effectively explains how to achieve desired outcomes. Teachers who effectively and clearly communicate their expectations by consistently offering instrumental help and support and by tailoring and adjusting teaching strategies to the level of each student are more likely to foster students' sense of efficaciousness and mastery in academic tasks. Numerous studies have found that perceptions of self-efficacy, ability, academic competence, and perceived control are robust predictors of students' effort and persistence in school (Skinner et al., 2008).

The SSMMD presumes that academic contexts that support student autonomy enhance subsequent student engagement. Teachers that are autonomy-supportive provide choice, share decision making with students, and allow students to follow their own interests within academic bounds. According to the SSMMD, autonomy is best fostered by the absence of external rewards, controls, and/or pressures (Skinner \& Belmont, 1993) because studies have found that these strategies undermine intrinsic motivation, which is a component of autonomy (see Deci \& Ryan, 1985, for review). 
Figure 3. Detail of Self-System Model of Motivational Development in the School Microsystem

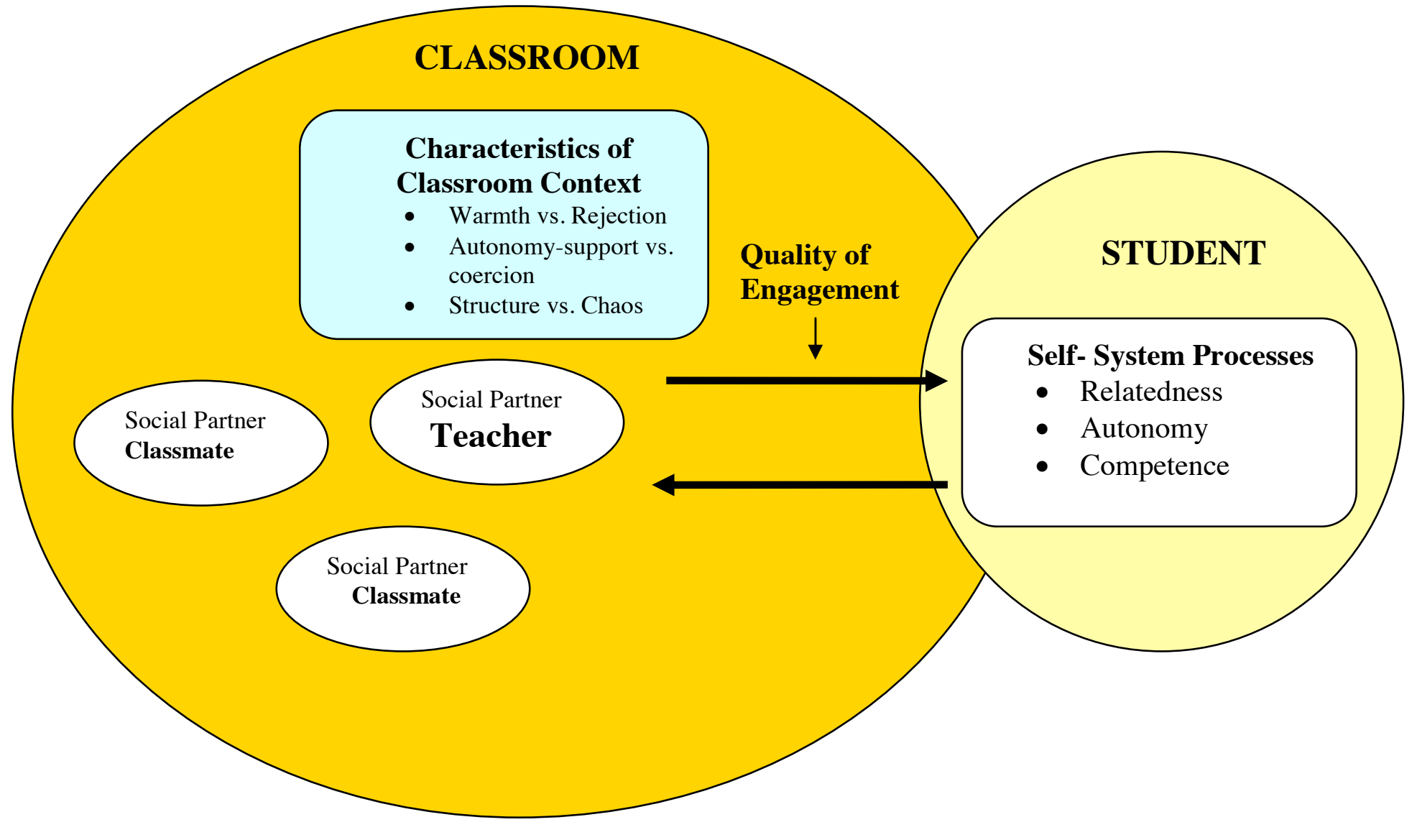


The motivational supports of warmth and involvement, structure, and autonomy also have their motivational opposites that undermine the fulfillment of students' needs, which in turn can exacerbate student disaffection over time. For example, if teachers are unfriendly or hostile towards students, these behaviors may communicate to students that they are not welcomed in school. To the extent that teachers are chaotic and unpredictable, these behaviors can undermine students' competence by confusing them about contingencies in the classroom or inconsistently enforcing classroom rules and practices. And, lastly, a student's autonomy can be undermined by teachers being coercive and controlling. It should be noted, however, that the direction of effects could be the opposite as well. As a student becomes more oppositional and less engaged in the learning tasks, teachers may also become more coercive and controlling. Research has documented that students who were more engaged received more involvement, structure and autonomy support from teachers whereas students who were more disaffected received more neglect, chaos, and coercion from their teachers (Connell, Spencer, \& Aber, 1994; Skinner \& Belmont, 1993).

The SSMMD holds that contextual features are critical in promoting student motivation (Connell \& Wellborn, 1991; Deci \& Ryan, 1985). Specifically, the quality of teacher- student relationships that are experienced as supportive and caring has been found to be a key predictor of school engagement, effort in the classroom, school liking, and achievement expectancies (Birch \& Ladd, 1997; Goodenow, 1993; Murray \& Greenburg, 2000; Murdock, 1999; Murray \& Greenberg, 2008; Ryan \& Powell, 1991; cited in Skinner et al., 2008). Although students' motivation is influenced by multiple 
social partners (e.g., family and peers; Garcia-Reid et al., 2005; Kindermann, 1993; Kindermann, 2007; Wooley \& Bowen, 2007), the current investigation will focus on the motivational supports provided by teachers and school in general.

\section{The Present Study}

There are three research goals in the proposed study. First, this study proposes a framework that attempts to understand the underlying motivations of why youth may join gangs. This framework highlights motivational dynamics of attraction towards gangs that may satisfy fundamental psychological needs and argues that gangs may serve a functional status by offering protection, support, and belongingness to youth who live in high risk environments. Secondly, there are no empirical studies to date that examine school engagement in students at risk for gang involvement. This study will distinguish between two student profiles of risk using traditional assessments of gang membership and an innovative assessment that is derived from the study's framework. And, third, using the Self-System Model of Motivational Development, the present study will explore the relationship between engagement versus disaffection and youth gang involvement and how motivational supports provided by teachers in particular and the school in general may influence this relationship through the fulfillment of students' basic needs of relatedness, competence, and autonomy. To date, the SSMMD has been tested on middle class European American students in elementary and middle school, with only three studies testing the model on African- American students (Connell, Halpern-Fesher, Clifford, Crichlow \& Usinger, 1995; Connell, Spencer \& Aber, 1994; 
Literature Review 41

Tucker et al., 2002). This will be one of the first studies that test this model on an ethnically/racially diverse, socio-economically homogenous student sample. 


\section{CHAPTER III}

\section{Statement of Purpose}

Criminological and sociological research on gangs has focused on identifying the risk factors associated with gang membership in multiple developmental domains. To date, there are no empirical studies that investigate protective factors that may buffer youth from joining gangs (Howell \& Egley, 2005). Qualitative studies have suggested that gangs may offer powerful psychological rewards in the form of protection, support, and belongingness. The present study proposes a framework for understanding the attraction and motivation of youth to join gangs and argues that the benefits that gangs provide may fulfill fundamental psychological needs that may help explain why some youth join gangs. This framework suggests that youth who live in high risk environments may seek out gangs in order to satisfy basic psychological needs that have not been met elsewhere and considers gang membership as an alternative means of adjustment to a youth's environment.

Educational and psychological research have found robust evidence that school engagement protects youth from a host of risky activities and negative outcomes (e.g., substance use, dropping out of school) and is correlated with learning and student achievement (Fredricks et al., 2004). Research on ethnic/racial minority and low SES students is suggesting that distal and proximal contextual factors (e.g., perceived neighborhood safety) have differential impacts on student engagement that may help explain why some students persist in academic endeavors while others do not. To date, no empirical studies have investigated the academic experiences of youth at risk for 
joining gangs. Only qualitative studies have captured the experiences of gang members in school in general and with teachers in particular (Calabrese \& Noboa, 1995; Reyes, 2006; Tellez \& Estep, 1997). Such studies do not portray a positive and welcoming environment to these students. Therefore, the purpose of the present study is three- fold: (1) to identify students who are risk for gangs; (2) to investigate whether school engagement can be a protective factor for youth at risk for joining gangs; and (3) to investigate whether a well-supported model of motivational development can account for the dynamics that may facilitate or undermine school engagement as a protective factor for gang involvement (GI).

\section{Research Questions and Hypotheses}

The overarching research questions guiding the present study are: Can school engagement be a protective factor for youth at risk for joining gangs? If so, what are the mechanisms through which school engagement can be supported for at risk youth? The Self- Systems Model of Motivational Development (SSMMD) will be used to formulate specific research questions that address the overarching research questions. Each research question will be followed by testable hypotheses.

Research Question 1. Can we construct an indicator assessing risk for gang involvement that taps personal attraction to gangs as a motivational precursor to actually joining a gang? Does this indicator tell us something about risk for gang involvement different from traditional methods of self-reports?

Traditional methods for assessing gang membership ask participants to acknowledge membership in gangs. Self-reported gang membership has been found to 
be a reliable indicator of gang membership because it has been found to highly correlate with delinquency (Esbensen, Winfree, He, \& Taylor, 2001). In addition, associating with delinquent peers increases a youth's risk of joining gangs (Curry \& Spergel, 1992). To date, no empirical studies have examined a youth's attraction to gangs as a potential risk factor for future gang involvement. However, it is possible that beyond the cumulative macro- and micro-level risk factors for gang involvement, there may be an individual motivation that may drive youth to seek out a gang. Youth may be attracted and motivated to a reference group such as a gang because it may provide for basic psychological needs such as protection, support, and belongingness.

Hence, in order to answer this research question, profiles of students with differential levels of risk for joining gangs will be distinguished. Two student profile groups will be discerned depending on their (1) level of gang involvement or (2) level of personal attraction to gangs. Each profile will have specific criteria for group classification. The reason for distinguishing two student profiles of risk is to explore whether a student's personal attraction to gangs may be a precursor to future gang involvement that has not yet been identified in research. For example, some students who are not involved in gangs may be nonetheless attracted to them and find gangs alluring and exciting.

Research Question 1b. Do the levels of risk for joining gangs differ across ethnic groups? In other words, are there certain ethnic groups particularly at risk for joining gangs? 
This research question examines whether some ethnic groups are particularly at risk for gang involvement. According to the National Youth Gang Survey (2001), Latinos and African Americans have higher rates of gang involvement (49\% and 34\% compared to $10 \%$ White and 6\% Asian youth). However, current research also suggests that the racial and ethnic composition of youth gangs reflects the demographic characteristics of a particular locality (Howell \& Egley, 2007). In fact, cities that are documenting emerging gang problems report a larger proportion of White gang members than any other racial/ethnic group (Howell, Egley, \& Gleason, 2002). Considering that gangs are endemic in socially disorganized neighborhoods (Curry \& Spergel, 1992), it is socio-economic conditions that give rise to gangs and expose youth to a host of risk factors that increases their vulnerability to joining a gang. Because race and SES are overlapping categories, that may help explain the higher rates of gang membership in ethnic minorities.

Therefore, I predict:

H1b1. Once socio-economic factors and neighborhood safety is taken into account, no ethnic group differences will be observed across levels of risk for joining gangs.

Research Question 2. Does engagement protect against gang involvement (GI) and gang attraction (GA) and promote achievement?

Robust evidence indicates that school engagement may be one of the most important factors not only related to school success, but also for protecting students from a host of risky activities and negative outcomes (Connell et al., 1995; Connell, 
Spencer, \& Aber, 1994; Finn \& Rock, 1997; Garcia-Reid et al., 2005; Jimerson et al., 2003; Pierson \& Connell, 1992; Ryan \& Patrick, 2001; Skinner, Zimmer-Gembeck, \& Connell, 1998; Wenzel, 1994). School engagement is especially important for school completion, which can set the stage for later life success. Therefore, I predict: For GI and GA:

H2a. Youth who are less engaged in school are more likely to be gang-involved. H2b. Youth who are more disaffected are more likely to be gang-involved. $\mathrm{H} 2 \mathrm{c}$. Youth who are less engaged in school are more likely to be attracted to gangs.

$\mathrm{H} 2 \mathrm{~d}$. Youth who are more disaffected are more likely to be attracted to gangs. H2e. Engagement will contribute to GI over and above disaffection. H2f. Disaffection will contribute to GI over and above engagement. H2g. Engagement will contribute to GA over and above disaffection. H2h. Disaffection will contribute to GA over and above engagement.

For achievement:

$\mathrm{H} 2 \mathrm{~g}$. Youth who are more engaged in school will perform better academically. $\mathrm{H} 2 \mathrm{~h}$. Youth who are more disaffected in school will perform worst academically.

H2f. Engagement and disaffection will be unique predictors of achievement.

Research Question 3. Do the motivational supports suggested by the larger process model, namely, school climate, teacher support, and the self-system processes 
of relatedness, competence, and autonomy, protect against GI and GA and promote achievement?

SSMMD says that context and self support engagement. So, if engagement protects against GI and GA and promotes achievement, then motivational supports should protect against GI and GA and promote achievement.

For GI and GA as outcome:

H3a. Each motivational support (namely, school climate, teacher support, and the self-system processes of relatedness, competence, and autonomy) will predict GI.

H3b. Each motivational support (namely, school climate, teacher support, and the self-system processes of relatedness, competence, and autonomy) will predict GA.

H3c. Achievement will predict GI and GA.

For achievement as outcome:

H3d. Each motivational support (namely, school climate, teacher support, and the self-system processes of relatedness, competence, and autonomy) will predict achievement.

Research Question 4. What are the processes through which school engagement can be supported?

4.1 Process 1: What is the relationship between the self-system processes, engagement, and disaffection? 
The SSMMD contends that three self-system processes (SSPs) should be instrumental in shaping engagement. Students' SSPs of relatedness, competence, and autonomy have been found to be key predictors of engagement and disaffection (Furrer \& Skinner, 2003; Patrick, Skinner, \& Connell, 1993; Skinner, Zimmer-Gembeck, \& Connell, 1998). However, because of its social nature, the SSP of relatedness is expected to have greater influence on engagement than the SSPs of competence and autonomy. Research has found that close and caring relationships with teachers and other adults in school are strong predictors of school engagement regardless of race, ethnicity, and SES (Brewster \& Bowen, 2004; Connell et al., 1994, 1995; Garcia-Reid, Reid \& Peterson, 2005; Woolley \& Bowen, 2007). Therefore, I predict:

H 4.1a The more students feel related, competent, autonomous, the more they will be engaged in school; whereas the lower students' SSPs, the more they will be disaffected.

$\mathrm{H}$ 4.1b Each SSP will be a unique predictor of engagement and disaffection, with relatedness being an especially important predictor.

4.2 Process 2: What is the relationship between school climate, teacher support, and engagement?

The characteristics of the context (i.e., teacher support) are hypothesized to be directly related to students' engagement and subsequent achievement. Research has shown that positive relationships with adults at school is positively related to school engagement, which can set the stage for later achievement (Brewster \& Bowen, 2004; Hamre \& Piante, 2001; Roderick, 2003; Stanton-Salazar, Chavez, \& Tai, 2001; Woolley 
\& Bowen, 2007). Stanton-Salazar (1997) asserts that teacher support as well as support from other adults in school may be more important for the academic success of racial/ethnic students because such support is harder to obtain. Therefore, I predict: H 4.2a The more students experience a supportive school climate and teacher support, the more they will be engaged in school; whereas students who experience lower school and teacher support will be more disaffected. H 4.2b School climate and teacher support will be unique predictors of engagement.

4.3 Process 3 . Is the relationship between overall school support and engagement mediated by self- system processes? Is the relationship between overall school support and disaffection mediated by self- system processes?

The motivational model asserts that the self-system processes develop through the interactions of the individual with his/her context. Therefore, depending on the motivational supports that the teacher and the school provide, it is expected that overall school support will influence engagement and disaffection through its role in the development of the SSPs. A composite score for "overall school support" will be calculated by aggregating school climate and teacher support. Three mediation models will be tested.

4.4. Process 4: Is the relationship between overall school support and each outcome (i.e., GI, GA, and achievement) mediated by engagement versus disaffection?

4.5. Process 5: Is the relationship between the SSPs and each outcome (i.e., GI, GA, and achievement) mediated by engagement versus disaffection? 
Statement of Purpose 50

Research Question 5. Does the larger process model provide a good account of GI and GA? Does the larger process model also provide a good account of achievement?

SSMMD states that context and self support engagement, which in turn protects against GI or GA and promotes achievement. This question evaluates (1) whether the SSPs mediates the relationship between overall school support and engagement; and (2) whether engagement mediates the relationship between motivational supports (i.e., overall school supports and the SSPs) and the outcomes (i.e, GI, GA, and achievement).

Research Question 6. What motivational supports are provided to youth who are involved in gangs compared to those who are not?

In order to answer this research question, profiles of levels of motivational supports will be examined for students with differential levels of gang involvement. Research question 6 will be subdivided into specific parts:

6.1 For contextual supports:

H6.1a Students who are gang-involved will experience lower levels of teacher support and school climate, compared to students who are not gang-involved.

H6.1b Students who are attracted to gangs will experience lower levels of teacher support and school climate, compared to students who are not attracted to gangs.

6.2 For SSPs: 
H6.2a Students who are gang-involved will feel less related, competent, and autonomous than students who are not gang involved.

H6.2b Students who are attracted to gangs will feel less related, competent, and autonomous than students who are not attracted to gangs.

6.3 For engagement and disaffection:

H6.3a Students who are gang-involved will be less engaged and more disaffected in school, compared to students who are not gang involved.

H6.3b Students who are attracted to gangs will be less engaged and more disaffected in school, compared to students who are not attracted to gangs.

6.4 For achievement:

H6.4a Students who are gang-involved will show lower levels of achievement than students who are not gang involved.

H6.4b Students who are attracted to gangs will show lower levels of achievement than students who are not attracted to gangs. 


\section{CHAPTER IV}

\section{Research Design and Method}

This study utilized a secondary analysis of data collected for a larger research project conducted by Dr. Ellen Skinner and colleagues at Portland State University (PSU). A collaborative academic partnership was established with the applicant's Dissertation Chair, Dr. Ellen Skinner, and Drs. Dilafruz Williams and Pramod Parajuli from the Graduate School of Education at PSU to evaluate the impact of participation in the garden-based program on students' engagement and learning. The evaluation evolved into a 5-year research program with the goal of examining the facilitators and dynamics of engagement as a framework for investigating the positive motivational development of youth in multiple domains within middle school, including a gardenbased program, Science, and school in general. The data on which this dissertation is based were collected in May 2008.

The garden-based program, broadly captured under the name of "Learning Gardens," is a joint community project of Portland State University (PSU), Portland Public Schools (PPS), and the city of Portland that was established in 2005. The project is part of the Portland International Initiative for Leadership in Ecology, Culture, and Learning (PIIECL), under the direction of Dilafruz Williams and Pramod Parajuli and a team of faculty, graduate students, and staff. It was designed to meet the needs of children and youth, parents, educators, and PSU students by offering demonstration, curriculum development, and research in the fields of leadership in sustainability, and sustainable technologies. 
Methods 53

The gardening program provides hands-on learning experiences to culturally diverse middle school students in planning, designing, planting, tending, growing, and harvesting a variety of plants, herbs, fruits, and vegetables. These direct learning experiences are used to enrich and enhance academic achievement goals especially in science, math, and literacy. In addition, the program serves the families, the surrounding neighborhoods, and community by addressing food security issues and supporting the local food economy.

\section{Participants}

Participants were recruited from a middle school located in Portland, OR. In the academic year 2007-2008, there were a total of 489 students between the ages of 11 and 15 years in grades $6^{\text {th }}$ to $8^{\text {th }}$. There were 33 teachers, 9 of whom taught Science. The middle school is considered one of the most culturally and linguistically diverse school in the Portland Public School district with $54.6 \%$ of its students being minorities (with 8.4\% African American, 24.1\% Latino/a, 15.3\% Asian, and 3.3\% Native American; 3.5 multiple ethnicities) and 41\% speak English as a second language. A total of 19 different languages are spoken by its students.

Students come from predominantly low socio-economic backgrounds, where $75 \%$ of students qualify for free or reduced lunch. The median family income is $\$ 41,267$ with an average family size of 3.22 persons. The school is located in a community that has a crime index (in all areas except murder) that is 1.5 to 3 times higher than the national average. A number of challenges are present in students' lives such as family instability due to unemployment, violence, drugs, or incarceration, 
linguistic barriers, and food insecurity. These challenges may contribute to low attendance and academic achievement, high rates of school dropout, and involvement in delinquency, drugs, alcohol, and gangs.

Design and Procedure

A cross-sectional design was used in the present study. Teachers administered self-report questionnaires to students in a 50-minute class session. At a different time and at their convenience, 6 out of 9 teachers also completed a survey that assessed student engagement in the classroom. Data were collected in May of 2008.

Students reported on the following information: (1) their engagement versus disaffection in school in general; (2) self-systems processes such as competence and autonomy; (3) belongingness, support, and engagement in the family and school domain, (4) school climate; (5) demographic information; and (6) involvement in extracurricular activities for self and friends. Respondents used a 5-point Likert-type scale to indicate whether each item was (1) totally not true, (2) a little bit true, (3) somewhat true, (4) fairly true, and (5) totally true. Negatively worded items will be reverse coded, and items in each scale will be averaged to calculate a composite score. Scale scores will range from 1 to 5, with higher scores indicating more of the respective constructs. Measures

The questionnaire used in the present study was comprised of selected items from validated measures (Belmont, Skinner, Wellborn, and Connell, 1991; Ryan \& Connell, 1989; Wellborn, Connell, \& Skinner, 1990). In addition, three additional scales (Belongingness, Support, and Engagement scales) were included that were developed in 
a prior study (Escribano, 2007). These latter scales were pilot tested on 39 Latino students enrolled in an alternative school. Each scale tapped into the construct of belongingness, support, and engagement in the family, school, and peer domains. The construct definitions were based on the study's theoretical conceptualization as well as on prior theory and research in the areas of attachment, support, and engagement (Armsden \& Greenberg, 1987; Bowlby, 1969/1982; Brewster \& Bowen, 2004; Goodenow, 1993; Wellborn et al., 2005). The initial psychometric properties for all three scales were satisfactory. More specific information about the scales follows. An index of study items by construct is presented in Table 4.1 .

Demographic items. Demographic items include 5 questions that ask students to report their age, race/ethnicity, month of birth, place of birth, and primary language(s) spoken at home.

Belongingness Scale (Escribano \& Skinner, in preparation). This scale assesses a youth's sense of belonging, membership, feelings of being valued, feeling important, safe, respected, and cared for/about in the family (14 items), school (14 items), and peer domain (13 items). It contains 41 items in total. The internal consistencies for the Family, School, and Peer subscales were .87, .81, and .86, respectively (Escribano, 2007). For the present study, 5 items were selected from the school domain. Example items are "I feel safe at this school" and "Sometimes I feel like I don't belong to this school," (reverse-coded).

Support Scale (Escribano \& Skinner, in preparation). This scale measures the degree to which the youth perceives his/her parents/teachers/peers as communicative, 
responsive, caring, positive, helpful, dependable, available, attuned, accepting, warm, and encouraging. It contains 44 items in total. The internal consistencies for the Family (15 items), School (15 items), and Peer (14 items) subscales were .87, .76, and .87, respectively (Escribano, 2007). For the present study, 3 items were selected from the school domain. Example items are "My teachers understand me" and "If I have a problem, I can go to my teachers.”

Engagement Scale (Escribano \& Skinner, in preparation). This scale taps into the level of involvement, participation, enjoyment, liking, persistence, and investment in the activities of the family, school, and peer domain. It contains 43 items in total. The internal consistencies for the Family (14 items), School (14 items), and Peer (15 items) subscales were $.89, .71$, and .89, respectively (Escribano, 2007). For the present study, 9 items were selected for assessing school engagement. Example items are "I look forward to coming to school" and "School makes me angry," (reverse-coded).

Teacher as a Social Context Questionnaire-Student-Report (Belmont, Skinner, Wellborn, and Connell, 1991). This measure is comprised of 52 items which taps into student experiences of their interactions with their teachers along three dimensions (i.e., involvement, structure, and autonomy support). It is comprised of the 3 subscales from which a total of 8 items were selected and adapted for the present study. The first subscale, Teacher Involvement, included 3 items that assesses students' experiences about their teacher's involvement in the classroom. These items taps warmth and affection, dedication of resources, knowledge about the student's needs, and dependability versus hostility and neglect. Example items are "My teachers just don't 
understand me" and "I can't really count on my teachers," (reserve-coded). Only negative items were included in this subscale. The second subscale, Teacher Provision of Structure, included 2 items measures the kind and amount of structure, including clarity of expectations and contingency, versus chaos experienced by students from their teachers. The items are "I know what my teacher expects of me in class" and "My teachers keep changing the rules in our class," (reverse-coded). The third subscale, Teacher Provision of Autonomy Support, included 3 items assesses students' perceptions of teachers providing choice, relevance, and respect versus controlling behavior. These items are "My teachers explain why the things I learn in school are important," "My teachers don't give me much choice about how I do my schoolwork," and "My teachers never talk about how I can use the things we learn in school," (reverse-coded). After reverse-coding the negative items, a composite score will be calculated by first aggregating these 8 items and the 3 items of teacher support and then averaging the 11 items.

Perceived Control and Competence. Student expectations about the extent to which they can achieve success in school and avoid failure will be assessed using the six-item Control Beliefs subscale of the Student perceptions of Control Questionnaire (Wellborn, Connell, \& Skinner, 1990). This measure taps into students' generalized beliefs about the extent to which they can produce desired outcomes and avoid negative ones in the academic domain. Example items are "If I decide to learn something, I can" and "I can't get good grades, no matter what I do," (reverse-coded). The internal 
consistency for this subscale is satisfactory (Cronbach's alpha = .70; Marchand \& Skinner, 2007).

Autonomy Orientation. Five items were selected from Ryan \& Connel's (1989) measure of academic autonomy, which is composed of 17 items that tap whether students engage in activities because they feel coerced or because they derive satisfaction and enjoyment from the learning task. These items are from two of the four subscales: (1) Intrinsic Self-Regulation (2 items), which refers to doing school work because it is inherently enjoyable; and (2) Identified Self-Regulation (4 items), which refers to reasons for undertaking a learning task due to a desire for learning and understanding. Example items are "Why do I do my homework? Because it is fun" (intrinsic) and "Why do I do my classwork? Because we are learning important things" (identified).

School Climate. Three items were developed that assess the psychological school environment experienced by the students. These items tap into student perceptions of their teacher's perceptions of their ability to succeed, fairness, and the relationships with school personnel. Example items are "People here know I can do good work" and "The rules at this school are so unfair," (reverse-coded).

Student Learning and Achievement. Student performance scores such as grades and achievement test scores in Science, Math, and Reading were gathered from student records. An aggregated measure of school performance will be computed. 
Operational Definitions for Assessing Students' Level of Involvement in Gangs

Self-nomination of gang involvement has been shown to be a valid indicator of GM (Esbensen, Winfree, He, \& Taylor, 2001). In addition, research has demonstrated that having peers that are involved in gangs is a potential risk factor for GM (Curry \& Spergel, 1992). Therefore, group classification for assessing the level of ganginvolvement is based on two criteria: (1) students' self-report of spending time with a gang; and (2) student report of friends' involvement with a gang. The items that assessed the level of gang-involvement were embedded within a series of activity options that were entitled "Things I like to do" and "Things my friends like to do." The other activity options were involvement in a sports team, church, youth group, etc. Students responded to the activity items using a 5- point Likert scale that ranged from 1 (totally not true) to 5 (totally true). The indirect method for assessing students' level of gang-involvement was in compliance with the School District's IRB concerns to safeguard student privacy that fell under the Protection of Pupil Rights Amendment (PPRA), which did not allow a "yes" or "no" response option.

The levels of gang-involvement were operationalized as follows:

1. Potential Gang Members: youth who self-disclosed that they and their friends spent time with a gang.

2. At-risk for gang-involvement: youth who self-disclosed that either they or their friends spent time with a gang. These youth were considered at risk for GM. 
3. Not-involved youth: youth who did not self-disclose that either they nor their friends spent time with a gang.

Attraction to Gangs. One item was included that assessed the students' level of attraction to gangs. This item was also embedded within a set of activities options (e.g., church, youth group, etc) that were entitled, "How much would I like to...?” Students responded to these items using a 5-point Likert scale that ranged from (1) not at all to (5) very much. Only one item that assessed students' level of attraction to gangs was included in order to be in compliance with the School District's IRB concerns to safeguard student privacy that fell under PPRA. 
Table 4.1

Index of Items by Study Constructs

Construct

School Climate

Teacher Support

Teacher Involvement

Teacher Structure

Teacher Autonomy Support

Self-System Processes

Relatedness

Competence
Items

People here know I can do good work.

The rules at this school are so unfair. (-)

People here are always telling me what to do. (-)

My teachers understand me.

My teachers really care about me.

If I have a problem, I can go to my teachers.

My teachers just don't understand me. (-)

Sometimes I wonder if my teachers really like me. (-)

I can't really count on my teachers. (-)

I know what my teacher expects of me in class.

My teachers treat me fairly.

My teachers keep changing the rules in our class. (-)

My teachers explain why the things I learn in school are important.

My teachers don't give me much choice about how I do my schoolwork. (-)

My teachers never talk about how I can use the things we learn in school. (-)

I feel safe at this school.

I feel like a real part of Lane.

I feel like people at this school don't understand me. (-)

I feel like an outsider at this school. (-)

Sometimes I feel as if I don't belong to this school. (-)

If I decide to learn something hard, I can.

I can do well in school if I want to.

I can get good grades in school.

I can't get good grades, no matter what I do. (-) 
I can't stop myself from doing poorly in school. (-)

I can't do well in school, even if I want to. (-)

\begin{tabular}{|c|c|}
\hline \multicolumn{2}{|l|}{ Autonomy } \\
\hline Intrinsic & Because it's fun. \\
\hline \multirow{5}{*}{ Identified } & Because it's interesting. \\
\hline & Because I want to understand the subject. \\
\hline & Because homework helps me learn more. \\
\hline & Because we are learning important things. \\
\hline & Because doing well in school is important to me. \\
\hline \multirow[t]{3}{*}{ Engagement } & I look forward to coming to school. \\
\hline & I enjoy learning new things in school. \\
\hline & I try hard to do well in school. \\
\hline \multirow[t]{6}{*}{ Disaffection } & When we work on something in class, I feel bored. (-) \\
\hline & When I'm in class, I feel mad. (-) \\
\hline & School makes me angry. (-) \\
\hline & When I'm in class, I just act like I'm working. (-) \\
\hline & In school, I don’t work very hard. (-) \\
\hline & I can't stand doing school work. (-) \\
\hline
\end{tabular}




\section{CHAPTER V}

\section{Results}

The central goal of the study was to examine engagement as a protective factor for youth gang involvement. Profiles of students with differential levels of risk for gang involvement were distinguished and examined across study constructs (e.g., engagement and disaffection). A secondary goal was to examine the mechanisms through which school engagement acts as a protective factor for youth at risk for joining gangs. A detailed description of the analyses that were conducted follows. Missing Data

The present study used a secondary data analysis from a larger project. After data entry, data cleaning, and verification, research team members reached the decision to delete 31 cases that were classified as invalid data from the dataset prior to examining missing data patterns. Invalid data classification was based on visual judgment of research assistants who entered the data. For example, surveys that had one value entered for all items throughout the survey were classified as invalid data.

SPSS 12.0 was used to examine missing data patterns for the dataset of 436 participants. One hundred and two items were collected from each participant in the dataset. A total of 122 cases had complete data. A case-wise analysis demonstrated that the number of missing items ranged from $1(1.0 \%)$ to $96(94.1 \%)$ items. A closer examination of the cases that were missing the most data ( $\geq 94 \%)$ showed that (1) 8 cases had no student survey data on the date of data collection; however, these cases still appeared on class rosters; and (2) 86 cases were absent on the day of data 
collection, but teacher-reported data were gathered from these students for the larger project. The decision was made to delete these cases prior to imputation as they did not fulfill “missing at random” (MAR) properties (Schafer \& Graham, 2002).

A variable-wise missing analysis demonstrated that the average number of participants who were missing data on any given variable ranged from 3 to 128 (.6$29 \%$ ), with the next highest number of participants missing data at 1 variable (27\%).

For the remaining variables, $26 \%$ or fewer of the participants were missing data. For the variables missing 128 responses (month of birth of participant), there also showed a tabulated pattern of missingness, where only 6 participants were missing only this item. Following this analysis of missing data patterns, the decision was made not to exclude any more cases from the analysis. SPSS 12.0 maximum likelihood (ML) estimation with an estimation maximization (EM) algorithm was used to impute the observed missing data. All variables except demographic information were used for imputation, resulting in a complete dataset that included 342 cases with complete data.

\section{Descriptive Analyses}

Measurement properties and descriptive statistics. All analyses were conducted using SPSS 12.0. Initial descriptive analyses were conducted to calculate the means, standard deviations, and internal consistencies (Cronbach's alpha) for all the variables used in the study. Table 5.1 presents the internal consistency reliabilities (Cronbach's alpha), means and standard deviations for all subscales.

Items of the survey were aggregated forming subscales that captured each construct (e.g., school belongingness). Subscales that tap into a particular construct 
contain both positively and negatively worded items (except for Disaffection, which only contained negatively worded items). Items from each scale were individually aggregated and then averaged to form a composite score, in which higher scores reflect higher levels of each respective construct. Negative items were reverse-coded and combined with positive items. Hence, internal consistency reliabilities using Cronbach's alpha for most subscales were satisfactory $(\leq .77)$. The internal consistencies for engagement ( $\alpha=.68)$, competence $(\alpha=.69)$, and teacher autonomy support $(\alpha=.64)$ were adequate. Low internal consistencies were found for the subscales of school climate $(\alpha=.50)$ and teacher structure $(\alpha=.60)$. Due to the low internal consistencies, the correlations between teacher structure and school climate may be attenuated. However, it should be noted that these scales also contained few items (e.g., school climate had only 3 items).

An examination of the means demonstrated that the distributions of all scales were slightly negatively skewed, except for disaffection which was positively skewed. Mean scores tended toward the upper half of the score range. On examining the skewness statistics, only one scale slightly exceeded the acceptable level of 1.0 (for disaffection, 1.01). The kurtosis analyses demonstrated that all variables fell below 2.5; therefore, no transformations were conducted (Kline, 2005). These observations suggest that the students viewed themselves as receiving support from teachers and other school staff, as competent and autonomous students who felt that they belonged to their school and were engaged in the learning process. 
Results 66

The standard deviations for all scales were moderate, ranging from .79 to 1.27, which suggests that the variability in scale scores between students is adequate to detect significant effects. An examination of the minimum and maximum scores demonstrated that the scales did not reach ceiling or floor effects.

\section{Table 5.1}

Summary of Means, Standard Deviations, and Internal Consistencies for each Construct.

\begin{tabular}{|c|c|c|c|c|}
\hline Scale & $\begin{array}{l}\text { Number } \\
\text { Of Items }\end{array}$ & $\alpha$ & $M$ & $S D$ \\
\hline Overall School Supports & 15 & .88 & 3.65 & .80 \\
\hline School Climate & 3 & .51 & 3.74 & .87 \\
\hline Teacher Support & 12 & .87 & 3.63 & .85 \\
\hline Teacher Involvement & 6 & .78 & 3.46 & .95 \\
\hline Teacher Structure & 3 & .61 & 3.87 & .94 \\
\hline $\begin{array}{l}\text { Teacher } \\
\text { Autonomy Support }\end{array}$ & 3 & .64 & 3.72 & .99 \\
\hline Self-System Processes & 17 & .86 & 3.71 & .72 \\
\hline $\begin{array}{l}\text { School Belongingness } \\
\text { (Relatedness) }\end{array}$ & 5 & .77 & 3.68 & .94 \\
\hline $\begin{array}{l}\text { Perceived Control and } \\
\text { Competence }\end{array}$ & 6 & .69 & 4.24 & .75 \\
\hline $\begin{array}{l}\text { Autonomy Orientation } \\
\text { Intrinsic }\end{array}$ & 6 & .90 & 3.21 & 1.10 \\
\hline $\begin{array}{l}\text { Self- Regulation } \\
\text { Identified }\end{array}$ & 2 & .85 & 2.38 & 1.27 \\
\hline Self-Regulation & 4 & .89 & 3.63 & 1.16 \\
\hline Engagement & 3 & .68 & 3.76 & .91 \\
\hline Disaffection & 6 & .79 & 2.04 & .79 \\
\hline
\end{tabular}

Note. $N=342$. Range of all scores are from 1-5. Higher scores indicate more of the respective construct. 
Intra-constructs correlations. Correlations among constructs were calculated as an indication of the degree of interdependence that may exist among constructs. All correlations among constructs were small to moderate ( $r$ ranged from .35 to .65 ) except for the correlations between teacher involvement and teacher structure $(r=.71)$. This high correlation (which approaches the level of the internal consistencies) suggests that the scales may be measuring the same underlying dimension and can be aggregated to calculate a total score. The bivariate relations among the constructs that comprised overall school support, the aggregate SSPs, and between engagement and disaffection were in the expected direction. For overall school support, student experiences of a supportive school environment correlated positively with student experiences of teacher involvement, teacher structure, and teacher autonomy. The same pattern of correlations was observed in student self-perceptions of relatedness, competence, and autonomy. Between engagement and disaffection, the expected negative relationship was observed. The more engaged students were in school, the less disaffection they reported. Tables 5.2, 5.3, and 5.4 show the intra-construct corrections among constructs. 
Table 5.2

Intra-Construct Correlations among Indicators of School Support

\begin{tabular}{|c|c|c|c|c|c|c|}
\hline & & \multirow[b]{2}{*}{$\begin{array}{l}\text { School } \\
\text { Climate }\end{array}$} & \multicolumn{4}{|c|}{ Overall School Support } \\
\hline & & & $\begin{array}{c}\text { Teacher } \\
\text { Involvement }\end{array}$ & $\begin{array}{l}\text { Teacher } \\
\text { Structure }\end{array}$ & $\begin{array}{c}\text { Teacher Autonomy } \\
\text { Support }\end{array}$ & $\begin{array}{l}\text { Total Teacher } \\
\text { Support }\end{array}$ \\
\hline \multirow[t]{4}{*}{$\begin{array}{l}\text { Overall School } \\
\text { Support }\end{array}$} & School Climate & -- & -- & -- & -- & -- \\
\hline & Teacher Involvement & .55 & -- & -- & -- & -- \\
\hline & Teacher Structure & .49 & .71 & -- & -- & -- \\
\hline & $\begin{array}{r}\text { Teacher Autonomy } \\
\text { Support }\end{array}$ & .52 & .65 & .60 & -- & -- \\
\hline
\end{tabular}

Note. All correlations are significant at a 0.01 level.

Table 5.3

Intra-Construct Correlations among the Self System Processes

\begin{tabular}{lcccc}
\hline & & \multicolumn{3}{c}{ Self-System Processes } \\
\cline { 3 - 5 } & & Relatedness & Competence & Autonomy \\
\hline SSPs & Relatedness & -- & -- & -- \\
& Competence & .43 & -- & -- \\
& Autonomy & .37 & .35 & -- \\
\hline
\end{tabular}

Note. All correlations are significant at a 0.01 level.

Table 5.4

Correlation between Engagement and Disaffection

\begin{tabular}{lcc} 
& Engagement & Disaffection \\
\hline Engagement & -- & -- \\
Disaffection & -.62 & -- \\
\hline Note. All correlations are significant at a 0.01 level. &
\end{tabular}


Research Question 1. Can we construct an indicator assessing risk for gang involvement that taps personal attraction to gangs as a motivational precursor to actually joining a gang?

The first goal of this study was to identify youth who were at risk for gangs and suggested a method of identifying youth who were attracted to gangs, but were not yet involved in gangs. This method was compared to traditional methods of identifying youth with differing levels of gang involvement.

\section{Profiles of Students At-Risk for Gang involvement}

Separate analyses were conducted on two student profiles depending on their level of risk for joining gangs. The first profile was based on reports of self and friend involvement with gangs. The second profile was based on student reports of the degree of their personal attraction towards gangs.

Student Profile (1): Levels of gang involvement. Students responded to the items that assessed potential gang involvement using a 5-point Likert scale that ranged from 1 (totally not true) to 5 (totally true). These items were "Things I like to do," and "Things my friends like to do.” Following Escribano's (2007) coding rationale, the continuous items were subsequently recoded to two extreme groups. The first group included cases that responded to the question as a 1 (i.e., totally not true). The second group included all other cases that responded to the question as a 2 or greater (i.e., from a little bit true to totally true).

Three groups were distinguished in order to differentiate levels of potential gang involvement. The criteria for classifying group membership depended on two 
conditions: (1) that the youth self-disclosed spending time with a gang or not; and (2) that the youth had friends who spend time with a gang or not. The following three groups were differentiated: (1) potential gang members, who self-disclosed spending time with a gang; (2) at-risk for gang involvement, who reported that they or their friends spend time with a gang; and (3) not-involved youth, who reported that neither they themselves nor their friends spend time with a gang. Table $5.5 \& 5.6$ summarizes group classification by gender and grade.

Table 5.5

Group Classification for Levels of Gang Involvement by Gender

\begin{tabular}{lccccc}
\hline \multirow{5}{*}{ Gender } & & \multicolumn{3}{c}{ Levels of Gang Involvement } & \\
\cline { 3 - 5 } & Female & Not Involved & At Risk & Potential GM & Total \\
\cline { 3 - 5 } & Male & $98(29)$ & $33(9.6)$ & $43(12.6)$ & $174(51)$ \\
& Total & $190(56)$ & $34(9.9)$ & $42(12.3)$ & $168(49)$ \\
& & $67(19.6)$ & $85(24.9)$ & $342(100)$ \\
\hline
\end{tabular}

Note. GM= Gang membership. Numbers in parentheses represent percentages from total sample.

Table 5.6

Group Classification for Levels of Gang Involvement by Grade

\begin{tabular}{cccccc} 
& & \multicolumn{3}{c}{ Levels of Gang Involvement } & \\
\cline { 3 - 5 } Grade & & Not Involved & At Risk & Potential GM & Total \\
\cline { 3 - 5 } & 6th & $85(25)$ & $22(6.4)$ & $21(6)$ & $128(37.4)$ \\
& 7 th & $64(19)$ & $22(6.4)$ & $37(11)$ & $123(36)$ \\
& 8th & $41(12)$ & $23(6.7)$ & $27(8)$ & $91(26.6)$ \\
& Total & $190(56)$ & $67(19.6)$ & $85(25)$ & $342(100)$ \\
\hline
\end{tabular}

Note. GM= Gang membership. Numbers in parentheses represent percentages from total sample.

As can be seen, approximately $25 \%$ of students reported that they and their friends spent time with a gang (i.e., potential GMs). Of this group, approximately 51\% were female. Approximately $16 \%$ of $6^{\text {th }}$ graders, $30 \%$ of $7^{\text {th }}$ graders, and $29.6 \%$ of $8^{\text {th }}$ graders were classified as potential gang members (GM), with $7^{\text {th }}$ graders having the 
highest percentage of potential GM within the group (44\%). For the at-risk group, approximately $20 \%$ of students reported that either they or their friends spent time with a gang. Of the at-risk group, approximately $49 \%$ were female. Approximately 17 to $25 \%$ of students from each grade were classified as students who are at-risk for gang involvement. And, lastly, $56 \%$ of students reported that neither they nor their friends spent time with a gang and, of this group, $52 \%$ were female. Of the students who were not-involved in gangs, approximately $45 \%$ were $6^{\text {th }}$ graders, $34 \%$ were $7^{\text {th }}$ graders, and $22 \%$ were $8^{\text {th }}$ graders.

Gender and grade differences across levels of GI. A chi- square test of independence was conducted to evaluate the relationship between gender and levels of GI. Results indicated that the proportion of the levels of GI did not significantly differ across gender, $\chi^{2}(2)=.11, n s$. A chi- square test of independence was conducted to evaluate the relationship between grade and levels of GI. Results indicated that the proportion of the levels of GI differed significantly across grade, $\chi^{2}(4)=12.73, p<.05$. The Holm's sequential Bonferroni method was used to control for Type I error at a .05 level across all 3 comparisons. The proportions of GI differed significantly between $6^{\text {th }}$ graders and $7^{\text {th }}$ graders, $\chi^{2}(2, n=251)=7.28, p<.05$, Cramer's $V=.17$. The proportions of GI differed significantly between $6^{\text {th }}$ graders and $8^{\text {th }}$ graders, $\chi^{2}(2, n=$ $219)=10.18, p<.01)$, Cramer's $V=.22$. The proportions of GI did not differ significantly between $7^{\text {th }}$ graders and $8^{\text {th }}$ graders, $\chi^{2}(2, n=214)=1.88, n s$.

Additional follow up test were conducted to differences among the proportions of levels of GI between $6^{\text {th }}$ and $7^{\text {th }}$ graders, and $6^{\text {th }}$ and $8^{\text {th }}$ graders. The pairwise 
comparison that evaluated the differences between "not involved in gangs" and "potential GMs" for $6^{\text {th }}$ grade versus $7^{\text {th }}$ grade students was significant, $\chi^{2}(1, n=207)=$ $7.26, p<.01$, Cramer's $V=.19$. The odds of a $7^{\text {th }}$ grade student being a potential GM are 2.3 times higher than the odds of a $6^{\text {th }}$ grade student being a potential GM. The pairwise comparison that evaluated the differences between "not involved in gangs" and "at risk for gangs" for $6^{\text {th }}$ grade versus $8^{\text {th }}$ grade students was significant, $\chi^{2}(1, n=171)$ $=4.88, p<.05$, Cramer's $V=.17$. The odds of a $8^{\text {th }}$ grade student being at risk for gangs are 2.2 times higher than the odds of a $6^{\text {th }}$ grade student being at risk for gangs. The pairwise comparison that evaluated the differences between "not involved in gangs" and “potential GMs" for $6^{\text {th }}$ grade versus $8^{\text {th }}$ grade students was significant, $\chi^{2}(1, n=174)=$ $8.21, p<.01$, Cramer's $V=.22$. The odds of a $8^{\text {th }}$ grade student being a potential GM are 2.6 times higher than the odds of a $6^{\text {th }}$ grade student being a potential GM. All other pairwise comparisons between $6^{\text {th }}$ and $7^{\text {th }}$ graders, and $6^{\text {th }}$ and $8^{\text {th }}$ graders in levels of GI were not significant. These results suggest that younger students are less likely to be at risk for gangs and gang-involved than their older counterparts. Table 5.7 displays the pairwise comparison between grades across levels of GI.

\section{Table 5.7}

Pairwise Comparison between Grades in levels of Gang Involvement

\begin{tabular}{|c|c|c|c|c|}
\hline Comparison & $\mathrm{n}$ & p-value & Odd Ratio & Referent Group \\
\hline \multicolumn{5}{|l|}{$6^{\text {th }}$ versus $7^{\text {th }}$ graders } \\
\hline Potential GMs versus Not Involved & 207 & $p<.01$ & 2.3 & $7^{\text {th }}$ graders \\
\hline \multicolumn{5}{|l|}{$\sigma^{\text {th }}$ versus $8^{\text {th }}$ graders } \\
\hline At Risk versus Not Involved & 171 & $p<.05$ & 2.2 & $8^{\text {th }}$ graders \\
\hline Potential GM versus Not Involved & 174 & $p<.01$ & 2.6 & $8^{\text {th }}$ graders \\
\hline
\end{tabular}

Note. All other pairwise comparisons were not significant at a .05 level. 
Student Profile (2): Levels of attraction to gangs. Two groups were differentiated contingent on student responses to a continuous item that assesses gang attraction. Students responded to the following item using a 5-point Likert-scale with (1) being not at all and (5) being very much: "How much would you like to join a gang?" Following Escribano's (2007) coding rationale, this continuous item was recoded into a dichotomous variable with two extreme groups. The first group included cases that responded to the question as a 1 (i.e., not at all). The second group included all other cases that responded to the question as a 2 or greater (i.e., from just a little to very $m и$ ch). The rationale for this distinction was based on the assumption that finding gangs "just a little" attractive can be considered a potential risk factor for GM. Table $5.8 \& 5.9$ summarizes the group classification by gender and grade for attraction to gangs.

Table 5.8

Group Classification for Levels of Gang Attraction by Gender

\begin{tabular}{ll|c|c|c}
\hline \multirow{3}{*}{ Gender } & \multicolumn{3}{c}{ Levels of Gang Attraction } \\
\cline { 2 - 5 } & Female & $128(37.4)$ & $46(13.5)$ & Total \\
& Male & $134(39.2)$ & $34(9.9)$ & $168(49)$ \\
& Total & $262(76.6)$ & $80(23.4)$ & $342(100)$ \\
\hline
\end{tabular}

Note. Numbers in parentheses represent percentages from sample. 
Table 5.9

Group Classification for Levels of Gang Attraction by Grade

\begin{tabular}{ccccc}
\hline & & \multicolumn{3}{c}{ Levels of Gang Attraction } \\
\cline { 3 - 5 } Grade & 6 th & $108(31.6)$ & $20(5.8)$ & $128(37.4)$ \\
\cline { 3 - 5 } & 7 th & $89(26)$ & $34(9.9)$ & $123(36)$ \\
& 8th & $65(19)$ & $26(7.6)$ & $91(26.6)$ \\
& Total & $262(76.6)$ & $80(23.4)$ & $342(100)$ \\
\hline
\end{tabular}

Note. Numbers in parentheses represent percentages from sample.

As can be seen, approximately $23 \%$ of students reported that they were attracted to gangs. Of this group, approximately $58 \%$ were female. Approximately $16 \%$ of $6^{\text {th }}$ graders, $28 \%$ of $7^{\text {th }}$ graders, and $29 \%$ of $8^{\text {th }}$ graders were found to be attracted to gangs. In contrast, $77 \%$ of students reported that they were not attracted to gangs. Of the notattracted group, approximately $49 \%$ were female. Approximately $84 \%$ of $6^{\text {th }}$ graders, $72 \%$ of $7^{\text {th }}$ graders, and $71 \%$ of $8^{\text {th }}$ graders reported that they were not attracted to gangs.

Gender and grade differences across levels of GA. A chi- square test of independence was conducted to evaluate the relationship between gender and levels of GA. Results indicated that the proportion of the levels of GA did not significantly differ across gender, $\chi^{2}(1)=1.83, n s$. A chi- square test of independence was conducted to evaluate the relationship between grade and levels of GA. Results indicated that the proportion of the levels of GI differed significantly across grade, $\chi^{2}(2)=6.91, p<.05$.

Follow up pairwise comparisons were conducted to evaluate the difference among the proportions. The Holm's sequential Bonferroni method was used to control for Type I error at a .05 level across all 3 comparisons. The pairwise comparison that evaluated the differences between "not attracted to gangs" and "attracted to gangs" for 
$6^{\text {th }}$ grade versus $7^{\text {th }}$ grade students was significant, $\chi^{2}(1, n=251)=5.37, p<.05$, Cramer's $V=.15$. The odds of a $7^{\text {th }}$ grade student being attracted to gangs are 2 times higher than the odds of a $6^{\text {th }}$ grade student being attracted to gangs. The pairwise comparison that evaluated the differences between "not attracted to gangs" and “attracted to gangs" for $6^{\text {th }}$ grade versus $8^{\text {th }}$ grade students was significant, $\chi^{2}(1, n=219)$ $=5.37, p<.05$, Cramer's $V=.16$. The odds of a $8^{\text {th }}$ grade student being attracted to gangs are 2.1 times higher than the odds of a $6^{\text {th }}$ grade student being attracted to gangs. The pairwise comparison that evaluated the differences between "not attracted to gangs" and "attracted to gangs" for $7^{\text {h }}$ grade versus $8^{\text {th }}$ grade students was not significant, $\chi^{2}(1, n=214)=.02, n s$. These results suggest that older students are more likely to be attracted to gangs than their younger counterparts. Table 5.10 displays the pairwise comparisons between grades across levels of GA.

Table 5.10

Pairwise Comparison between Grades in levels of Gang Attraction

\begin{tabular}{|l|l|c|c|c|}
\hline Comparison & $\mathrm{n}$ & $\mathrm{p}$-value & Odd Ratio & Referent Group \\
\hline $6^{\text {th }}$ versus $7^{\text {th }}$ graders & \multicolumn{5}{l|}{} \\
\hline Attracted versus Not Attracted & 251 & $p<.05$ & 2 & $7^{\text {th }}$ graders \\
\hline $6^{\text {th }}$ versus $8^{\text {th }}$ graders & \\
\hline Attracted versus Not Attracted & 219 & $p<.05$ & 2.1 & $8^{\text {th }}$ graders \\
\hline $7^{\text {th }}$ versus $8^{\text {th }}$ graders & $n s$ & & \\
\hline Attracted versus Not Attracted & 214 & $n s$ & \\
\hline
\end{tabular}


Does this attraction indicator tell us something about risk for gang involvement different from traditional methods of self-reports?

In order to answer this question, a cross tabulation is presented in which a contingency matrix displays the joint distribution of each student profile. Each cell gives the percentage of students who share each combination of categories. A chisquare test of independence examined if there was a relationship between each profile of risk for joining gangs. As expected, results indicated that personal attraction to gangs revealed a different distribution of students than the traditional method, $\left(\chi^{2}(2)=1.63, p\right.$ $<0.01)$. Considering these results, personal attraction to gangs may be considered a precursor to GI as it is found that some students that were "not involved in gangs" $(\mathrm{n}=5)$ were attracted to gangs. However, not all students who were classified as "potential GM" in Profile 1 were also attracted to gangs in Profile 2. That is, out of the 85 students who were classified as potential GM, 23 students $(27.1 \%)$ reported that they were not attracted to gangs. These unexpected results may suggest that some youth who spend time with a gang may not particularly enjoy it. These results could be explained in two ways: (1) some youth may spend time with a gang because they are either forced to or have no other options to meet other friends; or (2) they may enjoy "hanging out" with gang-involved friends and/or family members, but are not particularly interested in participating in gang activities. Table 5.11 displays the cross tabulation of both student profiles. 
Table 5.11

Cross Tabulation of Student Profiles of Risk

\begin{tabular}{|l|ccc|c|}
\hline & Not Involved & At-Risk & Potential GM & Total \\
\hline Not Attracted & 185 & 54 & 23 & 262 \\
Attracted & 5 & 13 & 62 & 80 \\
\hline Total & 190 & 67 & 85 & 342 \\
\hline
\end{tabular}

Note. $N=342$.

Research Question 1b. Do the levels of risk for joining gangs differ across ethnic groups? In other words, are there certain ethnic groups particularly at risk for joining gangs?

Profile (1): Levels of gang involvement. In order to answer this question, a cross tabulation is presented in which a contingency matrix displays the levels of gang involvement across ethnicity. A 4 x 3 contingency table analysis was conducted to evaluate whether there was a relationship between ethnicity and levels of gang involvement. Counter to expectations, ethnicity and levels of gang involvement were found to be significantly related $\left(\chi^{2}(6)=26.46, p<.01\right)$, Cramer's $V=.32$. That is, levels of gang involvement differed across ethnic groups. Follow up tests were conducted to evaluate the differences among the propositions of GI across ethnic groups. The Holm's sequential Bonferroni method was used to control for Type I error at a .05 level across all 6 comparisons. The proportions of the levels of GI differed significantly between White and Latino ethnic groups, $\chi^{2}(2, n=196)=24.10, p<.01$, Cramer's $V=.35$. All other pairwise comparisons between ethnic groups did not find the proportions of the levels of GI to be significantly different from each other. 
Additional follow up tests were conducted to evaluate the differences among the proportions of levels of GI across White and Latino groups. The pairwise comparison that evaluated the differences between "not involved in gangs" and "potential GMs" for White versus Latino students was significant, $\left.\chi^{2}(1, n=160)=23.96, p<.01\right)$, Cramer's $V=.39$. The odds of a Latino student being a potential GM versus not involved in gangs are 5 times higher than the odds of a White student being a potential GM versus not involved in gangs. The pairwise comparison that evaluated the differences between "at risk for gangs" and "potential GMs" for White versus Latino students was significant, $\chi^{2}$ $(1, n=86)=7.52, p<.01)$, Cramer's $V=.30$. The odds of a White student being at risk for gangs versus potential GM are 1.1 times higher than the odds of a Latino student being at risk for gangs versus potential GM. The pairwise comparison that evaluated the differences between "not involved in gangs" and "at risk for gangs" for White versus Latino students was not significant, $\chi^{2}(1, n=146)=1.53, n s$. Table 5.12 displays the cross tabulation of levels of gang involvement across ethnicity. Table 5.13 displays the pairwise comparisons between Latino and White ethnic groups in levels of GI.

Table 5.12

Cross Tabulation of Levels of Gang Involvement across Ethnicity

\begin{tabular}{|l|ccc|c|}
\hline & Not Involved & At-Risk & Potential GMs & Total \\
\hline White & 82 & 23 & 17 & 122 \\
\hline African American & 7 & 5 & 3 & 15 \\
\hline Latino & 28 & 13 & 33 & 74 \\
\hline Asian & 31 & 11 & 14 & 56 \\
\hline Total & 148 & 52 & 67 & 267 \\
\hline
\end{tabular}

Note. $n=267$. Multiracial, Native American, and Native Hawaiian Pacific Islander students were not included in analyses. 
Results 79

Table 5.13

Pairwise Comparison between Latino and White ethnic groups in levels of Gang Involvement

\begin{tabular}{|l|l|c|c|c|}
\hline Comparison & $\mathrm{n}$ & $\mathrm{p}$-value & Odd Ratio & Referent Group \\
\hline At Risk versus Not Involved & 146 & $n s$ & & \\
\hline Potential GM versus Not Involved & 160 & $p<.01$ & 5 & Latinos \\
\hline At Risk versus Potential GM & 86 & $p<.01$ & 1.1 & White \\
\hline
\end{tabular}

Profile (2): Levels of gang attraction. A chi-square test of independence was also conducted to evaluate whether there was a relationship between ethnicity and personal attraction to gangs. Counter to expectations, ethnicity and personal attraction to gangs were found to be significantly related, $\chi^{2}(3)=12.63, p<.01$, Cramer's $V=.28$. Follow up tests were conducted to evaluate the differences among the propositions of GA across ethnic groups. The Holm's sequential Bonferroni method was used to control for Type I error at a .05 level across all 6 comparisons. The proportions of GA differed significantly between White and Latino ethnic groups, $\chi^{2}(1, n=196)=12.09, p<.01$, Cramer's $V=.25$. The odds of a Latino student being attracted to gangs are 3.3 times higher than the odds of a White student being attracted to gangs. The proportions of GA differed significantly between White and Asian ethnic groups, $\chi^{2}(1, n=178)=5.45, p<$ .05 , Cramer's $V=.18$. The odds of an Asian student being attracted to gangs are 2.5 times higher than the odds of a White student being attracted to gangs. All other pairwise comparisons between ethnic groups did not find the proportions of the levels of GA to be significantly different from each other. Table 5.14 displays the cross 
tabulation of ethnic groups across GA. Table 5.15 displays the pairwise comparisons between ethnic groups across levels of GA.

Table 5.14

Cross Tabulation of Personal Attraction to Gangs across Ethnicity

\begin{tabular}{|l|cc|c|}
\hline & $\begin{array}{c}\text { Not } \\
\text { Attracted }\end{array}$ & Attracted & Total \\
\hline White & 105 & 17 & 122 \\
\hline African American & 11 & 4 & 15 \\
\hline Latino & 48 & 26 & 74 \\
\hline Asian & 40 & 16 & 56 \\
\hline Total & 204 & 63 & 267 \\
\hline
\end{tabular}

Note. $n=267$. Multiracial, Native American, and Native Hawaiian Pacific Islander students were not included in analyses.

Table 5.15

Pairwise Comparison between Ethnic groups in levels of Gang Attraction

\begin{tabular}{|l|l|l|l|l|}
\hline Comparison & $n$ & $p$-value & Odd ratios & Referent Group \\
\hline Latino versus White & 196 & $p<.01$ & 3.3 & Latinos \\
\hline Asian versus White & 178 & $p<.05$ & 2.5 & Asians \\
\hline
\end{tabular}

Note. All other pairwise comparisons between ethnic groups were not significant at a .05 level.

Although not initially proposed, the following research questions and analyses were conducted to further investigate ethnic differences in gang attraction.

Research Question 1c. Do the levels of risk for joining gangs differ depending on the immigrant status of the student?

Profile (1): Levels of gang involvement. A cross tabulation is presented in which a contingency matrix displays the levels of gang involvement across immigrant status. A chi-square test of independence was conducted to evaluate whether there was a 
relationship between levels of gang involvement and immigrant status. Immigrant and levels of gang involvement were found to be significantly related, $\chi^{2}(2)=13.25, p<$ .01 , Cramer's $V=.22$. Follow up tests were conducted to evaluate the differences among the propositions of GI across immigrant status. The Holm's sequential Bonferroni method was used to control for Type I error at a .05 level across all 3 comparisons. All three pairwise comparisons were significant. The proportions of students "not involved in gangs" and "at risk for gangs" differed significantly between immigrant and USA born groups, $\chi^{2}(1, n=216)=4.44, p<.05$, Cramer's $V=.14$. The odds of US born student being at risk for gangs versus not involved in gangs are 3.6 times higher than the odds of an immigrant student being risk for gangs versus not involved in gangs. The proportions of students "not involved in gangs" and "potential GMs" differed significantly between immigrant and US born groups, $\chi^{2}(1, n=230)=5.53, p<.05$, Cramer's $V=.16$. The odds of an immigrant student being potential GM versus not being involved in gangs are 2.2 times higher than the odds of a USA born student being potential GM versus not being involved in gangs. The proportions of students "at risk for gangs" and "potential GMs" differed significantly between immigrant and USA born groups, $\chi^{2}(1, n=118)=12.18, p<.01$, Cramer's $V=.32$. The odds of an immigrant student being potential GM versus at risk for gangs are 7.6 times higher than the odds of a USA born student being potential GM versus at risk for gangs. Table 5.16 displays the cross tabulation of levels of gang involvement across immigrant status. Table 5.17 displays the pairwise comparisons between immigrant and US born students across levels of GI. 
Table 5.16

Cross Tabulation of Levels of Gang Involvement across Immigrant Status

\begin{tabular}{|l|ccc|c|}
\hline & Not Involved & At-Risk & Potential GMs & Total \\
\hline US Born & 135 & 49 & 45 & 229 \\
\hline Immigrants & 29 & 3 & 21 & 53 \\
\hline Total & 164 & 52 & 66 & 282 \\
\hline
\end{tabular}

Note. $\mathrm{N}=282$.

Table 5.17

Pairwise Comparison between Immigrant versus US born students in levels of Gang Involvement

\begin{tabular}{|l|l|l|c|c|}
\hline Comparison & $\mathrm{n}$ & $\mathrm{p}$-value & Odd Ratio & Referent Group \\
\hline At Risk versus Not Involved & 216 & $p<.05$ & 3.6 & US born \\
\hline Potential GM versus Not Involved & 230 & $p<.05$ & 2.2 & Immigrant \\
\hline Potential GM versus At Risk & 118 & $p<.01$ & 7.6 & Immigrant \\
\hline
\end{tabular}

Profile (2): Levels of gang attraction. A chi-square test of independence was also conducted to evaluate whether there was a relationship between personal attraction to gangs and immigrant status. Immigrant status and personal attraction to gangs were found to be significantly related $\left(\chi^{2}(1)=6.27, p<.05\right.$, Cramer's $\left.V=.15\right)$. The odds of an immigrant student being attracted to gangs are 2.3 times higher than the odds of a USA born student being attracted to gangs. Table 5.18 displays the cross tabulation of personal attraction to gangs across immigrant status. 
Table 5.18

Cross Tabulation of Personal Attraction to Gangs across Immigrant Status

\begin{tabular}{|l|cc|c|}
\hline & $\begin{array}{c}\text { Not } \\
\text { Attracted }\end{array}$ & Attracted & Total \\
\hline US Born & 187 & 42 & 229 \\
\hline Immigrants* & 35 & 18 & 53 \\
\hline Total & 222 & 60 & 282 \\
\hline
\end{tabular}

Note. $\mathrm{N}=282$. $*$ The odds of an immigrant student being attracted to gangs were 2.3 times higher than a US born student.

Research question 1d. Does the proportion of immigrant versus US born students differ across ethnic groups?

A chi-square test of independence was also conducted to evaluate whether there was a relationship between ethnicity and immigrant status. Ethnicity and immigrant status were not found to be significantly related $\left(\chi^{2}(3)=7.08, n s\right)$. The proportions of immigrant versus US born students were similar across ethnic groups. Table 5.19 displays the cross tabulation of ethnicity and immigrant status.

Table 5.19

Cross Tabulation of Ethnicity and Immigrant Status

\begin{tabular}{|l|cc|c|}
\hline & US Born & Immigrants & Total \\
\hline White & 88 & 15 & 103 \\
\hline African American & 11 & 3 & 14 \\
\hline Latino & 47 & 12 & 59 \\
\hline Asian & 32 & 16 & 48 \\
\hline Total & 178 & 46 & 224 \\
\hline
\end{tabular}

Note. $\mathrm{N}=224$. 
The following analyses were conducted to further explore the significant results found in (1) the levels of GI between Latino and White ethnic groups and (2) the levels of GA in Latino, Asian, and White ethnic groups.

Research Question 1e. Do the levels of risk for joining gangs between Latino and White, and between Asian and White ethnic groups differ depending on the language spoken at home by the student?

Profile (1): Levels of gang involvement. A cross tabulation is presented in which a contingency matrix displays the levels of gang involvement across language spoken at home by the student. Three language categories were calculated: (1) English, (2) Spanish, and (3) Bilingual (i.e., English and Spanish was spoken at home). A chisquare test of independence was conducted to evaluate whether there was a relationship between levels of gang involvement and language spoken at home. Language spoken at home and levels of gang involvement were found to be significantly related, $\chi^{2}$ (4, $n=215)=28.37, p<.01$, Cramer's $V=.36$. Follow up tests were conducted to evaluate the differences among the propositions of GI across language spoken at home. The Holm's sequential Bonferroni method was used to control for Type I error at a .05 level across all 3 comparisons. The proportions of the levels of GI differed significantly between English and Spanish speaking students, $\chi^{2}(2, n=171)=17.35, p<.01$, Cramer's $V=.32$. The proportions of the levels of GI differed significantly between English and Bilingual students, $\chi^{2}(2, n=184)=20.89, p<.01$, Cramer's $V=.34$. The 
proportions of the levels of GI did not significantly differ between Spanish and Bilingual students, $\chi^{2}(2, n=75)=2.99, n s$.

Additional follow up tests were conducted to evaluate the differences among the proportions of levels of GI across English and Spanish speaking student, and between English and Bilingual students. The pairwise comparison that evaluated the differences between "not involved in gangs" and "potential GMs" for English versus Spanish speaking students was significant, $\chi^{2}(1, n=130)=17.61, p<.01$, Cramer's $V=.37$. The odds of a Spanish speaking student being a potential GM versus not involved in gangs are 6.8 times higher than the odds of an English speaking student being a potential GM versus not involved in gangs. The pairwise comparison that evaluated the differences between "at risk for gangs" and "potential GMs" for Spanish versus English speaking students was significant, $\left.\chi^{2}(1, n=71)=4.72, p<.05\right)$, Cramer's $V=.26$. The odds of a Spanish speaking student being potential GM versus at risk for gangs are 3.1 times higher than the odds of an English speaking student being potential GM versus at risk for gangs. The pairwise comparison that evaluated the differences between "not involved in gangs" and "at risk for gangs" for Spanish versus English speaking students was not significant, $\chi^{2}(1, n=141)=2.36, n s$.

The pairwise comparison that evaluated the differences between "not involved in gangs" and "potential GMs" for bilingual versus English speaking students was significant, $\chi^{2}(1, n=146)=16.58, p<.01$, Cramer's $V=.34$. The odds of a bilingual student being a potential GM versus not involved in gangs are 5 times higher than the odds of an English speaking student being a potential GM versus not involved in gangs. 
The pairwise comparison that evaluated the differences between "at risk for gangs" and “potential GMs” for bilingual versus English speaking students was significant, $\chi^{2}$ (1, $n=74)=13.24, p<.01)$, Cramer's $V=.42$. The odds of a bilingual student being potential GM versus at risk for gangs are 7.3 times higher than the odds of a English speaking student being potential GM versus at risk for gangs. The pairwise comparison that evaluated the differences between "not involved in gangs" and "at risk for gangs" for bilingual versus English speaking students was not significant, $\chi^{2}(1, n=148)=.51$, $n s$. Table 5.20 displays the cross tabulation of Language spoken at home across levels of gang involvement. Table 5.21 displays the pairwise comparisons between language spoken at home and the levels of GI.

Table 5.20

Cross Tabulation of Levels of Gang Involvement across English, Spanish, and Bilingual Spanish Language

\begin{tabular}{|l|ccc|c|}
\hline & Not Involved & At-Risk & Potential GMs & Total \\
\hline English & 90 & 33 & 17 & 140 \\
\hline Spanish & 10 & 8 & 13 & 31 \\
\hline Bilingual & 20 & 5 & 19 & 44 \\
\hline Total & 120 & 46 & 49 & 215 \\
\hline
\end{tabular}

Note. $\mathrm{N}=215$. 
Table 5.21

Pairwise Comparison between English, Spanish, and Bilingual Spanish Language and Levels of Gang Involvement

\begin{tabular}{|l|c|c|c|c|}
\hline Comparison & $\mathrm{n}$ & $\mathrm{p}$-value & Odd Ratio & Referent Group \\
\hline English versus Spanish & 141 & $n s$ & & \\
\hline At Risk versus Not Involved & 130 & $p<.01$ & 6.8 & Spanish \\
\hline Potential GM versus Not Involved & 71 & $p<.05$ & 3.1 & Spanish \\
\hline Potential GM versus At Risk & 71 & & \\
\hline English versus Bilingual & 148 & $n s$ & & Bilingual \\
\hline At Risk versus Not Involved & 146 & $p<.01$ & 5 & Bilingual \\
\hline Potential GM versus Not Involved & 74 & $p<.01$ & 7.3 & \\
\hline Potential GM versus At Risk &
\end{tabular}

Note. No significant differences were observed between Spanish speaking and bilingual students in levels of GI.

Profile (2): Levels of gang attraction. Three chi-square test of independence were also conducted to evaluate whether there was a relationship between personal attraction to gangs and language spoken at home. The first chi-square explored the relationship between English, Spanish, and Spanish bilingual students and GA. The second chi-square explored the relationship between English, Asian, and Asian bilingual students and GA. All languages spoken in Asian countries (i.e., Thai, Vietnamese, Hmong, etc) were classified as Asian. All languages spoken in Asian countries in addition to English were classified as Bilingual Asian. The third chi-square explored the relationship between English, Russian/Ukrainian, and Bilingual Russian/Ukrainian and GA.

(1) English, Spanish, and Bilingual Spanish. Language and personal attraction to gangs were found to be significantly related $\left(\chi^{2}(2)=19.83, p<.01\right.$, Cramer's $\left.V=.30\right)$. Follow up tests were conducted to evaluate the differences among the propositions of GA across language spoken at home. The Holm's sequential Bonferroni method was 
used to control for Type I error at a .05 level across all 3 comparisons. The proportions of the levels of GA differed significantly between English and Spanish speaking students, $\chi^{2}(1, n=171)=10.42, p<.01$, Cramer's $V=.25$. The odds of a Spanish speaking student being attracted to gangs are 4.4 times higher than the odds of a English speaking student being attracted to gangs. The proportions of the levels of GA differed significantly between English and bilingual speaking students, $\chi^{2}(1, n=184)=17.05, p$ $<.01$, Cramer's $V=.30$. The odds of a Bilingual speaking student being attracted to gangs are 5.2 times higher than the odds of an English speaking student being attracted to gangs. The proportions of the levels of GA did not significantly differ between Spanish and bilingual speaking students, $\chi^{2}(1, n=75)=.14, n s$. Table 5.22 displays the cross tabulation of language spoken at home (i.e., comparisons between English, Spanish, and Bilingual Spanish) across levels of GA. Table 5.23 summarizes the pairwise comparisons between language spoken at home and GA.

Table 5.22

Cross Tabulation across English, Spanish, and Bilingual Spanish Language and Levels of Gang Attraction

\begin{tabular}{|l|cc|c|}
\hline & Not Attracted & Attracted & Total \\
\hline English & 126 & 14 & 140 \\
\hline Spanish & 21 & 10 & 31 \\
\hline Bilingual Spanish & 28 & 16 & 44 \\
\hline Total & 175 & 40 & 215 \\
\hline
\end{tabular}

Note. $N=215$. 
Table 5.23

Pairwise Comparison across English, Spanish, and Bilingual Spanish Language and Levels of Gang Attraction

\begin{tabular}{|l|c|c|c|c|}
\hline Comparison & $\mathrm{n}$ & $\mathrm{p}$-value & Odd Ratio & Referent Group \\
\hline English versus Spanish & 171 & $p<.01$ & 4.4 & Spanish \\
\hline Attracted versus Not Attracted & 17. & \\
\hline English versus Bilingual & & & & \\
\hline Attracted versus Not Attracted & 184 & $p<.01$ & 5.2 & Bilingual \\
\hline Spanish versus Bilingual & & $n s$ & & \\
\hline Attracted versus Not Attracted & 75 & $n s$ &
\end{tabular}

(2) English, Asian, and Bilingual Asian. Language and personal attraction to gangs were found to be significantly related $\left(\chi^{2}(2, n=198)=9.26, p<.05\right.$, Cramer's $V=.22$ ). Follow up tests were conducted to evaluate the differences among the propositions of GA across language spoken at home. The Holm's sequential Bonferroni method was used to control for Type I error at a .05 level across all 3 comparisons. The proportions of the levels of GA differed significantly between English and Asian speaking students, $\chi^{2}(1, n=176)=3.91, p<.05$, Cramer's $V=.15$. The odds of an Asian speaking student being attracted to gangs are 2.9 times higher than the odds of a English speaking student being attracted to gangs. The proportions of the levels of GA differed significantly between English and Bilingual Asian speaking students, $\chi^{2}(1, n=$ $162)=8.02, p<.01$, Cramer's $V=.22$. The odds of a Bilingual Asian speaking student being attracted to gangs are 4.2 times higher than the odds of an English speaking student being attracted to gangs. The proportions of the levels of GA did not significantly differ between Asian and Bilingual Asian speaking students, $\chi^{2}(1, n=58)$ $=.66, n s$. Table 5.24 displays the cross tabulation of language spoken at home (i.e., 
comparisons between English, Asian, and Bilingual Asian) across levels of GA. Table 5.25 summarizes the pairwise comparisons between language spoken at home and GA.

Table 5.24

Cross Tabulation across English, Asian, and Bilingual Asian Language and Levels of Gang Attraction

\begin{tabular}{|l|cc|c|}
\hline & Not Attracted & Attracted & Total \\
\hline English & 126 & 14 & 140 \\
\hline Asian & 28 & 8 & 36 \\
\hline Bilingual Asian & 15 & 7 & 22 \\
\hline Total & 169 & 29 & 198 \\
\hline
\end{tabular}

Note. $N=198$.

Table 5.25

Pairwise Comparison across English, Asian, and Bilingual Asian Language and Levels of Gang Attraction

\begin{tabular}{|l|c|c|c|c|}
\hline Comparison & $\mathrm{n}$ & $\mathrm{p}$-value & Odd Ratio & Referent Group \\
\hline English versus Asian & \multicolumn{5}{|l|}{} \\
\hline Attracted versus Not Attracted & 176 & $p<.05$ & 2.9 & Asian \\
\hline English versus Bilingual Asian \\
\hline Attracted versus Not Attracted & 162 & $p<.01$ & 4.2 & Bilingual Asian \\
\hline Asian versus Bilingual Asian & & & & \\
\hline Attracted versus Not Attracted & 58 & $n s$ & & \\
\hline
\end{tabular}

(3) English, Russian/Ukrainian, and Bilingual Russian/Ukrainian. Language and personal attraction to gangs were found to be significantly related $\left(\chi^{2}(2, n=166)=\right.$ $7.06, p<.05$, Cramer's $V=.21)$. Follow up tests were conducted to evaluate the differences among the propositions of GA across language spoken at home. The Holm's sequential Bonferroni method was used to control for Type I error at a .05 level across all 3 comparisons. The proportions of the levels of GA differed significantly between 
English and Russian/Ukrainian speaking students, $\chi^{2}(1, n=155)=6.86, p<.01$, Cramer's $V=.21$. The odds of a Russian/Ukrainian speaking student being attracted to gangs are 4.5 times higher than the odds of a English speaking student being attracted to gangs. The proportions of the levels of GA did not significantly differ between English and Russian/Ukrainian Bilingual speaking students, $\chi^{2}(1, n=151)=.009, n s$, Cramer's $V=.22$. The proportions of the levels of GA did not significantly differ between Russian/Ukrainian and Russian/Ukrainian Bilingual speaking students, $\chi^{2}(1, n=26)=$ 2.10, ns. Table 5.26 displays the cross tabulation of language spoken at home (i.e., comparisons between English, Russian, and Russian/Ukrainian Bilingual) across levels of GA.

Table 5.26

Cross Tabulation across English, Russian/Ukrainian, and Bilingual Russian/Ukrainian Language and Levels of Gang Attraction

\begin{tabular}{|l|cc|c|}
\hline & Not Attracted & Attracted & Total \\
\hline English & 126 & 14 & 140 \\
\hline Russian/Ukrainian & 10 & $5^{*}$ & 15 \\
\hline $\begin{array}{l}\text { Russian/Ukrainian } \\
\text { Bilingual }\end{array}$ & 10 & 1 & 11 \\
\hline Total & 146 & 20 & 166 \\
\hline
\end{tabular}

Note. $N=166$. *Russian/Ukrainian speaking students 4.5 times more likely to be attracted to gangs than English speaking students.

Research question 1 . Is there a relationship between immigrant status and language spoken at home (i.e, between English, Spanish, and Bilingual Spanish speaking students)? 
A chi-square test of independence was conducted to evaluate whether there was a relationship between language spoken at home (i.e., English, Spanish, and Bilingual Spanish) and immigrant status. Language spoken at home and immigrant status were found to be significantly related, $\chi^{2}(2, n=187)=34.74, p<.01$, Cramer's $V=.43$. Follow up tests were conducted to evaluate the differences among immigrant status spoken at home. The Holm's sequential Bonferroni method was used to control for Type I error at a .05 level across all 3 comparisons. The proportions of the immigrant status differed significantly between English and Spanish speaking students, $\chi^{2}(1, n=$ $171)=36.20, p<.01$, Cramer's $V=.59$. The odds of an English speaking student being US born versus an immigrant are 58 times higher than the odds of a Spanish speaking student being US born versus an immigrant. The proportions of the immigrant status differed significantly between English and Bilingual speaking students, $\chi^{2}(1, n=159)=$ $6.42, p<.05$, Cramer's $V=.20$. The odds of an English speaking student being US born versus an immigrant are 11.1 times higher than the odds of a Bilingual student being US born versus an immigrant. The proportions of the immigrant status differed significantly between Spanish and Bilingual speaking students, $\chi^{2}(1, n=64)=5.86, p<.05$, Cramer's $V=.30$. The odds of a Bilingual speaking student being US born versus an immigrant are 5.2 times higher than the odds of a Spanish student being US born versus an immigrant. Table 5.27 displays the cross tabulation of immigrant status across language spoken at home (i.e., comparisons between English, Spanish, and Bilingual Spanish). Table 5.28 summarizes the pairwise comparisons between language spoken at home and immigrant status. 
Table 5.27

Cross Tabulation of Levels of Gang Involvement across English, Spanish, and Bilingual Spanish Language

\begin{tabular}{|l|cc|c|}
\hline & US born & Immigrant & Total \\
\hline English & 122 & 1 & 123 \\
\hline Spanish & 19 & 9 & 28 \\
\hline Bilingual & 33 & 3 & 36 \\
\hline Total & 174 & 13 & 187 \\
\hline
\end{tabular}

Note. Only immigrant that spoke English at home was born in Panama.

Table 5.28

Pairwise Comparison between English, Spanish, and Bilingual Spanish

Language and Immigrant Status

\begin{tabular}{|l|l|l|c|c|}
\hline Comparison & $\mathrm{n}$ & $\mathrm{p}$-value & Odd Ratio & Referent Group \\
\hline English versus Spanish & \multicolumn{5}{|l|}{} \\
\hline US born versus Immigrant & 171 & $p<.01$ & 58 & English \\
\hline English versus Bilingual \\
\hline US born versus Immigrant & 159 & $p<.05$ & 11.1 & English \\
\hline Spanish versus Bilingual Spanish \\
\hline US born versus Immigrant & 64 & $p<.05$ & 5.2 & Bilingual \\
\hline
\end{tabular}

Research question $1 \mathrm{~g}$. Is there a relationship between immigrant status and language spoken at home (i.e, between English, Asian, and Bilingual Asian speaking students)?

A chi-square test of independence was conducted to evaluate whether there was a relationship between language spoken at home (i.e., English, Asian, and Bilingual Asian) and immigrant status. Language spoken at home and immigrant status were found to be significantly related, $\chi^{2}(2, n=187)=40.50, p<.01$, Cramer's $V=.48$. Follow up tests were conducted to evaluate the differences among immigrant status 
across language spoken at home. The Holm's sequential Bonferroni method was used to control for Type I error at a .05 level across all 3 comparisons. The proportions of the immigrant status differed significantly between English and Asian speaking students, $\chi^{2}$ $(1, n=157)=41.70, p<.01$, Cramer's $V=.52$. The odds of an English speaking student being US born versus an immigrant are 66.7 times higher than the odds of an Asian speaking student being US born versus an immigrant. The proportions of the immigrant status differed significantly between English and Bilingual Asian speaking students, $\chi^{2}$ $(1, n=142)=26.45, p<.01$, Cramer's $V=.43$. The odds of an English speaking student being US born versus an immigrant are 43.6 times higher than the odds of a Bilingual Asian student being US born versus an immigrant. The proportions of the immigrant status differed significantly between Asian and Bilingual Asian speaking students, $\chi^{2}$ (1, $n=53)=.45, n s$. Table 5.29 displays the cross tabulation of immigrant status across language spoken at home (i.e., comparisons between English, Asian, and Bilingual Asian). Table 5.30 summarizes the pairwise comparisons between language spoken at home and immigrant status.

Table 5.29

Cross Tabulation of Levels of Gang Involvement across English, Asian, and Bilingual Asian Language

\begin{tabular}{|l|cc|c|}
\hline & US born & Immigrant & Total \\
\hline English & 122 & 1 & 123 \\
\hline Asian & 22 & 12 & 34 \\
\hline Bilingual Asian & 14 & 5 & 19 \\
\hline Total & 158 & 18 & 176 \\
\hline
\end{tabular}

Note. Only immigrant that spoke English at home was born in Panana. 
Table 5.30

Pairwise Comparison between English, Asian, and Bilingual Asian Language and Immigrant Status

\begin{tabular}{|c|c|c|c|c|}
\hline Comparison & $\mathrm{n}$ & p-value & Odd Ratio & Referent Group \\
\hline \multicolumn{5}{|l|}{ English versus Asian } \\
\hline US born versus Immigrant & 157 & $p<.01$ & 66.7 & English \\
\hline \multicolumn{5}{|c|}{ English versus Bilingual Asian } \\
\hline US born versus Immigrant & 142 & $p<.05$ & 43.6 & English \\
\hline \multicolumn{5}{|l|}{ Asian versus Bilingual Asian } \\
\hline US born versus Immigrant & 53 & $n s$ & & \\
\hline
\end{tabular}

\section{Gender and Grade Differences across Study Constructs}

Differences in gender and grade were evaluated in order to consider if controlling for each variable was necessary for subsequent analyses. Research has shown that engagement declines as students progress through school, with boys being particularly vulnerable to these declines. In addition, research has shown that boys are more at risk for gang involvement (GI) than girls, with the average age of gang membership being 13 years. Therefore, by controlling for grade and gender, interpretations about differences in engagement, disaffection, and achievement between different student profiles would not be confounded with normative age and gender differences in the respective variables.

Gender differences. A multivariate analysis of variance (MANOVA) was conducted to determine the effect of gender on all dependent variables (i.e., study variables). No significant gender differences were found among the study constructs, Wilks' $\Lambda=.96, F(9,332)=1.51, n s$. The partial $\eta^{2}$ was .04 . Although the MANOVA was not significant, follow up ANOVAs were conducted on each variable. Except for teacher structure, gender differences were found in all dependent variables. For overall 
school support, $F(1,340)=6.80, p<.05$; for school climate, $F(1,340)=6.61, p<.05$; for teacher support, $F(1,340)=5.70, p<.05$; for teacher involvement, $F(1,340)=$ $4.55, p<.05$; for teacher autonomy support, $F(1,340)=6.72, p<.05$; for relatedness, $F(1,340)=4.41, p<.05 ;$ for competence, $F(1,340)=6.15, p<.05 ;$ for autonomy, $F$ $(1,340)=6.96, p<.01 ;$ for engagement, $F(1,340)=8.18, p<.05 ;$ for disaffection, $F$ $(1,340)=8.52, p<.01 ;$ for aggregated SSPs, $F(1,340)=10.14, p<.01$. Except for teacher structure, girls scored higher in all dependent variables than boys. In addition, girls were less disaffected from school than boys. Therefore, gender will be entered as a covariate in subsequent analyses. Table 5.31 summarizes the means and standard deviations in study constructs by gender.

Table 5.31

Descriptive Statistics for Gender Differences in Study Constructs

\begin{tabular}{lcccc}
\hline & \multicolumn{3}{c}{ Girls } & \multicolumn{2}{c}{ Boys } \\
\cline { 2 - 5 } & $M$ & $S D$ & $M$ & $S D$ \\
\hline School Contextual Supports & 3.76 & .74 & 3.54 & .83 \\
School Climate & 3.86 & .81 & 3.62 & .92 \\
Teacher Support & 3.73 & .80 & 3.52 & .89 \\
Teacher Involvement & 3.56 & .91 & 3.35 & .97 \\
Teacher Structure & 3.95 & .89 & 3.79 & .98 \\
Teacher Autonomy Support & 3.85 & .89 & 3.58 & 1.07 \\
Self-System Processes & 3.83 & .68 & 3.59 & .73 \\
Relatedness & 3.78 & .86 & 3.57 & 1.01 \\
Competence & 4.34 & .71 & 4.14 & .78 \\
Autonomy & 3.37 & 1.06 & 3.05 & 1.13 \\
Engagement & 3.89 & .86 & 3.62 & .94 \\
Disaffection & 1.92 & .74 & 2.17 & .82 \\
\hline
\end{tabular}

Note. $N=342$. Girls, $n=174 ;$ Boys, $n=168$.

Grade Differences. A MANOVA was conducted to determine the effect of grade on all dependent variables (i.e., study constructs). Significant grade differences were 
found among the study constructs, Wilks' $\Lambda=.70, F(18,664)=6.80, p<.01$. The partial $\eta^{2}$ was .16. Analyses of variance (ANOVA) on each dependent variable were conducted as follow up tests to the MANOVA. All ANOVAs were significant except for competence, $F(2,339)=1.34, n s$. For overall school support, $F(2,339)=42.49, p$ $<.01$; for school climate, $F(2,339)=6.20, p<.01$; for teacher support, $F(2,339)=$ $49.75, p<.01$; for teacher involvement, $F(2,339)=36.93, p<.01$; for teacher structure, $F(2,339)=44.52, p<.01$; for teacher autonomy, $F(2,339)=31.96, p<.01$; for aggregate SSPs, $F(2,339)=10.52, p<.01$; for belongingness, $F(2,339)=7.95, p$ $<.01$; for autonomy, $F(2,339)=11.45, p<.01 ;$ for engagement, $F(2,339)=13.45, p$ $<.01$; and for disaffection, $F(2,339)=8.59, p<.01$.

Post hoc analyses for all significant ANOVAs were conducted consisting of pairwise comparisons between each grade. Except for autonomy, $7^{\text {th }}$ graders scored significantly lower in all variables (i.e., overall school support, school climate, etc.) than $6^{\text {th }}$ and $8^{\text {th }}$ graders. Eighth graders did not score significantly different than $6^{\text {th }}$ graders in all study variables except for autonomy. For autonomy, $6^{\text {th }}$ graders scored higher $(M=$ $3.55, S D=.99)$ in autonomy than $7^{\text {th }}(M=2.91, S D=1.28)$ and $8^{\text {th }}$ graders $(M=3.16$, $S D=1.10)$. Seventh graders did not score significantly different than $8^{\text {th }}$ graders in autonomy. This pattern of differences, which is different from the typical pattern in which all variables show declines in functioning from sixth to eighth grade, likely reflects selection effects in eighth grade in which more engaged eighth graders agreed to participate in the study. Therefore, grade will be entered as a covariate in subsequent 
Results 98

analyses. Table 5.32 summarizes the means and standard deviations in study constructs by grade.

Table 5.32

Descriptive Statistics of Constructs across Grades

\begin{tabular}{lcccccc}
\hline & \multicolumn{2}{c}{ Grade 6} & \multicolumn{2}{c}{ Grade 7} & \multicolumn{2}{c}{ Grade 8} \\
\cline { 2 - 7 } & $M$ & $S D$ & $M$ & $S D$ & $M$ & $S D$ \\
\hline School Contextual Supports & $3.97^{\mathrm{a}}$ & .65 & $3.18^{\mathrm{b}}$ & .83 & $3.83^{\mathrm{a}}$ & .61 \\
School Climate & $3.88^{\mathrm{c}}$ & .80 & $3.53^{\mathrm{d}}$ & 1.02 & $3.85^{\mathrm{c}}$ & .69 \\
Teacher Support & $3.99^{\mathrm{e}}$ & .69 & $3.09^{\mathrm{f}}$ & .86 & $3.83^{\mathrm{e}}$ & .66 \\
Teacher Involvement & $3.85^{\mathrm{g}}$ & .86 & $2.94^{\mathrm{h}}$ & .89 & $3.61^{\mathrm{g}}$ & .82 \\
Teacher Structure & $4.24^{\mathrm{i}}$ & .74 & $3.31^{\mathrm{j}}$ & 1.01 & $4.11^{\mathrm{i}}$ & .69 \\
Teacher Autonomy Support & $4.03^{\mathrm{k}}$ & .84 & $3.19^{\mathrm{l}}$ & 1.06 & $3.99^{\mathrm{k}}$ & .79 \\
Self-System Processes & $3.89^{\mathrm{m}}$ & .64 & $3.49^{\mathrm{n}}$ & .73 & $3.75^{\mathrm{m}}$ & .73 \\
Relatedness & $3.83^{\mathrm{o}}$ & .88 & $3.41^{\mathrm{p}}$ & .99 & $3.83^{\mathrm{o}}$ & .88 \\
Competence & 4.30 & .72 & 4.15 & .77 & 4.28 & .77 \\
Autonomy & $3.55^{\mathrm{r}}$ & .99 & $2.91^{\mathrm{q}}$ & 1.13 & $3.16^{\mathrm{q}}$ & 1.11 \\
Engagement & $4.04^{\mathrm{s}}$ & .81 & $3.46^{\mathrm{t}}$ & .95 & $3.77^{\mathrm{s}}$ & .86 \\
Disaffection & $1.89^{\mathrm{u}}$ & .71 & $2.27^{\mathrm{v}}$ & .84 & $1.95^{\mathrm{u}}$ & .77 \\
\hline
\end{tabular}

Note. $N=342$. Grade 6, $n=128$; Grade 7, $n=123$; Grade 8, $n=91$. Subscripts a-u : Mean level were significantly different across study variables at least at $\mathrm{p}<.05$ as determined by Bonferroni post hoc comparisons for all variables, except means marked by the same letter.

Research Question 2. Does engagement protect against gang involvement (GI) and gang attraction (GA) and promote achievement?

The second goal of this study was to test whether engagement protects against GI and GA and promotes achievement. As can be seen in Table 5.33, correlations between engagement, disaffection, GI and GA, and between engagement and achievement were consistent with the hypothesis. That is, engagement showed a negative relationship to GI and GA, and a positive relationship to achievement, whereas disaffection showed a positive relationship to GI and GA, and a negative relationship with achievement. These initial results suggest that students who were more engaged in 
school reported less attraction and involvement in gangs, and higher achievement.

Students who were more disaffected reported more attraction and involvement in gangs, and less achievement.

Table 5.33

Correlations between Engagement, Disaffection, Gang-Involvement, Gang Attraction, and Achievement

\begin{tabular}{|l|c|c|c|c|c|}
\hline & Engagement & Disaffection & GI & GA & Achievement \\
\hline Engagement & -- & -- & -- & -- & -- \\
\hline Disaffection & $-.62 * *$ & -- & -- & -- & -- \\
\hline GI & $-.22 * *$ & $.20 * *$ & -- & -- & -- \\
\hline GA & $-.13 *$ & $.17 * *$ & $.67 * *$ & -- & -- \\
\hline Achievement & $.38 * *$ & $-.38 * *$ & $-.18 * *$ & -.09 & -- \\
\hline
\end{tabular}

Note. GI= Gang Involvement, GA= Gang Attraction. $* p \leq 0.05 . * * p \leq 0.01$.

\section{Testing RQ2 with GI as outcome}

Engagement predicting GI. In order to test whether engagement predicted GI, multinomial logistic regression was conducted to evaluate the relationship between the likelihood of being gang-involved and school engagement. The predictor was engagement and the outcome variable was gang involvement, with $1=$ not-involved, $2=$ at-risk, and 3= potential gang members (GMs). Grade and gender were entered as covariates. Potential GMs was used as referent or baseline outcome and logit functions were formed comparing students who were not gang-involved and students who were at risk for gangs to students who were gang-involved. Results demonstrated that the predictors were significantly related to the multinomial log odds of being ganginvolved, $\chi^{2}(6)=25.91, p<0.01$. 
Gang-Involved versus Not-Involved in Gangs. Controlling for grade and gender, with each unit increase in engagement, the relative risk of a student being involved in gangs relative to not being gang-involved decreases by a factor of 1.77 , Wald $\chi^{2}(1)=$ $14.27, p<0.01$. That is, as engagement in school increases, the less likely students are to be involved in gangs than not gang-involved.

Gang-Involved versus At Risk for Gangs. Controlling for grade and gender, with each unit increase in engagement, the relative risk of a student being involved in gangs relative to being at risk for gangs decreases by a factor of 1.60 , Wald $\chi^{2}(1)=6.36, p<$ 0.05. As engagement in school increases, the less likely students are involved in gangs than at risk for gangs. This results highlights that, in the context of gang involvement, it is preferable for a student to be at risk for gangs than being involved in gangs.

Disaffection predicting GI. A multinomial logistic regression was conducted to evaluate the relationship between the likelihood of being gang-involved and disaffection. The predictor was disaffection and the outcome variable was gang involvement, with $1=$ not-involved, $2=$ at-risk, and $3=$ potential gang members. Grade and gender were entered as covariates. Results demonstrated that the predictors were significantly related to the multinomial log odds of being gang- involved, $\chi^{2}(6)=27.87$, $p<0.01$.

Gang-Involved versus Not-Involved in Gangs. Controlling for grade and gender, with each unit increase in disaffection, the relative risk of a student being involved in gangs relative to not being gang-involved increased by a factor of .54 , Wald $\chi^{2}(1)=$ 
Results 101

13.39, $p<0.01$. As disaffection in school increases, the multinomial log odds of a student who is involved in gangs relative to not being gang-involved increases.

Gang-Involved versus At-Risk for Gangs. Controlling for grade and gender, with each unit increase in disaffection, the relative risk of a student being involved in gangs relative to being gang-involved increased by a factor of .48 , Wald $\chi^{2}(1)=10.78, p<$ 0.01. As disaffection in school increases, the multinomial log odds of a student being involved in gangs relative to being at risk for gangs increases.

Engagement and Disaffection predicting GI. A multinomial logistic regression was conducted to evaluate the relationship between engagement and disaffection, and the likelihood of being gang-involved. The predictors were engagement and disaffection. The outcome variable was gang involvement, with $1=$ not-involved, $2=$ atrisk, and 3= potential gang members. Grade and gender were entered as covariates. Results demonstrated that the predictors were significantly related to the multinomial log odds of being gang- involved, $\chi^{2}(8)=32.17, p<0.01$.

Gang-involved versus Not-Involved in Gangs. Holding disaffection constant, engagement was found to be related to a student involved in gangs relative to not being gang involved after adjusting for preexisting grade and gender differences, Wald $\chi^{2}(1)$ $=3.96, p<.05$. That is, as engagement in school increases, the relative risk of a student being involved in gangs relative to not being gang-involved decreases by a factor of 1.46. Holding engagement constant, disaffection was not related to the relative risk of a student being involved in gangs relative to being not gang-involved after adjusting for preexisting grade and gender differences, Wald $\chi^{2}(1)=3.07, n s$. 
Gang-involved versus At Risk for Gangs. Holding engagement constant, with each unit increase in disaffection, the relative risk of a student being involved in gangs relative to being at risk for gangs increased by a factor of .52 , after adjusting for preexisting grade and gender differences, Wald $\chi^{2}(1)=5.55, p<0.05$. Holding disaffection constant and after adjusting for preexisting grade and gender differences, engagement was not found to be related to the relative risk of a student being involved in gangs relative to being at risk for gangs, Wald $\chi^{2}(1)=.37, n s$.

Testing RQ2 with GA as outcome.

Engagement predicting GA. In order to test whether engagement predicted GA, a logistic regression was conducted to evaluate the relationship between the likelihood of being attracted to gangs and school engagement. The predictor was engagement and the outcome variable was gang attraction, with $0=$ not attracted, $1=$ attracted. Grade and gender were entered as covariates. Results indicated that the predictors were significantly related to the log odds of being attracted to gangs, $\chi^{2}(3)=12.77, p<0.05$, Cox-Snell $R^{2}=.037$. Engagement was negatively related to the log odds of gang attraction after adjusting for preexisting grade and gender differences, Wald $\chi^{2}(1)=$ $5.40, p<0.05$. For each unit increase in engagement, the log odds of a student being attracted to gangs decreases by .72 . That is, as engagement in school increased, the likelihood of a student being attracted to gangs decreased.

Disaffection predicting GA. A logistic regression was conducted to evaluate the relationship between the likelihood of being attracted to gangs and disaffection. The predictor was disaffection and the outcome variable was gang attraction, with $0=$ not 
attracted, $1=$ attracted. Results indicated that the predictors were significantly related to the log odds of being attracted to gangs, $\chi^{2}(3)=18.11, p<0.01$, Cox-Snell $R^{2}=.05$. Disaffection was related to the log odds of being attracted to gangs after adjusting for preexisting grade and gender differences, Wald $\chi^{2}(1)=10.68, p<0.01$. For each unit increase in disaffection, the log odds of a student being attracted to gangs increases by 1.69.

\section{Engagement and disaffection predicting GA. A logistic regression was} conducted to evaluate the relationship between engagement and disaffection and the likelihood of being attracted to gangs. The predictors were engagement and disaffection. The outcome variable was gang attraction, with $0=$ not attracted, $1=$ attracted. Grade and gender were entered as covariates. Results indicated that the predictors were significantly related to the log odds of being attracted to gangs, $\chi^{2}(4)=$ 18.29, $p<0.01$, Cox-Snell $R^{2}=.05$. Controlling for disaffection and preexisting grade and gender differences, engagement was not found to be related to the log odds of gang attraction, Wald $\chi^{2}(1)=.18, n s$. Controlling for engagement, disaffection is significantly related to the log odds of being attracted to gangs, after controlling for preexisting grade and gender differences, Wald $\chi^{2}(1)=5.46, p<0.05$. Specifically, for each unit increase in disaffection, the log odds of a student being attracted to gangs increases by 1.60. Similar to Profile 1 for levels of gang involvement, these findings suggest that disaffection is an important contributing variable for explaining the differences in levels of GA. 
Testing RQ2 with achievement as outcome.

Engagement and disaffection predicting achievement. In order to test whether engagement and disaffection were each uniquely related to achievement, a multiple regression analysis was conducted which included engagement and disaffection as predictors of student achievement. Grade and gender were entered as covariates.

Results indicated that the predictors were related to achievement, $F(4,332)=$ $21.06, p<.01$. The sample multiple correlation coefficient was .19 , indicating that $19 \%$ of the variance of achievement can be accounted for the linear combination of engagement and disaffection. Controlling for disaffection and adjusting for grade and gender differences, engagement was positively related to achievement, $\beta=.21, p<.01$. Engagement was found to be uniquely related to achievement above and beyond the contribution of disaffection. Controlling for engagement and adjusting for preexisting grade and gender differences, disaffection was found to be related to achievement, $\beta=-$ $.24, p<.01$. Disaffection was found to be uniquely related to achievement above and beyond the contribution of engagement. Table 5.34 presents the results of the regression analyses.

Table 5.34

Regression Analyses for Engagement and Disaffection as Predictors of Achievement

\begin{tabular}{|c|c|c|c|}
\hline Predictors & $B$ & $S E$ & $\beta$ \\
\hline Engagement & $.20^{*}$ & .06 & .21 \\
\hline Disaffection & $-.26^{*}$ & .07 & -.24 \\
\hline
\end{tabular}

Note. Controlling for grade and gender level. $* p<.01$ 
Results 105

Research Question 3. Do the motivational supports suggested by the larger process model, namely, school climate, teacher support, and the self-system processes of relatedness, competence, and autonomy, protect against GI and GA and promote achievement?

The third goal of this study was to test whether the motivational supports uniquely protect against GI and GA and promote achievement. As can be seen in Table 5.35, except for the SSP of autonomy, the correlations between the motivational supports and GI and GA were consistent with predictions. That is, except for the SSP of autonomy, the motivational supports showed a negative relationship to GI and GA. The motivational supports of teacher support and the SSPs of relatedness, competence, and autonomy demonstrated a positive relationship with achievement. In other words, students who experienced teachers and school staff as supportive showed less attraction and involvement in gangs. Students who felt that they belonged to their school and experienced themselves as competent in their learning demonstrated less attraction and involvement in gangs. 
Table 5.35

Correlations between the Motivational Supports, Gang Involvement, Gang Attraction, and Achievement

\begin{tabular}{|l|c|c|c|c|c|c|c|c|} 
& $\begin{array}{c}\text { School } \\
\text { Climate }\end{array}$ & $\begin{array}{c}\text { Teacher } \\
\text { Support }\end{array}$ & Relatedness & Competence & Autonomy & GI & GA & Achievement \\
\hline School Climate & -- & -- & -- & -- & -- & -- & -- & -- \\
\hline $\begin{array}{l}\text { Teacher } \\
\text { Support }\end{array}$ & $.60^{* *}$ & -- & -- & -- & -- & -- & -- & -- \\
\hline Relatedness & $.60^{* *}$ & $.64^{* *}$ & -- & -- & -- & -- & -- & -- \\
\hline Competence & $.44^{* *}$ & $.46^{* *}$ & $.43^{* *}$ & -- & -- & -- & -- & -- \\
\hline Autonomy & $.45^{* *}$ & $.56^{* *}$ & $.37^{* *}$ & $.35^{* *}$ & -- & -- & -- & -- \\
\hline GI & $-.21^{* *}$ & $-.26^{* *}$ & $-.17^{* *}$ & $-.11^{*}$ & $-.12^{*}$ & -- & - & -- \\
\hline GA & $-.19^{* *}$ & $-.21^{* *}$ & $-.16^{* *}$ & $-.14^{*}$ & -.09 & $.67^{* *}$ & -- & -- \\
\hline Achievement & $.37^{* *}$ & $.38^{* *}$ & $.27^{* *}$ & $.32^{* *}$ & $.31^{* *}$ & $-.18^{* *}$ & -.09 & -- \\
\hline
\end{tabular}

Note. GI $=$ Gang Involvement, GA= Gang Attraction.

$$
* * p<0.01 * p<0.05
$$




\section{Testing RQ3 with GI as outcome}

Motivational supports predicting GI. In order to test whether the motivational supports predicted GI, two multinomial logistic regressions were conducted to evaluate the relationship between the likelihood of being gang-involved and the motivational supports (i.e., school climate, teacher support, and the SSPs). The predictors for the first multinomial logistic regression were school climate and teacher support. For the second multinomial logistic regression, the predictors were relatedness, competence, and autonomy. The outcome variable for the three models were gang involvement, with $1=$ not-involved, $2=$ at-risk, and 3= potential gang members. Grade and gender were entered as covariates. Teacher support was calculated by averaging teacher involvement, teacher structure, and teacher autonomy support (Cronbach's $\alpha=.87$ ).

\section{Unique effects of school climate and teacher support on GI. Results}

demonstrated that the predictors were significantly related to the multinomial log odds of a student being gang- involved, $\chi^{2}(8)=36.00, p<.01$.

Gang-Involved versus Not-Involved in Gangs. Controlling for teacher support and adjusting for grade and gender differences, school climate was not related to the relative risk of a student being involved in gangs relative to not being gang-involved, Wald $\chi^{2}(1)=2.48, n s$. Controlling for school climate and adjusting for grade and gender differences, teacher support was related to the relative risk of a student being involved in gangs relative to not being gang-involved, Wald $\chi^{2}(1)=7.07, p<.01$. That is, as teacher support increases, the relative risk of a student being involved in gangs relative to not being GI decreases by a factor of 1.73 . 
Gang-Involved versus At Risk for Gangs. Controlling for teacher support and adjusting for grade and gender differences, school climate was not found to be related to the relative risk of a student being involved in gangs relative to being at risk for gangs, Wald $\chi^{2}(1)=3.46, n s$. Controlling for school climate and adjusting for grade and gender differences, teacher support was not related to the relative risk of a student being involved in gangs relative to being at risk for gangs, Wald $\chi^{2}(1)=.19, n s$.

Unique effects of Relatedness, competence, and autonomy on GI. Results demonstrated that the predictors were significantly related to the multinomial log odds of a student being gang-involved, $\chi^{2}(10)=29.81, p<.01$.

Gang-Involved versus Not-Involved in Gangs. After controlling for grade and gender differences and the other SSPs, only relatedness was found to be related to the relative risk of a student being involved in gangs relative to not being gang-involved, Wald $\chi^{2}(1)=3.99, p<.01$. That is, as relatedness increases, the relative risk of a student being involved in gangs relative to not being GI decreased by a factor of 1.38.

Gang-Involved versus At Risk for Gangs. After controlling for grade and gender differences and the other SSPs, only competence was found to be related to the relative risk of a student at risk for gangs relative to being gang-involved, Wald $\chi^{2}(1)=7.61, p$ $<.01$. That is, as competence increases, the relative risk of a student being involved in gangs relative to being at risk for gangs decreased by a factor of 2.08. The SSP of competence distinguishes itself as an important variable in distinguishing students who are gang-involved versus at risk for gangs. 
Results 109

Achievement predicting GI. A multinomial logistic regression was conducted to evaluate the relationship between the likelihood of being involved in gangs and achievement. The predictor was achievement and the outcome variable was gang involvement, with $1=$ not-involved, $2=$ at-risk, and 3= potential gang members. Grade and gender were entered as covariates. Results demonstrated that the predictors were significantly related to the multinomial log odds of being gang-involved, $\chi^{2}(6)=17.32$, $p<.01$.

Gang-Involved versus Not-Involved in Gangs. After controlling for grade and gender, achievement was found to be related to the relative risk of a student being involved in gangs relative to not being gang-involved, Wald $\chi^{2}(1)=8.28, p<.01$. That is, as achievement increases, the relative risk of a student being involved in gangs relative to not being gang-involved decreased by a factor of 1.56 .

Gang-Involved versus At Risk for Gangs._After adjusting for grade and gender, achievement was not found to be related to the relative risk of a student being involved in gangs relative to being at risk for gangs, Wald $\chi^{2}(1)=3.06, n s$. According to these results, achievement is an important distinguishing factor for gang-involved versus notgang involved youth, but not for gang-involved and at risk youth.

\section{Testing RQ3 with GA as outcome.}

Unique effects of school climate and teacher support on GA. A logistic regression was conducted to evaluate the relationship between the likelihood of being attracted to gangs and school climate and teacher support. Grade and gender were 
Results 110

entered as covariates. Results indicated that the predictors were significantly related to the $\log$ odds of a student being attracted to gangs, $\chi^{2}(4)=25.11, p<.01$, Cox-Snell $R^{2}$ $=.07$. Controlling for teacher support and adjusting for grade and gender differences, school climate was not related to the relative risk of a student being attracted to gangs, Wald $\chi^{2}(1)=3.00, n s$. Controlling for school climate and adjusting for grade and gender differences, teacher support was related to the relative risk of a student being attracted to gangs, Wald $\chi^{2}(1)=3.98, p<.05$. Holding school climate constant and adjusting for grade and gender differences, for each unit increase in teacher support, the relative risk of a student being attracted to gangs decreased by a factor of .68 .

Unique effects of relatedness, competence, and autonomy on GA. Results demonstrated that the predictors were related to the log odds of a student being attracted to gangs, $\chi^{2}(5)=19.02, p<.01$, Cox-Snell $R^{2}=.05$. Controlling for the other predictors and adjusting for grade and gender differences, only relatedness were found to uniquely related to the relative risk of a student being attracted to gangs, Wald $\chi^{2}(1)=4.02, p$ $<.05$. Holding competence and autonomy constant and adjusting for grade and gender differences, for each unit increase in relatedness, the relative risk of a student being attracted to gangs decreased by a factor of .74.

Achievement predicting GA. Results demonstrated that the predictors were related to the log odds of a student being attracted to gangs, $\chi^{2}(3)=8.48, p<.05$, CoxSnell $R^{2}=.03$. However, achievement was not significantly related to the log odds of being attracted to gangs after adjusting for preexisting grade and gender differences, Wald $\chi^{2}(1)=2.14, n s$. 
Testing RQ3 with achievement as outcome.

\section{Unique effects of school climate and teacher support on achievement. A}

regression was conducted to determine whether school climate and teacher support each made unique contributions to achievement after adjusting for preexisting grade and gender differences. Results indicated that predictors were related to achievement, $F$ (4, $332)=21.10, p<.01$. The sample multiple correlation coefficient was .45 , indicating that $20 \%$ of the variance of achievement can be accounted for the linear combination of predictors. Controlling for teacher support and adjusting for preexisting grade and gender differences, school climate was significantly related to achievement, $\beta=.23, p<$ .01. Controlling for school climate and preexisting grade and gender differences, teacher support was significantly related to achievement, $\beta=.22, p<.05$. Both school climate and teacher support uniquely contributed to the prediction of achievement after controlling for preexisting grade and gender differences.

\section{Unique effects of relatedness, competence, and autonomy predicting}

achievement. Regression analyses were conducted to determine whether relatedness, competence, and autonomy each made unique contributions to achievement after adjusting for preexisting grade and gender differences. Results indicated that the predictors were related to achievement, $F(5,331)=14.87, p<.01$. The sample multiple correlation coefficient was .43 , indicating that $18 \%$ of the variance of achievement can be accounted for the linear combination of the predictors.

Only competence and autonomy were found to uniquely contribute to the prediction of achievement. After adjusting for preexisting differences in grade and 
gender and controlling for competence and autonomy, relatedness was not found to significantly related to achievement, $\beta=.11, n s$. After adjusting for preexisting differences in grade and gender and controlling for relatedness and autonomy, competence was found to significantly related to achievement, $\beta=.21, p<.01$. For each unit increase in competence, achievement increased by .24, after controlling for all other variables. After adjusting for preexisting differences in grade and gender and controlling for relatedness and competence, autonomy was found to significantly related to achievement, $\beta=.16, p<.01$.

Research Question 4. What are the processes through which school engagement can be supported?

In order to answer this question, three process models will be tested, each derived from the SSMMD.

4.1 Process 1: What is the relationship between the self-system processes, engagement, and disaffection?

Correlations between each SSP, engagement, and disaffection were in the expected direction. That is, the SSPs of relatedness, competence, and autonomy showed small to moderate positive relationships with engagement and moderate negative relationships with disaffection. Table 5.35 summarizes the correlations between each SSP, engagement, and disaffection. Students who perceived themselves as related to their teachers and competent and autonomous in their learning tended to be engaged in school, whereas those students who did not perceive themselves as related to their 
teachers or competent and autonomous in their learning tended to be more disaffected from school.

Table 5.36

Correlations between the Self-Systems, Engagement, and Disaffection

\begin{tabular}{|l|ccccc|}
\hline & Relatedness & Competence & Autonomy & Engagement & Disaffection \\
\hline Relatedness & -- & -- & -- & -- & -- \\
Competence & .43 & -- & -- & -- & - \\
Autonomy & .37 & .35 & -- & -- & -- \\
\hline Engagement & .47 & .38 & .67 & -- & -- \\
Disaffection & -.54 & -.46 & -.55 & -.62 & -- \\
\hline
\end{tabular}

Note. All correlations are significant at a 0.01 level.

What are the unique effects of the self-systems on engagement and disaffection?

Unique effects of self-systems on engagement. A multiple regression analysis was conducted to evaluate whether each SSP made a unique contribution to engagement after adjusting for preexisting grade and gender differences. Results demonstrated that the predictors was significantly related to engagement, $F(5,336)=73.01, p<.01$. The multiple correlation coefficient was .72 , indicating that $52 \%$ of the variance in engagement can be accounted for by the predictors.

In Table 5.37, indices are presented which reflect the relative strength of the individual predictors. Controlling for competence and autonomy and adjusting for preexisting grade and gender differences, relatedness related to engagement, $\beta=.23, p$ $<.01$; specifically, for each unit increase in relatedness, engagement increased by .23 , holding constant the other variables. Controlling for relatedness and autonomy and adjusting for preexisting grade and gender differences, competence was not found to be 
related to engagement, $\beta=.08, n s$. Controlling for relatedness and competence and adjusting for preexisting grade and gender differences, students who feel autonomous in their learning tend to be more engaged in school, $\beta=.55, p<.01$; that is, for each unit increase in autonomy, engagement increased by .45 , holding constant the other variables. These results demonstrate that both relatedness and autonomy were unique predictors of engagement.

Unique effects of self-systems on disaffection. A multiple regression analysis was conducted to evaluate whether each SSP made a unique contribution to disaffection after adjusting for preexisting grade and gender differences. Results demonstrated that the predictors were significantly related to disaffection, $F(5,336)=58.69, p<.01$. The multiple correlation coefficient was .68 , indicating that $47 \%$ of the variance in disaffection can be accounted for by the linear combination of the predictors.

In Table 5.37, indices are presented which reflect the relative strength of the individual predictors. Controlling for competence and autonomy and adjusting for preexisting grade and gender differences, relatedness negatively related to disaffection, $\beta=-.33, p<.01 ;$ specifically, for each unit increase in relatedness, disaffection decreased by .27 , holding constant the other variables. Controlling for relatedness and autonomy and adjusting for preexisting grade and gender differences, students who feel competent in school tend to be less disaffected from school, $\beta=-.18, p<.01$; that is, for each unit increase in competence, disaffection decreased by .19 , holding constant the other variables. Controlling for relatedness and competence and adjusting for preexisting grade and gender differences, students who feel autonomous in their 
learning tend to be less disaffected from school, $\beta=-.36, p<.01$; that is, for each unit increase in autonomy, disaffection decreased by .26 , holding constant the other variables. These results show that all three SSPs were unique predictors of disaffection.

Table 5.37

Multiple Regression Analyses for the Self-System Processes as Predictors of Engagement and Disaffection

\begin{tabular}{|c|c|c|c|c|}
\hline Outcome & Predictors & $B$ & $S E$ & $\beta$ \\
\hline Engagement & Relatedness & $.23^{* *}$ & .04 & .23 \\
\hline & Competence & .10 & .05 & .08 \\
\hline & Autonomy & $.45^{* *}$ & .04 & .55 \\
\hline Disaffection & Relatedness & $-.27 * *$ & .04 & -.33 \\
\hline & Competence & $-.19^{* *}$ & .05 & -.18 \\
\hline & Autonomy & $-.26^{* *}$ & .03 & -.36 \\
\hline
\end{tabular}

Note. Controlling for gender and grade levels. $* * p<.01 \quad$.

4.2 Process 2: What is the relationship between school climate, teacher support, engagement and disaffection?

Correlations were calculated between school climate, teacher support, engagement and disaffection. All correlations were in the expected direction. That is, the school climate and teacher support showed a moderate positive relationship with engagement and a moderate negative relationship with disaffection. Students who experienced a supportive school environment tended to be engaged in school and less disaffected. Table 5.38 summarizes the correlations between school climate, teacher support, engagement and disaffection. 
Results 116

Table 5.38

Correlations between School Climate, Teacher Support, Engagement, and Disaffection

\begin{tabular}{|l|cccc|}
\hline & School Climate & Teacher Support & Engagement & Disaffection \\
\hline School Climate & -- & -- & -- & -- \\
Teacher Support & .60 & -- & -- & -- \\
\hline Engagement & .53 & .61 & -- & -- \\
Disaffection & -.63 & -.63 & -.62 & -- \\
\hline
\end{tabular}

Note. All correlations are significant at 0.01 level.

What are the unique effects of school climate and teacher support on engagement and disaffection?

Unique effects of school climate and teacher support on engagement. A multiple regression analysis was conducted to evaluate whether school climate and teacher support each made unique contributions to engagement after adjusting for preexisting grade and gender differences. Results indicated that the predictors were significantly related to engagement, $F(4,337)=63.15, p<.01$. The multiple correlation coefficient was .66 , indicating that $43 \%$ of the variance in engagement can be accounted for by the linear combination of predictors.

In Table 5.39, indices are presented to indicate the relative strength of the individual predictors. Controlling for teacher support and adjusting for grade and gender differences, school climate was related to engagement, $\beta=.26, p<.01$; specifically, for each unit increase in school climate, engagement increased by .27 , holding constant teacher support and adjusting for grade and gender differences. Controlling for school climate and adjusting for preexisting grade and gender differences, students who experience supportive teachers tend to be more engaged in school, $\beta=.44, p<.01$; that is, for each unit increase in teacher support, engagement increased by .47 , holding 
constant school climate and adjusting for grade and gender differences. Although moderately correlated, school climate and teacher support each made unique contributions on engagement.

Table 5.39

Multiple Regression Analyses for the School Climate and Teacher Support as Predictors of Engagement

\begin{tabular}{|c|c|c|c|}
\hline Predictors & $B$ & $S E$ & $\beta$ \\
\hline School Climate & $.27 *$ & .05 & .26 \\
\hline Teacher Support & $.47^{*}$ & .06 & .44 \\
\hline
\end{tabular}

Note. Controlling for grade and gender levels. $* p<.01$.

Unique effects of school climate and teacher support on disaffection. A multiple regression analysis was conducted to evaluate whether school climate and teacher support each made unique contributions to disaffection after adjusting for preexisting grade and gender differences. Results indicated that the predictors were significantly related to disaffection, $F(4,337)=85.08, p<.01$. The multiple correlation coefficient was .71 , indicating that $50 \%$ of the variance in disaffection can be accounted for by the linear combination of the predictors.

In Table 5.40, indices are presented to indicate the relative strength of the individual predictors. Controlling for teacher support and adjusting for preexisting grade and gender differences, school climate was negatively related to disaffection, $\beta=$ $-.40, p<.01$. Holding constant teacher support and adjusting for grade and gender differences, for each unit increase in school climate, disaffection decreased by .36 . Controlling for school climate and adjusting for grade and gender differences, students 
who experience supportive teachers tend to be less disaffected from school, $\beta=-.39, p<$ .01 . Holding constant school climate and adjusting for grade and gender differences, for each unit increase in teacher support, disaffection decreased by .36. Although moderately correlated, school climate and teacher support each made unique contributions on disaffection.

Table 5.40

Multiple Regression Analyses for the School Climate and Teacher Support as Predictors of Disaffection

\begin{tabular}{|c|c|c|c|}
\hline Predictors & $B$ & $S E$ & $\beta$ \\
\hline School Climate & $-.36^{*}$ & .04 & -.40 \\
\hline Teacher Support & $-.36^{*}$ & .05 & -.39 \\
\hline
\end{tabular}

Note. Controlling for grade and gender levels. $* p<.01$.

4.3a Process 3a. Is the relationship between overall school support and engagement mediated by self- system processes?

Mediating effects of the self-system processes. In order to test the hypothesis of whether overall school support shapes student engagement (and disaffection) through its influence on their self-system processes, mediational models were tested. Overall school support was calculated by averaging school climate and teacher support (Cronbach's $\alpha=.88$ ). Grade and gender were entered as covariates.

Following Baron and Kenny's (1986) procedures for establishing mediation, each self-system process was specified as a separate mediator between overall school support and engagement (and disaffection) in each model. In order to establish a mediated relationship, the following conditions must be met: (a) the dependent variable 
(e.g., engagement) must be significantly related to the predictor (overall school support); (b) the mediating variable (e.g., relatedness) must be significantly related to the predictor (overall school support) and (c) the dependent variable (e.g., engagement) must be significantly related to the mediating variable (e.g., relatedness). If the unique effect of the self-system remains significant and the unique effect of overall school support is significantly reduced, this would indicate partial mediation. However, if the unique effect of the self-system remains significant and the unique effect of overall school support is no longer significant, then full mediation would be established for that self-system. The Sobel test was also conducted to evaluate the mediation model. Table 5.40 summarizes the correlations between overall school support, self-system processes, engagement and disaffection. 
Table 5.41

Correlations between Overall School Support, Self-System Processes, Engagement, and Disaffection

\begin{tabular}{|c|c|c|c|c|c|c|c|}
\hline & $\begin{array}{c}\text { Overall } \\
\text { School } \\
\text { Support }\end{array}$ & Relatedness & Competence & Autonomy & $\begin{array}{l}\text { Aggregated } \\
\text { SSPs }\end{array}$ & Engagement & Disaffection \\
\hline $\begin{array}{l}\text { Overall School } \\
\text { Support }\end{array}$ & -- & -- & -- & -- & -- & -- & 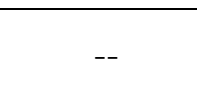 \\
\hline Relatedness & .68 & -- & -- & -- & -- & -- & -- \\
\hline Competence & .49 & .43 & -- & -- & -- & -- & -- \\
\hline Autonomy & .58 & .37 & .36 & -- & -- & -- & -- \\
\hline $\begin{array}{l}\text { Aggregated } \\
\text { SSPs }\end{array}$ & .76 & .75 & .73 & .81 & -- & -- & -- \\
\hline Engagement & .64 & .47 & .38 & .67 & .69 & -- & -- \\
\hline Disaffection & -.68 & -.54 & -.44 & -.55 & -.68 & -.62 & -- \\
\hline
\end{tabular}


Testing relatedness as mediator between overall school support and engagement. As can be seen in Table 5.40, overall school support (OSS) was significantly related with engagement and relatedness. The SSP of relatedness was also significantly related to engagement. To test the direct and indirect effects of OSS and relatedness on engagement, engagement was regressed on OSS and relatedness. Results demonstrated that when both predictors are included in the model, OSS had a positive effect on engagement $(\beta=.57, p<.01)$. However, the relationship between relatedness and engagement dropped to non significance $(\beta=.08, n s)$, suggesting that either OSS is the mediator between relatedness and engagement or that the part of relatedness that is connected to engagement reflects a supportive school climate. This model suggests that a student's self- perceptions of relatedness shape their engagement through their overall experience of school support. The Sobel test (as cited by Baron and Kenny, 1986) found the indirect effects of relatedness on engagement to be significant, Sobel test $=8.31, p<$ .01. Figure 4 depicts the meditational model for OSS as mediator between relatedness and engagement. 


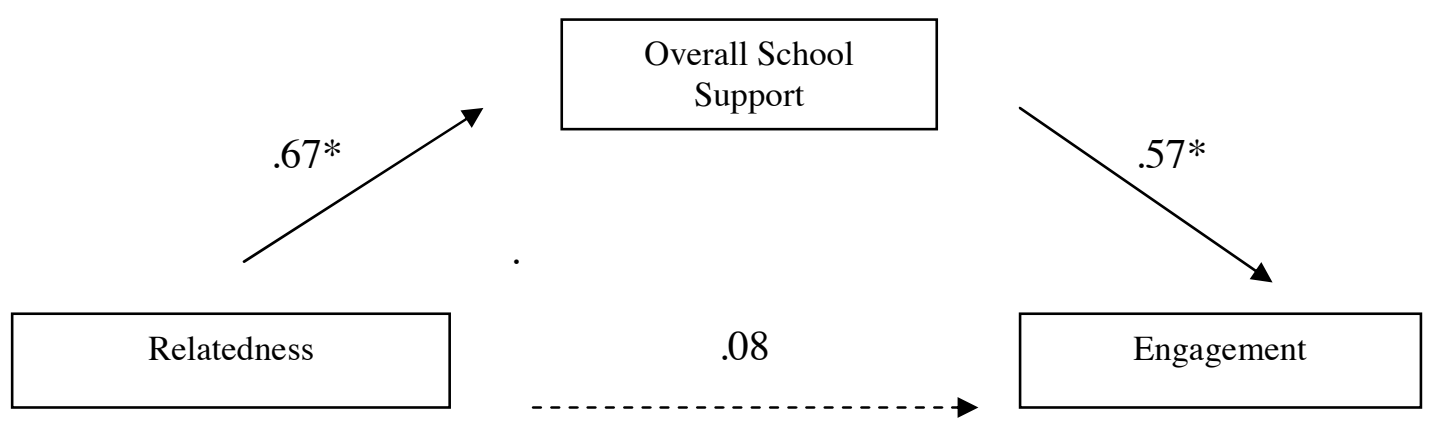

Figure 4. Mediational model for overall school support as a mediator between relatedness and engagement.

Note. Standardized regression coefficients are presented. ${ }^{*} p<.01$.

Testing competence as mediator between overall school support and engagement. As can be seen in Table 5.40, OSS was significantly related with engagement and competence. The SSP of competence was also significantly related to engagement. To test the direct and indirect effects of OSS and competence on engagement, engagement was regressed on OSS and competence. Results demonstrated that when both predictors are included in the model, OSS had a positive effect on engagement $(\beta=.58, p<.01)$. However, the relationship between competence and engagement dropped to non significance $(\beta=.08, n s)$, suggesting that either OSS is the mediator between competence and engagement or that the part of competence that is connected to engagement reflects a supportive school climate. This model suggests that a student's self- perceptions of competence shape their engagement through their overall experience of school support. The Sobel test (as cited by Baron and Kenny, 
1986) found the indirect effects of competence on engagement to be significant, Sobel test $=7.45, p<.01$. Figure 5 depicts the meditational model for OSS as mediator between competence and engagement.

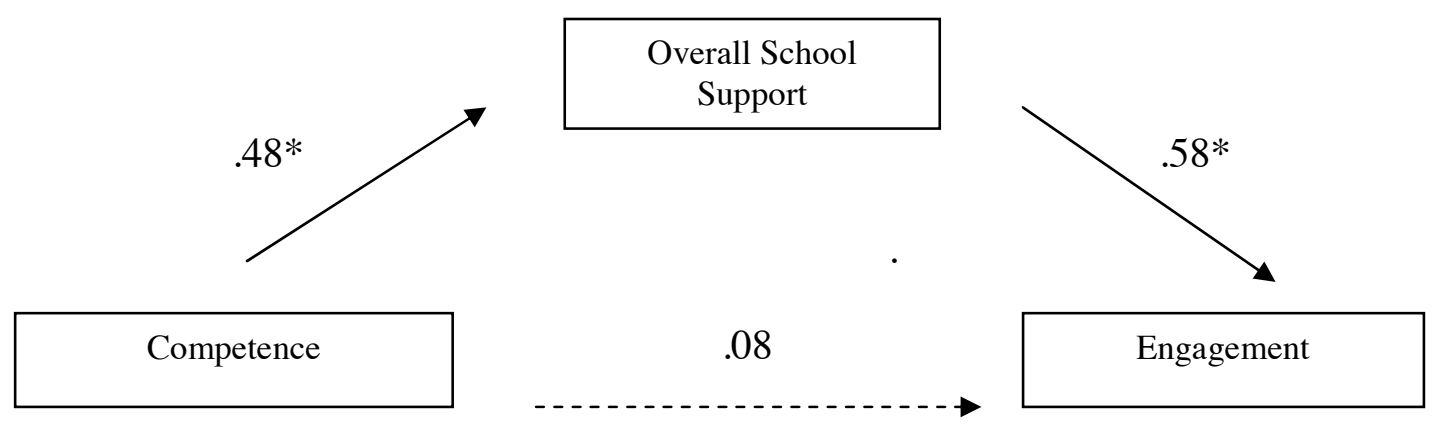

Figure 5. Mediational model for overall school support as a mediator between competence and engagement.

Note. Standardized regression coefficients are presented. $* p<.01$.

Testing autonomy as mediator between overall school support and engagement.

As can be seen in Table 5.40, OSS was significantly related with engagement and autonomy. The SSP of autonomy was also significantly related to engagement. To test the direct and indirect effects of OSS and autonomy on engagement, engagement was regressed on OSS and autonomy. Results demonstrated that when both predictors are included in the model, both OSS and autonomy had direct effects on engagement (for OSS, $\beta=.37, p<.01$; for autonomy, $\beta=.45, p<.01$ ). The Sobel test (as cited by Baron and Kenny, 1986) found the indirect effects of OSS on engagement to be significant, Sobel test $=7.50, p<.01$. These results suggest that autonomy partially mediates the relationship between OSS and engagement. Overall, 55\% of the variance in engagement 
was explained by overall school support and the SSP of autonomy. Figure 6 depicts the meditational model for autonomy as mediator between OSS and engagement.

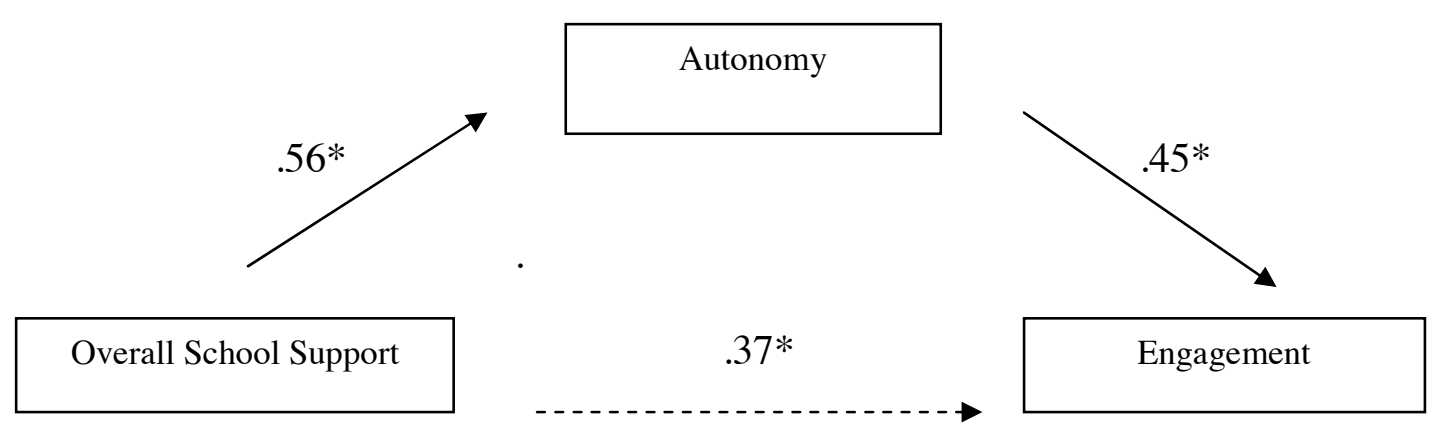

Figure 6. Mediational model for autonomy as a partial mediator between overall school support and engagement.

Note. Standardized regression coefficients are presented. ${ }^{*} p<.01$.

Testing aggregate of Self-System Processes as mediator between overall school

support and engagement. In order to examine whether the findings that overall school support (OSS) was a stronger predictor of engagement than any of the SSPs alone were due to the superior psychometric properties of the measure of OSS, an aggregate score of overall self-system processes was created. As can be seen in Table 5.40, OSS was significantly related with engagement and the aggregate SSPs. The aggregate SSPs were also significantly related to engagement. To test the direct and indirect effects of OSS and the aggregate SSPs on engagement, engagement was regressed on OSS and the aggregate SSPs. Results demonstrated that when both predictors are included in the model, both OSS and the aggregate SSPs had direct effects on engagement (for OSS, $\beta=$ 
Results 125

$.27, p<.01$; for aggregate SSPs, $\beta=.47, p<.01$ ). The Sobel test (as cited by Baron and Kenny, 1986) found the indirect effects of OSS on engagement to be significant, Sobel test $=8.00, p<.01$.These results suggest that the aggregate SSPs partially mediates the relationship between OSS and engagement. Overall, 51\% of the variance in engagement was explained by overall school support and the aggregate SSPs. Figure 7 depicts the meditational model for the SSPs as the mediator between OSS and engagement.

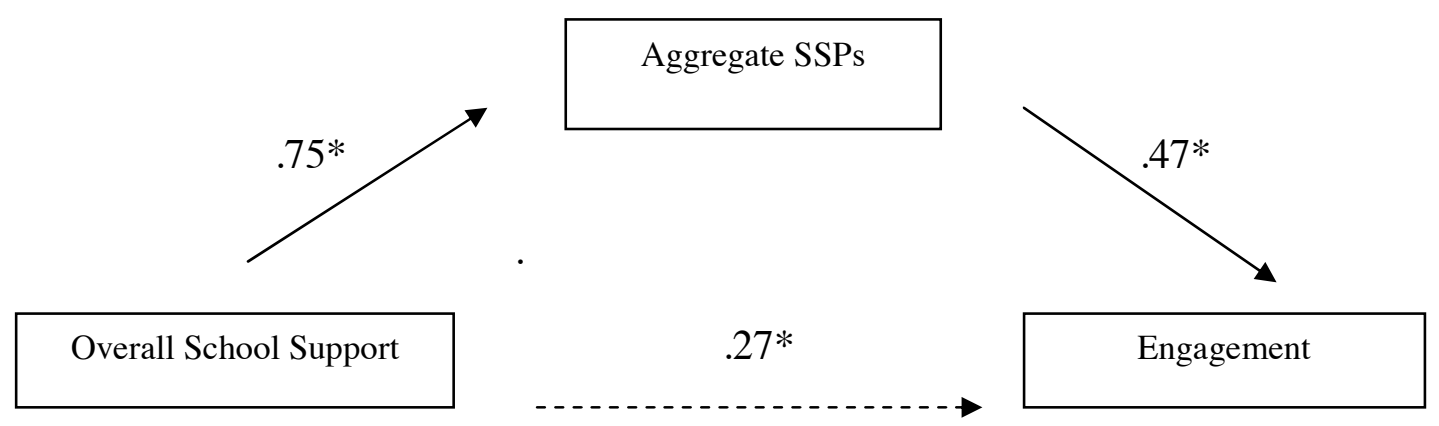

Figure 7. Mediational model for aggregate SSPs as a mediator between overall school support and engagement.

Note. Standardized regression coefficients are presented. $* p<.01$.

$4.3 \mathrm{~b}$ Process $3 \mathrm{~b}$. Is the relationship between overall school support and disaffection mediated by self- system processes?

Testing relatedness as mediator between overall school support and disaffection. As can be seen in Table 5.40, overall school support (OSS) was significantly related with disaffection and relatedness. The SSP of relatedness was also significantly related to disaffection. To test the direct and indirect effects of OSS and 
relatedness on disaffection, disaffection was regressed on OSS and relatedness. Results demonstrated that when both predictors are included in the model, both OSS and relatedness had negative effects on disaffection (for OSS, $\beta=-.57, p<.01$; for relatedness, $\beta=-.15, p<.01$ ). The Sobel test (as cited by Baron and Kenny, 1986) found the indirect effects of OSS on disaffection to be not significant, Sobel test $=-2.57, n s$, which suggests that relatedness does not partially mediate the relationship between OSS and disaffection. A follow-up Sobel test was conducted to test the indirect effects of relatedness to disaffection. The test was not significant, Sobel test $=-9.60, n s$, which suggests that OSS does not partially mediate the relationship between OSS and disaffection. These results indicate that both OSS and relatedness made unique contributions on disaffection. Students who experienced a less supportive school environment and felt less relatedness tended to be more disaffected from school.

Testing competence as mediator between overall school support and disaffection. As can be seen in Table 5.40, OSS was negatively related to disaffection and positively related to competence. The SSP of competence was negatively significantly related to disaffection. To test the direct and indirect effects of OSS and competence on disaffection, disaffection was regressed on OSS and competence. Results demonstrated that when both predictors are included in the model, both OSS and competence had direct negative effects on disaffection (for OSS, $\beta=-.59, p<.01$; for competence, $\beta=-.16, p<.01$ ). The Sobel test (as cited by Baron and Kenny, 1986) was conducted to test the indirect effects of OSS on disaffection. Results were not significant, Sobel test $=-3.19, n s$, which suggests that competence does not partially 
mediate the relationship between OSS and disaffection. A follow-up Sobel test was conducted to test the indirect effects of competence on disaffection. The test was not significant, Sobel test $=-7.63, n s$, which suggests that OSS does not partially mediate the relationship between competence and disaffection. These results indicate the both OSS and competence made unique contributions to disaffection. Students who experienced a less supportive school environment and felt less competent in their learning tended to be more disaffected from school.

Testing autonomy as mediator between overall school support and disaffection. As can be seen in Table 5.40, OSS was negatively related to disaffection and positively related to autonomy. The SSP of autonomy was negatively related to disaffection. To test the direct and indirect effects of OSS and autonomy on disaffection, disaffection was regressed on OSS and autonomy. Results demonstrated that when both predictors are included in the model, both OSS and autonomy had direct negative effects on disaffection (for OSS, $\beta=-.54, p<.01$; for autonomy, $\beta=-.24, p<.01$ ). The Sobel test (as cited by Baron and Kenny, 1986) found the indirect effects of OSS on disaffection to be not significant, Sobel test $=-5.18, n s$. In addition, the Sobel test found the indirect effects of autonomy on disaffection to be not significant, Sobel test $=-8.38, n s$. Evidence for mediation was not found. These results suggest that both OSS and autonomy made unique contributions to disaffection. Students who experienced a less supportive school environment and felt less autonomous in their learning tended to be more disaffected from school. 
Results 128

Testing the SSPs as mediator of overall school support and disaffection. As can be seen in Table 5.40, OSS was negatively related with disaffection and positively related to the SSPs. The SSPs were also negatively related to disaffection. To test the direct and indirect effects of OSS and the SSPs on disaffection, disaffection was regressed on OSS and the SSPs. Results demonstrated that when both predictors are included in the model, both OSS and the SSPs had direct negative effects on disaffection (for OSS, $\beta=-.39, p<.01$; for the SSPs, $\beta=-.38, p<.01$ respectively). The Sobel test found the indirect effects of OSS on disaffection to be not significant, Sobel test $=-6.68, n s$. In addition, the Sobel test found the indirect effects of the SSPs on disaffection to be not significant, Sobel test $=-6.06, n s$. Evidence for mediation was not found. These results suggest that both OSS and the SSPs made unique contributions to disaffection. Students who experienced a less supportive school environment and felt less relatedness, competent, and autonomous in their learning tended to be more disaffected from school.

4.4. Process 4: Is the relationship between overall school support and each outcome (i.e., GI, GA, and achievement) mediated by engagement versus disaffection?

Student Profile (1): Levels of gang involvement. As can be seen in Table 5.42, the overall school support was negatively related to GI and positively related to engagement versus disaffection. Engagement versus disaffection was negatively related to GI. To test the direct and indirect effects of the motivational supports and 
engagement versus disaffection on GI, a multinomial logistic regression was conducted to evaluate whether engagement versus disaffection mediated the relationship between overall school support and the likelihood of a student being gang-involved after adjusting for preexisting grade and gender differences. Results demonstrated that the predictors were significantly related to the multinomial log odds of being ganginvolved, $\chi^{2}(8)=40.88, p<.01$.

Gang-Involved versus Not-Involved in Gangs. Controlling for engagement versus disaffection, overall school support was uniquely related to the relative risk of a student being involved in gangs, Wald $\chi^{2}(1)=6.33, p<.05$. That is, controlling for engagement versus disaffection, for every unit increase in overall school support, the the relative risk of a student being involved in gangs relative to not being gang-involved decreased by 1.88. Controlling for overall school support, engagement versus disaffection was not uniquely related to the relative risk of a student not being involved in gangs relative to being gang-involved, Wald $\chi^{2}(1)=1.05, n s$. These findings suggest that overall school support may mediate the relationship between engagement versus disaffection and GI instead of the reverse. The Sobel test was conducted to test the indirect effects of engagement versus disaffection on the likelihood of a student being gang-involved (Baron, 1996; Herr, 2006). For levels of GI (for gang-involved relative to not gang-involved), evidence for mediation was found, Sobel test $=2.60, p<.01$. Students' experiences of overall school support mediated the relationship between engagement versus disaffection and the likelihood of a student being involved in gangs 
Results 130

relative to not being gang-involved. In other words, more engaged students received more support and were less gang-involved.

Gang-Involved versus At Risk for Gangs. Holding constant engagement versus disaffection, overall school support was not found to be uniquely related to the relative risk of student being involved in gangs relative to students being at risk for gangs, Wald $\chi^{2}(1)=.11, n s$. Holding constant the overall school support, engagement versus disaffection was found to be uniquely related to the relative risk of student being involved in gangs relative to students being at risk for gangs, Wald $\chi^{2}(1)=6.67, p<.05$. For each unit increase in engagement versus disaffection, the relative risk of a student being involved in gangs relative to a student being at risk for gangs decreased by 2.34 . The Sobel test was conducted to test the indirect effects of overall school support on the likelihood of a student being gang-involved relative to being at risk for gangs (Baron, 1996; Herr, 2006). For levels of GI (gang-involved relative to being at risk for gangs), evidence for mediation was found, Sobel test $=2.50, p<.01$. Students' experiences of engagement versus disaffection mediated the relationship between the overall school support and the likelihood of a student being gang-involved relative to being at risk for gangs. 
Table 5.42

Correlations between the Motivational Supports, Gang Involvement, Gang Attraction, and Achievement

\begin{tabular}{|c|c|c|c|c|c|c|}
\hline & 1. & 2. & 3. & 4. & 5. & 6. \\
\hline 1. Overall School Support & -- & -- & -- & -- & -- & -- \\
\hline 2. SSPs & $.76^{*}$ & -- & -- & -- & -- & -- \\
\hline 3. Engagement versus Disaffection & $.73 *$ & $.75^{*}$ & -- & -- & -- & -- \\
\hline 4. GI & $-.27 *$ & $-.17 *$ & $-.23 *$ & -- & -- & -- \\
\hline 5. GA & $-.22 *$ & $-.16^{*}$ & $-.17 *$ & $.67 *$ & -- & -- \\
\hline 6. Achievement & $.41 *$ & $.39 *$ & $.42 *$ & $-.18 *$ & -.09 & -- \\
\hline
\end{tabular}

Note. GI= Gang Involvement, GA= Gang Attraction.

$* p<0.01$. 
Student Profile (2): Levels of gang attraction. As can be seen in Table 5.42, overall school support was negatively related with GA and positively related to engagement versus disaffection. Engagement versus disaffection was negatively related to GA. To test the direct and indirect effects of overall school support and engagement versus disaffection on GA, a logistic regression was conducted to evaluate whether engagement versus disaffection mediated the relationship between overall school support and the likelihood of a student being attracted to gangs after adjusting for preexisting grade and gender differences. Results demonstrated that the predictors were significantly related to the log odds of being attracted to gangs, $\chi^{2}(4)=24.24, p<.01$. Controlling for engagement versus disaffection, overall school support was negatively related to the log odds of a student being attracted to gangs, Wald $\chi^{2}(1)=$ $6.23, p<.05$. Specifically, holding engagement versus disaffection constant, for each unit increase in overall school support, the relative risk of a student being attracted to gangs decreased by .55. Controlling for overall school support, engagement versus disaffection was not found to be related to the relative risk of a student being attracted to gangs, Wald $\chi^{2}(1)=.19, n s$. These findings suggests that overall school support may mediate the relationship between engagement versus disaffection and GA instead of the reverse. The Sobel test was conducted to test the indirect effects of engagement versus disaffection on the likelihood of a student being attracted to gangs (Baron, 1996; Herr, 2006). For levels of GA, evidence for mediation was found, Sobel test $=-2.50, p<.01$. Students' experiences of overall school support mediated the relationship between the engagement versus disaffection and the likelihood of a student being attracted to gangs. 
Results 133

Achievement. As can be seen in Table 5.42, overall school support was significantly related with achievement and engagement versus disaffection. Engagement versus disaffection was also significantly related to achievement. To test the direct and indirect effects of overall school support and engagement versus disaffection on achievement, achievement was regressed on overall school support and engagement versus disaffection. Grade and gender were entered as covariates. Results demonstrated that when both predictors are included in the model, both OSS and engagement versus disaffection had direct effects on disaffection (for OSS, $\beta=.21, p<.01$; for engagement versus disaffection, $\beta=.26, p<.01$ ). The Sobel test (as cited by Baron and Kenny, 1986) found the indirect effects of OSS on achievement to be significant, Sobel test = $3.66, p<.01$. Evidence for partial mediation was found. These results indicate that engagement versus disaffection partially mediates the relationship between OSS and achievement.

4.5. Process 5: Is the relationship between the SSPs and each outcome (i.e., GI, GA, and achievement) mediated by engagement versus disaffection?

Student Profile (1): Levels of gang involvement. As can be seen in Table 5.42, the aggregated SSP was negatively related to GI and positively related to engagement versus disaffection. Engagement versus disaffection was negatively related to GI. To test the direct and indirect effects of the aggregated SSP and engagement versus disaffection on GI, a multinomial logistic regression was conducted to evaluate whether engagement versus disaffection mediated the relationship between the aggregated SSP and the likelihood of a student being gang-involved after adjusting for preexisting grade 
and gender differences. Results demonstrated that the predictors were related to the multinomial log odds of being gang- involved, $\chi^{2}(8)=30.46, p<.01$.

Gang-Involved versus Not-Involved in Gangs. Controlling for engagement versus disaffection, the aggregated SSP was not related to the relative risk of a student being involved in gangs, Wald $\chi^{2}(1)=.01, n s$. Controlling for the aggregated SSP, engagement versus disaffection was uniquely related to the relative risk of a student being involved in gangs relative to not being gang-involved, Wald $\chi^{2}(1)=7.76, p<.01$. Specifically, for each unit increase in engagement versus disaffection, the log odds of a student being involved in gangs relative to a student not being gang-involved decreased by 2.11. The Sobel test was conducted to test the indirect effects of the aggregated SSP on the likelihood of a student being gang-involved (Baron, 1996; Herr, 2006). For levels of GI (for gang-involved relative to not gang-involved), evidence for mediation was found, Sobel test $=2.70, p<.01$. Engagement versus disaffection fully mediated the relationship between the aggregated SSP and the likelihood of a student being involved in gangs relative to not being gang-involved.

Gang-Involved versus At Risk for Gangs. Holding constant engagement versus disaffection, the aggregated SSP was not found to be uniquely related to the relative risk of student being gang-involved relative to students being at risk for gangs, Wald $\chi^{2}$ $(1)=.01, n s$. Holding constant the aggregated SSP, engagement versus disaffection was found to be uniquely related to the relative risk of student being gang-involved relative to students being at risk for gangs, Wald $\chi^{2}(1)=5.20, p<.05$. Specifically, for each unit increase in engagement versus disaffection, the relative risk of a student being involved 
in gangs relative to a student being at risk for gangs decreased by 2.17 . The Sobel test was conducted to test the indirect effects of the aggregated SSP on the likelihood of a student being gang-involved relative to being at risk for gangs (Baron, 1996; Herr, 2006). For levels of GI (being gang-involved relative to being at risk for gangs), evidence for mediation was found, Sobel test $=2.37, p<.05$. Students' experiences of engagement versus disaffection fully mediated the relationship between the aggregated SSP and the likelihood of a student being gang-involved relative to being at risk for gangs.

Student Profile (2): Levels of gang attraction. As can be seen in Table 5.42, the aggregated SSP was negatively related with GA and positively related to engagement versus disaffection. Engagement versus disaffection was negatively related to GA. To test the direct and indirect effects of the aggregated SSP and engagement versus disaffection on GA, a logistic regression was conducted to evaluate whether engagement versus disaffection mediated the relationship between the aggregated SSP and the likelihood of a student being attracted to gangs after adjusting for preexisting grade and gender differences. Results demonstrated that the predictors together were significantly related to the log odds of being attracted to gangs, $\chi^{2}(4)=18.87, p<.01$. However, holding constant the other variable, no predictor was found to uniquely contribute to the relative risk of a student being attracted to gangs (for the aggregated SSP, Wald $\chi^{2}(1)=.96, n s$; for engagement versus disaffection, Wald $\left.\chi^{2}(1)=2.14, n s\right)$. Evidence for mediation was not found. 
Achievement. As can be seen in Table 5.42, the aggregated SSP was significantly related with achievement and engagement versus disaffection. Engagement versus disaffection was also significantly related to achievement. To test the direct and indirect effects of the aggregated SSP and engagement versus disaffection on achievement, achievement was regressed on the aggregated SSP and engagement versus disaffection. Grade and gender were entered as covariates. Results demonstrated that when both predictors are included in the model, both the aggregated SSP and engagement versus disaffection had direct effects on achievement (for SSPs, $\beta=.16, p<$ .05 ; for engagement versus disaffection, $\beta=.28, p<.01$ ). The Sobel test (as cited by Baron and Kenny, 1986) found the indirect effects of the aggregated SSP on achievement to be significant, Sobel test $=3.51, p<.01$. Evidence for partial mediation was found. These results suggest that engagement versus disaffection partially mediates the relationship between the aggregated SSP and achievement.

Research Question 5. Does the larger process model provide a good account of GI and GA? Does the larger process model also provide a good account of achievement?

In order to test whether the larger process model provided a good account of each outcome (i.e., GI, GA, and achievement), the following steps were conducted. First, correlations were calculated between OSS and the aggregated SSP. Secondly, sequential regression analyses (path analyses) were conducted to test each subsequent link of the SSMMD model (see figure 2): (1) Engagement versus disaffection was regressed on OSS and the aggregated SSP and (2) each outcome was regressed on OSS, 
the aggregated SSP, and engagement versus disaffection. Grade and gender were entered as covariates. For GI, multinomial logistic regression was used. For GA, logistic regression was used and, for achievement, OLS regression was conducted.

As seen in Table 5.42, OSS was strongly related to the aggregated SSP $(r=$ .76). Students who experienced a supportive school environment tended to feel more related, competent, and autonomous in their learning. Next, results from the first regression analyses indicated that the aggregated SSP had a direct positive effect on engagement versus disaffection, $\beta=.46, p<.01$, and OSS had an indirect positive effect on engagement versus disaffection, $\beta=.38, p<.01$. And finally, regression analyses were conducted on each outcome using OSS, the aggregated SSP, and engagement versus disaffection as predictors. Results are as follows.

Student Profile (1): Levels of Gang Involvement as outcome. A multinomial regression was conducted to evaluate the relationship between the likelihood of being gang-involved and OSS, the aggregated SSP, and engagement versus disaffection. Results indicated that the predictors were related to the multinomial log odds of being gang-involved after adjusting for preexisting grade and gender differences, $\chi^{2}(10)=$ $43.83, p<.01$.

Gang-Involved versus Not-Involved in Gangs. Controlling for OSS and the aggregated SSP, engagement versus disaffection was not related to the relative risk of a student being involved in gangs relative to not being gang-involved, Wald $\chi^{2}(1)=2.34$, $n s$. Controlling for the OSS and engagement versus disaffection, the aggregated SSP was not related to the relative risk of a student being involved in gangs relative to not 
being gang-involved, Wald $\chi^{2}(1)=1.91, n s$. Controlling for the aggregated SSP and engagement versus disaffection, OSS was related to the relative risk of a student being involved in gangs versus not being gang-involved, Wald $\chi^{2}(1)=8.19, p<.01$. With each unit increase in OSS, the relative risk of a student being involved in gangs relative to not being gang-involved decreases by a factor of 2.26. Figure 10 depicts the path analytic model for the SSMMD with GI (GI relative to Not-Involved) as outcome. 


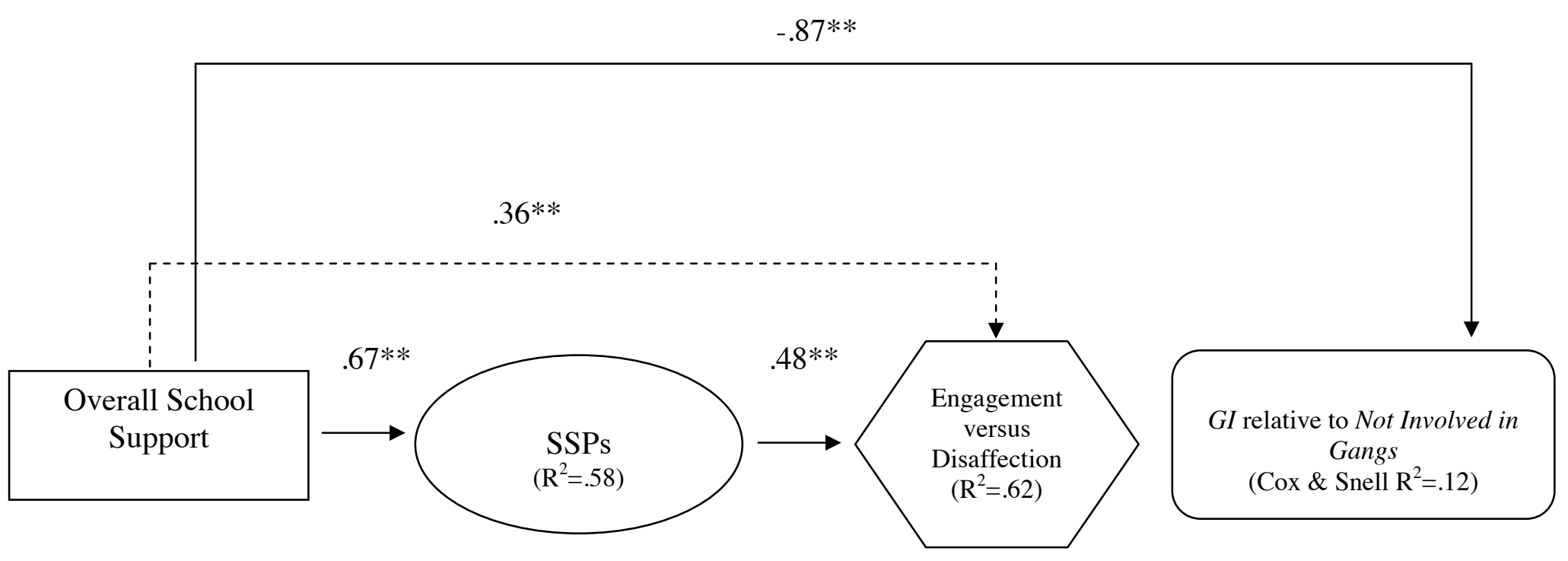

Figure 8. Results of regression and multinomial regression analyses for GI (GI relative to Not-Involved in Gangs). N=342. Unstandardized regression coefficients and adjusted $R^{2} s$ are presented. $* * p<.01$. 
Results 140

Gang-Involved versus At Risk for Gangs. Controlling for OSS and the aggregated SSP, engagement versus disaffection was related to the relative risk of a student being gang-involved relative to being at risk for gangs, Wald $\chi^{2}(1)=4.99, p<$ .05 . With each unit increase in engagement versus disaffection, the relative risk of a student being gang-involved relative to being at risk for gangs decreases by a factor of 2.26. Controlling for the OSS and engagement versus disaffection, the aggregated SSP was not related to the relative risk of a student being gang-involved relative to being at risk for gangs, Wald $\chi^{2}(1)=.03, n s$. Controlling for the aggregated SSP and engagement versus disaffection, OSS was not related to the relative risk of a student being gang-involved versus being at risk for gangs, Wald $\chi^{2}(1)=.14, n s$. Figure 11 depicts the path analytic model for the SSMMD with GI (GI relative to At Risk for Gangs) as outcome. 


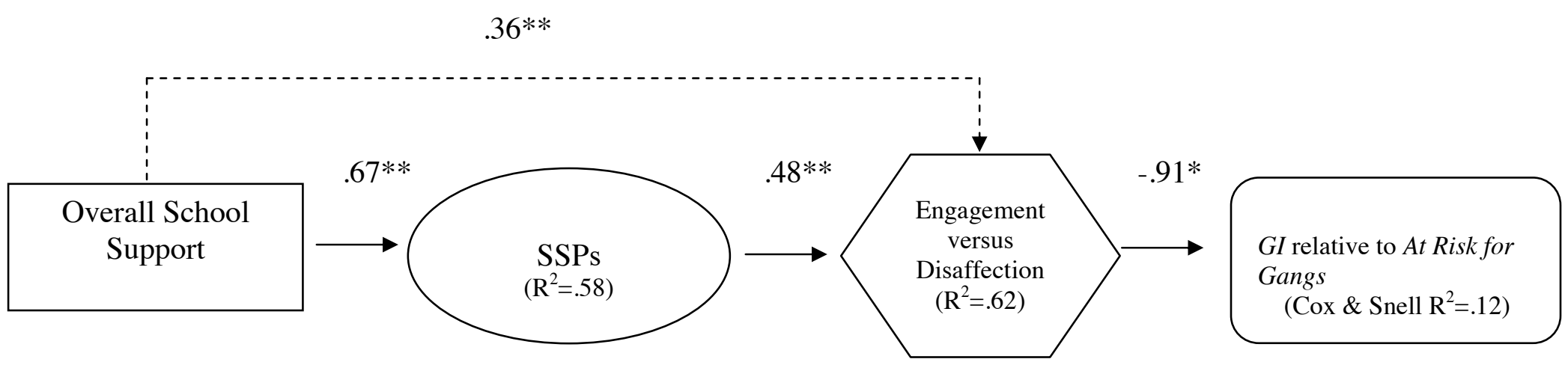

Figure 9. Results of regression and multinomial regression analyses for GI (GI relative to At-Risk for Gangs). N=342. Unstandardized regression coefficients and adjusted $R^{2} s$ are presented. $* p<.05, * * p<.01$. 
Results 142

Student Profile (2): Levels of Gang Attraction as outcome. A logistic regression was conducted to evaluate the relationship between the likelihood of a student being attracted to gangs and OSS, the aggregated SSP, and engagement versus disaffection. Results indicated that the predictors were significantly related to the log odds of a student being attracted to gangs, after adjusting for preexisting grade and gender differences, $\chi^{2}(5)=24.26, p<.01$. Controlling for all the other variables, OSS was the only predictor found to be related to the relative risk of a student being attracted to gangs, Wald $\chi^{2}(1)=5.34, p<.05$. Holding constant the SSPs and engagement versus disaffection, for each unit increase in OSS, the relative risk of a student being attracted to gangs decreased by a factor of .54 . Figure 12 depicts the path analytic model for the SSMMD with GA as outcome. 


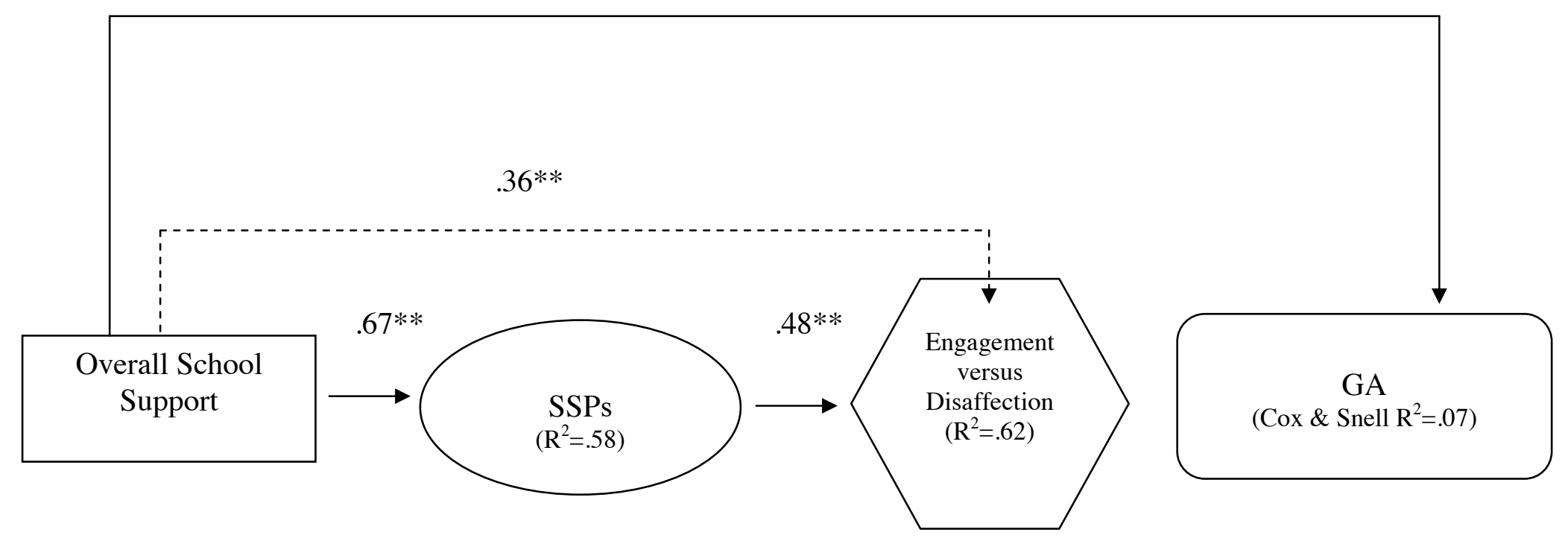

Figure 10. Results of regression and multinomial regression analyses for GA. $N=342$. Unstandardized regression coefficients and adjusted $R^{2} s$ are presented. $* * p<.01, * p<.05$. 


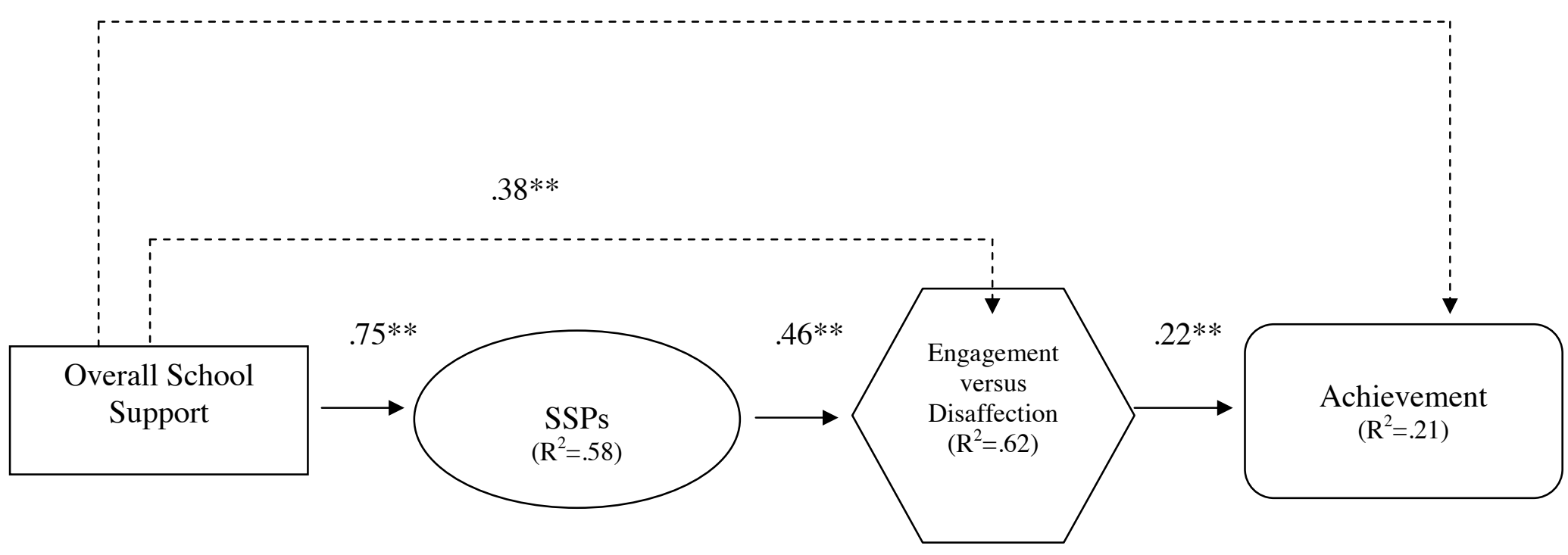

Figure 11. Results of regression and multinomial regression analyses for Achievement. $N=342$. Standardized regression coefficients and adjusted $R^{2} s$ are presented. $* * p<.01, * p<.05$. 
Achievement as outcome. A multiple regression analysis was conducted to examine the relationship between OSS, the SSPs, engagement versus disaffection and achievement. Results indicated that the predictors were significantly related to achievement, after adjusting for preexisting grade and gender differences, $F(5,331)=$ 18.86, $p<.01$. Controlling OSS and the SSPs, engagement versus disaffection was uniquely related to achievement, $\beta=.22, p<.01$. For each unit increase in engagement versus disaffection, achievement increased by .25 . Controlling for the SSPs and engagement versus disaffection, OSS was uniquely related to achievement, $\beta=.16, p<$ .05. For each unit increase in OSS, achievement increased by .17. Controlling for the OSS and engagement versus disaffection, the SSPs were not found to be uniquely related to achievement, $\beta=.09, n s$. Figure 13 depicts the measurement model for the SSMMD with achievement as outcome.

Research Question 6. What motivational supports are provided to youth who are involved in gangs compared to those who are not?

In order to answer this research question, levels of motivational supports were examined for students with differential levels of gang involvement. For all analyses except achievement, grade was entered as a covariate. Gender was not entered as a covariate in these analyses as the assumption of homogeneity of slopes was not held. However, to examine whether differences in motivational supports were related to differences between boys and girls in levels of gang involvement, interactions between gender and each student profile were conducted. For achievement, grade and gender were entered as covariates as the assumptions of homogeneity of slopes were met. 
Results 146

6.1 For contextual supports: These analyses examined mean levels differences in the school climate and teacher support. It was hypothesized that (1) students who are gang-involved will experience lower levels of teacher support and school climate, compared to students who are not gang-involved; and (2) students who are attracted to gangs will experience lower levels of teacher support and school climate, compared to students who are not attracted to gangs.

Student Profile (1): Levels of Gang Involvement. A multivariate analysis of covariance (MANCOVA) was conducted to determine the differences in school climate and teacher support as a function of the levels of gang involvement (GI) adjusting for preexisting grade differences. One factor, group classification, had three levels: (1) potential GM, (2) at- risk, and (3) not-involved. The dependent variables (DVs) were school climate and teacher support. Significant differences were found among levels of GI on the dependent variables after adjusting for preexisting grade differences, Wilks' $\Lambda=.93, F(4,674)=6.58, p<.01$. The multivariate partial $\eta^{2}$ based on Wilks' $\Lambda$ was small, .04. Table 5.43 summarizes the means and standard deviations on the dependent variables for the three groups.

Analyses of variance (ANCOVA) on each dependent variable were conducted as follow up tests on the MANCOVA. The ANCOVA for school climate was significant after adjusting for preexisting grade differences, $F(2,338)=8.69, p<.01, \eta^{2}=.05$. The ANCOVA for teacher support was significant after adjusting for preexisting grade differences, $F(2,338)=11.06, p<.01, \eta^{2}=.06$. Post hoc analyses to the univariate ANCOVA for GI consisted of conducting pair-wise comparisons to find which level of 
GI differed in school climate and teacher support. As predicted, students who were gang-involved experienced lower levels of school climate $(M=3.41, S D=.91)$ in comparison with either students who were not gang-involved $(M=3.87, S D=.87)$ and students who were at-risk for GM $(M=3.80, S D=.72)$. The students who were not involved in gang were not significantly different from students who were at risk for gangs in school climate. For teacher support, students who were gang-involved experienced lower levels of teacher support $(M=3.28, S D=.82)$ in comparison to students who were not gang-involved $(M=3.81, S D=.84)$. Students who were ganginvolved were not significantly different from students who were at-risk for GM $(M=$ $3.55, S D=.77)$ in levels of teacher support.

Interactions with gender and GI. For school climate, results indicated that the interaction between gender and school climate was not significant, $F(2,336)=1.76$. $n s$. For teacher support, the interaction between gender and teacher support was significant, $F(2,336)=3.93, p<.05$. Follow up tests were conducted to evaluate the three pairwise differences among the means of boys and girls in teacher support across levels of GI. Girls who were not involved in gangs $(M=4.02, S D=.70)$ scored significantly higher in levels of teacher support than boys who were not involved in gangs $(M=3.59, S D=$ .91). Girls who were at risk for gangs $(M=3.54, S D=.76)$ did not significantly differ in levels of teacher support than boys who were at risk for gangs $(M=3.57, S D=.78)$.

Girls who were potentially GM $(M=3.23, S D=.75)$ did not significantly differ in levels of teacher support than boys who were potentially GM $(M=3.32, S D=.90)$. 
Results 148

Student Profile (2): Levels of Attraction to Gangs. A MANCOVA was conducted to determine the differences in school climate and teacher support as a function of the levels of gang attraction (GA) adjusting for grade differences. One factor, group classification, had two levels: (1) attracted and (2) not attracted. The dependent variables (DVs) were school climate and teacher support. Significant differences were found among levels of GA on the dependent variables, Wilks' $\Lambda=.95$, $F(2,338)=8.14, p<0.01$. The multivariate partial $\eta^{2}$ based on Wilks' $\Lambda$ was small, .05 . Table 5.43 summarizes the means and standard deviations on the dependent variables for the two groups.

Analyses of covariance (ANCOVA) on each dependent variable were conducted as follow up tests on the MANCOVA. The ANCOVA for school climate was significant after adjusting for grade differences, $F(1,339)=12.49, p<0.01, \eta^{2}=.04$. Students who were attracted to gangs $(M=3.44, S D=.93)$ experienced lower levels of 
Table 5.43

Means and Standard Deviations of Study Constructs across Levels of Gang Involvement and Gang Attraction

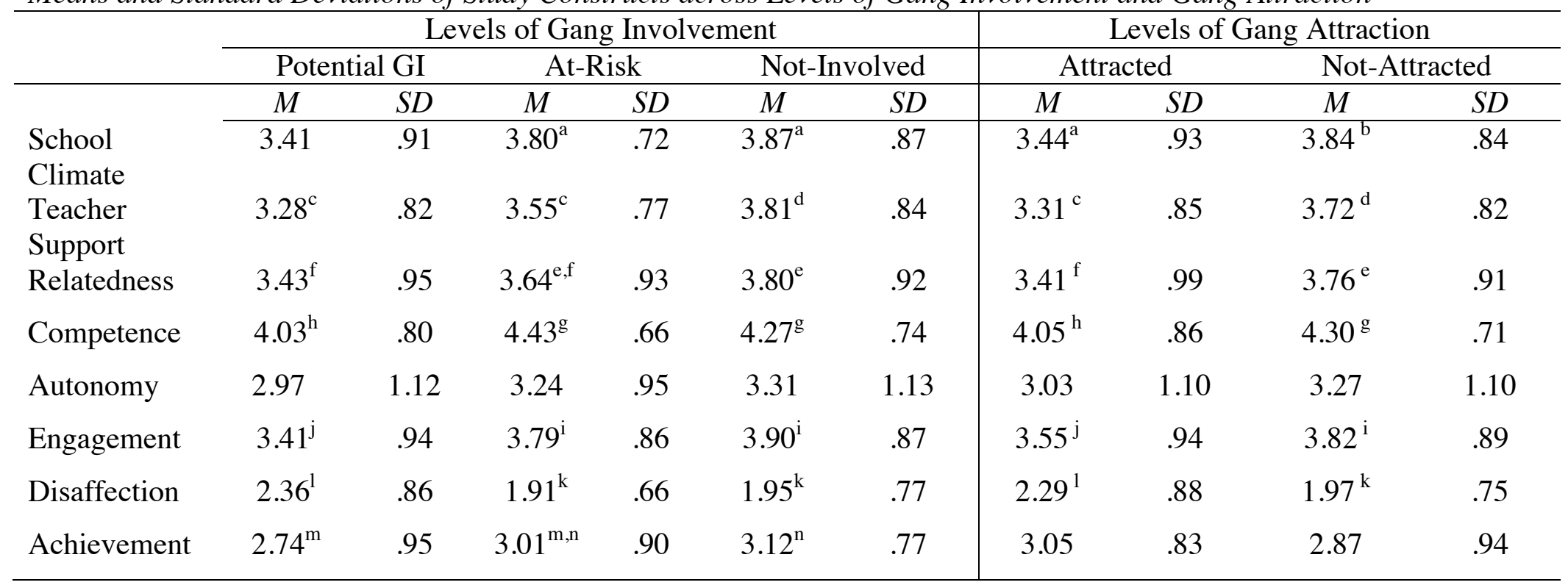

Note. $N=342$ for all study constructs except achievement. For achievement, $N=337$. Different superscripts indicate that mean levels were significantly different across levels of gang involvement and attraction at least at $\mathrm{p}<.05$ as determined by Bonferroni post hoc comparison. Means marked by the same letter are not significantly different. 
school climate in comparison to students who were not attracted to gangs $(M=3.84$, $S D=.84)$. The ANCOVA for teacher support was significant after adjusting for grade differences, $F(1,339)=13.28, p<0.01, \eta^{2}=.04$. Students who were attracted to gangs $(M=3.31, S D=.85)$ experienced lower levels of teacher support in comparison to students who are not attracted to gangs $(M=3.72, S D=.82)$.

Interactions with gender and GA. For school climate, results indicated that the interaction between gender and school climate was not significant, $F(1,338)=.59$. $n s$. For teacher support, the interaction between gender and teacher support was not significant, $F(1,338)=1.65, n s$.

6.2 For SSPs: These analyses examined mean levels differences in the relatedness, competence, and autonomy. It was hypothesized that (1) students who are gang-involved will feel less related, competent, and autonomous than students who are not gang involved; and (2) students who are attracted to gangs will feel less related, competent, and autonomous than students who are not attracted to gangs.

Student Profile (1): Levels of GI. A MANCOVA was conducted to determine the the differences in relatedness, competence, and autonomy as a function of the levels of GI after adjusting for grade differences. One factor, group classification, had three levels: (1) potential GM, (2) at- risk, and (3) not-involved. The dependent variables (DVs) were relatedness, competence, and autonomy. Significant differences were found among levels of GI on the dependent variables, Wilks' $\Lambda=.95, F(6,672)=3.20, p$ $<0.01$. The multivariate partial $\eta^{2}$ based on Wilks' $\Lambda$ was small, .03 . 
Results 151

Analyses of covariance (ANCOVA) on each dependent variable were conducted as follow up tests on the MANCOVA. The ANCOVA for relatedness was significant after adjusting for preexisting grade differences, $F(2,338)=4.79, p<.01, \eta^{2}=.03$. The ANCOVA for competence was significant after adjusting for preexisting grade differences, $F(2,338)=3.22, p<.01, \eta^{2}=.03$. The ANCOVA for autonomy was not significant after adjusting for preexisting grade differences, $F(2,338)=2.29, n s$. Post hoc analyses to the univariate ANCOVA for GI consisted of conducting pair-wise comparisons to find which level of GI differed on relatedness and competence. For relatedness, students who were gang-involved scored significantly lower in relatedness $(M=3.43, S D=.95)$ in comparison to students who were not gang-involved $(M=3.80$, $S D=.92)$. Students who were at risk for gangs $(M=3.64, S D=.93)$ were not significantly different in relatedness from either students who were gang-involved and students who were not gang-involved. For competence, students who were ganginvolved scored significantly lower in competence $(M=4.03, S D=.80)$ in comparison to both students who were not gang-involved $(M=4.27, S D=.74)$ and students who are at-risk for GM $(M=4.43, S D=.66)$. The students who were not gang-involved and students who were at risk for gangs were not significantly different from each other in levels of competence.

Interactions with gender and GI. For relatedness, results indicated that the interaction between gender and relatedness was significant, $F(2,336)=3.84, p<.05$. Follow up tests were conducted to evaluate the three pairwise differences among the means of boys and girls in relatedness across levels of GI. Girls who were not involved 
in gangs $(M=3.95, S D=.85)$ scored significantly higher in levels of relatedness than boys who were not involved in gangs $(M=3.65, S D=.97)$. Girls who were at risk for gangs $(M=3.47, S D=.91)$ did not significantly differ in levels of relatedness than boys who were at risk for gangs $(M=3.81, S D=.94)$. Girls who were potentially GM $(M=$ 3.64, $S D=.77)$ scored significantly higher in levels of relatedness than boys who were potentially GM $(M=3.21, S D=1.07)$.

For competence, the interaction between gender and competence was not significant, $F(2,336)=1.59, n s$. For autonomy, the interaction between gender and autonomy was not significant, $F(2,336)=.69, n s$.

\section{Student Profile (2): Levels of Attraction to Gangs. A MANCOVA was}

conducted to determine the differences in relatedness, competence, and autonomy as a function of the levels of GA after adjusting for preexisting grade differences. One factor, group classification, had two levels: (1) attracted and (2) not attracted. The dependent variables (DVs) were relatedness, competence, and autonomy. Significant differences were found among levels of GA on the dependent variables, Wilks' $\Lambda=.97$, $F(3,337)=3.52, p<.05$. The multivariate partial $\eta^{2}$ based on Wilks' $\Lambda$ was small, .03 .

Analyses of covariance (ANCOVA) on each dependent variable were conducted as follow up tests on the MANCOVA. The ANCOVA for relatedness was significant, after adjusting for grade differences, $F(1,339)=8.51, p<.01, \eta^{2}=.02$. Students who were attracted to gangs $(M=3.41, S D=.99)$ scored significantly lower in relatedness in comparison to students who were not attracted to gangs $(M=3.76, S D=.91)$. The ANCOVA for competence was significant, after adjusting for grade differences, $F$ (1, 
Results 153

$339)=6.45, p<.05, \eta^{2}=.02$. Students who were attracted to gangs $(M=4.05, S D=.86)$ scored significantly lower in competence in comparison to students who were not attracted to gangs $(M=4.30, S D=.71)$ The ANCOVA for autonomy was not significant, after adjusting for grade differences, $F(1,339)=1.84, n s$. Students who were attracted to gangs $(M=3.03, S D=1.10)$ and students who were not attracted to gangs $(M=3.27$, $S D=1.10)$ were not significantly different from each other in levels of autonomy.

Interactions between gender and GA. For relatedness, the interaction between gender and relatedness was not significant, $F(1,338)=.10, n s$. For competence, the interaction between gender and competence was not significant, $F(1,338)=.64$, ns . For autonomy, the interaction was significant, $F(1,338)=4.02, p<.05$. Follow up tests were conducted to evaluate the three pairwise differences among the means of boys and girls in autonomy across levels of GA. Girls who were not attracted to gangs $(M=3.50, S D=1.02)$ scored significantly higher in levels of autonomy than boys who were not attracted to gangs $(M=3.05, S D=1.13)$. Girls who were attracted to gangs $(M=2.99, S D=1.08)$ did not significantly differ in levels of autonomy than boys who were attracted to gangs $(M=3.09, S D=1.12)$.

6.3 For engagement and disaffection: These analyses examined mean levels differences in engagement and disaffection. It was hypothesized that (1) students who are gang-involved will be less engaged and more disaffected in school, compared to students who are not gang involved; and (2) students who are attracted to gangs will be less engaged and more disaffected in school, compared to students who are not attracted to gangs. 
Results 154

Student Profile (1): Levels of Gang Involvement. A MANCOVA was conducted to determine the differences in engagement and disaffection as a function of the levels of GI after adjusting for preexisting grade differences. One factor, group classification, had three levels: (1) potential GM, (2) at- risk, and (3) not-involved. The dependent variables (DVs) were engagement and disaffection. Significant differences were found among levels of GI on the dependent variables, Wilks' $\Lambda=.94, F(4,674)=5.55, p<$ .01 . The multivariate partial $\eta^{2}$ based on Wilks' $\Lambda$ was small, .03 .

Analyses of covariance (ANCOVA) on each dependent variable were conducted as follow up tests on the MANCOVA. The ANCOVA for engagement was significant, after adjusting for preexisting grade differences, $F(2,338)=7.86, p<.01, \eta^{2}=.04$. The ANCOVA for disaffection was significant, after adjusting for grade differencs, $F$ (2, $338)=9.15, p<.01, \eta^{2}=.05$. Post hoc analyses to the univariate ANCOVA for GI consisted of conducting pair-wise comparisons to find which level of GI differed on engagement and disaffection. Students who were gang-involved $(M=3.41, S D=.94)$ scored significantly lower in engagement in comparison with either students who were not gang-involved $(M=3.90, S D=.87)$ and students who were at-risk for GM $(M=3.79$, $S D=.86)$. The students who were not gang-involved and students who were at risk for gangs were not significantly different from each other in levels of engagement. For disaffection, students who were gang-involved $(M=2.36, S D=.86)$ scored significantly higher in disaffection in comparison with either students who were not gang-involved $(M=1.95, S D=.77)$ and students who were at-risk for $\mathrm{GM}(M=1.91, S D=.66)$. 
Students who were not involved in gangs and students who were at risk for gangs were not significantly different from each other in levels of engagement.

Interactions between gender and GI. For engagement, the interaction between gender and engagement was not significant, $F(2,336)=.11, n s$. For disaffection, the interaction between gender and disaffection was not significant, $F(2,336)=2.00$, $n s$.

Student Profile (2): Levels of Attraction to Gangs. . A MANCOVA was conducted to determine the differences in engagement and disaffection levels of GA, after adjusting for preexisting grade differences. One factor, group classification, had two levels: (1) attracted and (2) not attracted. The dependent variables (DVs) were engagement and disaffection. Significant differences were found among levels of GA on the dependent variables after adjusting for grade differences, Wilks' $\Lambda=.97, F(2$, $338)=4.81, p<.01$. The multivariate partial $\eta^{2}$ based on Wilks' $\Lambda$ was small, .03 .

Analyses of covariance (ANCOVA) on each dependent variable were conducted as follow up tests on the MANCOVA. The ANCOVA for engagement was significant after adjusting for grade differences, $F(1,339)=4.23, p<.05, \eta^{2}=.01$. Students who were attracted to gangs $(M=3.55, S D=.94)$ scored significantly lower in engagement than students who were not attracted to gangs $(M=3.82, S D=.89)$. The ANCOVA for disaffection was significant after adjusting for preexisting grade differences, $F(1,339)$ $=9.61, p<.01, \eta^{2}=.03$. Students who were attracted to gangs $(M=2.29, S D=.88)$ scored significantly higher in disaffection than students who were not attracted to gangs $(M=1.97, S D=.75)$. 
Results 156

Interactions between gender and GA. For engagement, the interaction between gender and engagement was not significant, $F(1,338)=.80, n s$. For disaffection, the interaction between gender and disaffection was not significant, $F(1,338)=.71, n s$.

6.4 For achievement: These analyses examined mean levels differences in achievement. It was hypothesized that (1) students who are gang-involved will show lower levels of achievement than students who are not gang involved; and (2) students who are attracted to gangs will show lower levels of achievement than students who are not attracted to gangs.

Student Profile (1): Levels of Gang Involvement. An ANCOVA was conducted to evaluate the differences in achievement as a function of the levels of GI after adjusting for preexisting grade and gender differences. The factor, group classification, had three levels: (1) potential GM, (2) at- risk, and (3) not-involved. The dependent variable (DV) was achievement. The ANCOVA was significant, after adjusting for preexisting grade and gender differences, $F(2,332)=4.49, p<.05 . \eta^{2}=.03$. Students who were gang-involved ( $M=2.74, S D=.95)$ scored significantly lower in achievement scores than students who were not gang-involved $(M=3.13, S D=.77)$. Students who were at-risk for GM $(M=3.01, S D=.90)$ did not significantly differ in achievement scores from students who were gang-involved or students who were not involved in gangs in achievement scores.

Student Profile (2): Levels of Attraction to Gangs. An ANCOVA was conducted to evaluate the differences in achievement as a function of the levels of GA, after adjusting for grade and gender differences. The factor, group classification, had two 
levels: (1) attracted and (2) not attracted. The dependent variable (DV) was achievement. The ANCOVA was not significant, after adjusting for preexisting grade and gender differences, $F(1,333)=2.19, n s$. The achievement scores of students who were attracted to gangs $(M=2.87, S D=.94)$ did not differ from the scores of students who were not attracted to gangs $(M=3.05, S D=.83)$. 
Table 5.44

Hypothesis Tests Results

Research Question (RQ) 1. Can we construct an indicator assessing risk for gang involvement that taps personal attraction to gangs as a motivational precursor to actually joining a gang? Does this indicator tell us something about risk for gang involvement different from traditional methods of self-reports?

Hypothesis (H) 1. Student profile (2): Gang Attraction will Result (R) 1. Supported reveal a different distribution of students than the traditional methods of self-reported gang involvement.

RQ1b. Do the levels of risk for joining gangs differ across ethnic groups? In other words, are there certain ethnic groups particularly at risk for joining gangs?

H1b. Once socio-economic factors and neighborhood safety is taken into account, no ethnic group differences will be observed across levels of risk for joining gangs.

H1b.Not supported; For levels of gang involved (GI), Latino students more likely to be gang-involved than White students.

For levels of gang attraction (GA), Latino students and Asian students more likely to be attracted to gangs than White students.

\section{RQ1c. Do the levels of risk for joining gangs differ depending on the immigrant status of the student?}

H1c. There will be no differences in levels of risk for joining gangs depending of the immigrant status of the student.
R1c. Not supported. For GI, immigrant students more likely to be at risk for gangs and gang-involved than US born students. US born students more likely to be at risk for gangs than not involved in gangs than immigrant students.

For GA, immigrant students more likely to be attracted to gangs than US born students. 


\begin{tabular}{|c|c|}
\hline $\begin{array}{l}\mathrm{H} 2 \mathrm{a} \text {. Youth who are less engaged in school are more likely } \\
\text { to be gang-involved. }\end{array}$ & R2a. Supported \\
\hline $\begin{array}{l}\text { H2b. Youth who are more disaffected are more likely to be } \\
\text { gang-involved. }\end{array}$ & R2b. Supported. \\
\hline $\begin{array}{l}\mathrm{H} 2 \mathrm{c} \text {. Youth who are less engaged in school are more likely } \\
\text { to be attracted to gangs. }\end{array}$ & R2c. Supported. \\
\hline $\begin{array}{l}\mathrm{H} 2 \mathrm{~d} \text {. Youth who are more disaffected are more likely to be } \\
\text { attracted to gangs. }\end{array}$ & R2d. Supported. \\
\hline $\begin{array}{l}\text { H2e. Engagement will contribute to GI over and above } \\
\text { disaffection. }\end{array}$ & $\begin{array}{l}\text { R2e. Supported for Not-involved (NI) versus Gang-Involved } \\
\text { (GI). Not supported for At-Risk (AR) versus GI. }\end{array}$ \\
\hline $\begin{array}{l}\text { H2f. Disaffection will contribute to GI over and above } \\
\text { engagement. }\end{array}$ & $\begin{array}{l}\text { R2f. Not supported for NI versus GI. Supported for AR } \\
\text { versus GI. }\end{array}$ \\
\hline $\begin{array}{l}\mathrm{H} 2 \mathrm{~g} \text {. Engagement will contribute to GA over and above } \\
\text { disaffection. }\end{array}$ & R2g. Not supported. \\
\hline $\begin{array}{l}\text { H2h. Disaffection will contribute to GA over and above } \\
\text { engagement. }\end{array}$ & R2h. Supported. \\
\hline $\begin{array}{l}\mathrm{H} 2 \mathrm{i} \text {. Youth who are more engaged in school will perform } \\
\text { better academically. }\end{array}$ & H2i. Supported. \\
\hline
\end{tabular}




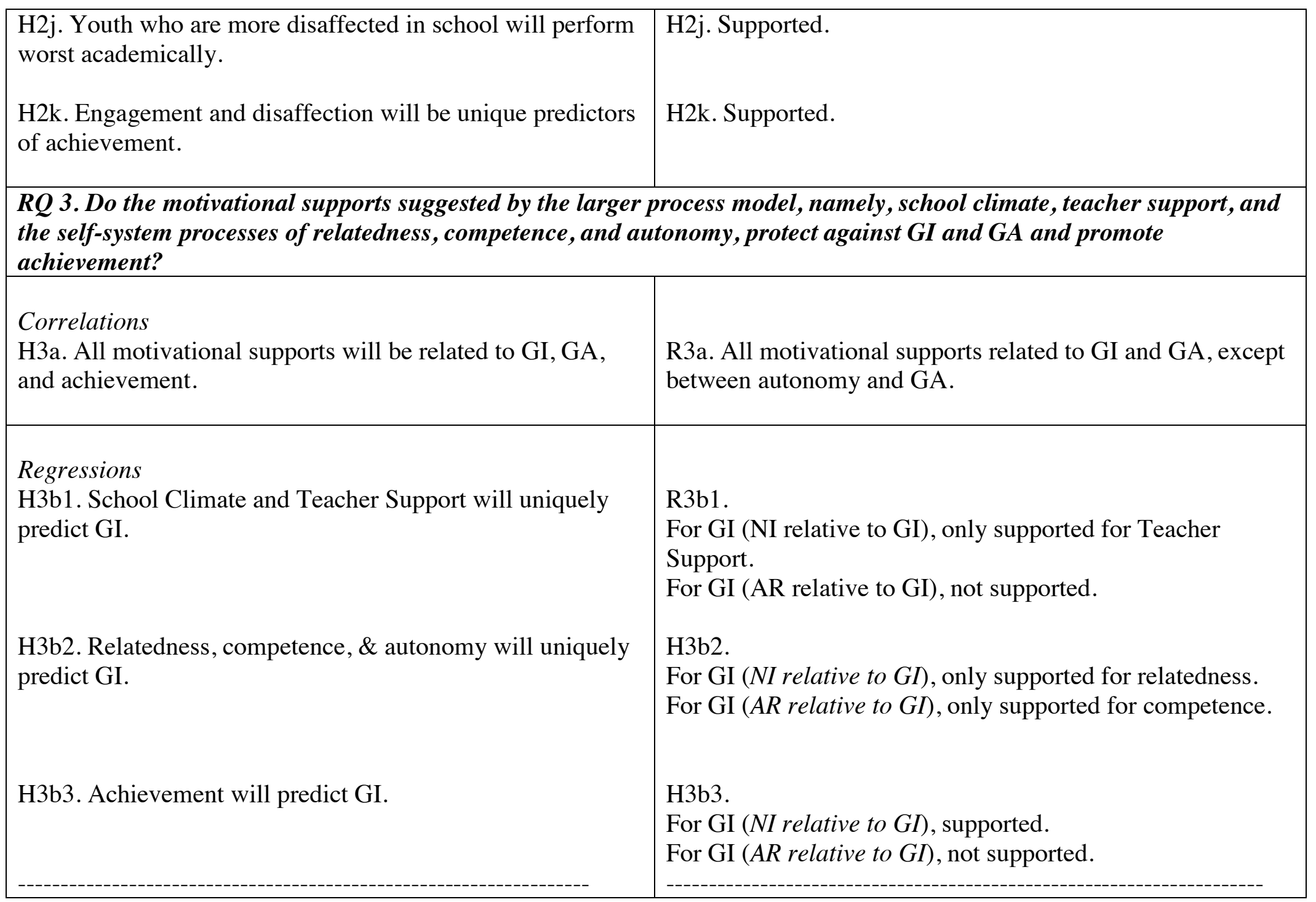




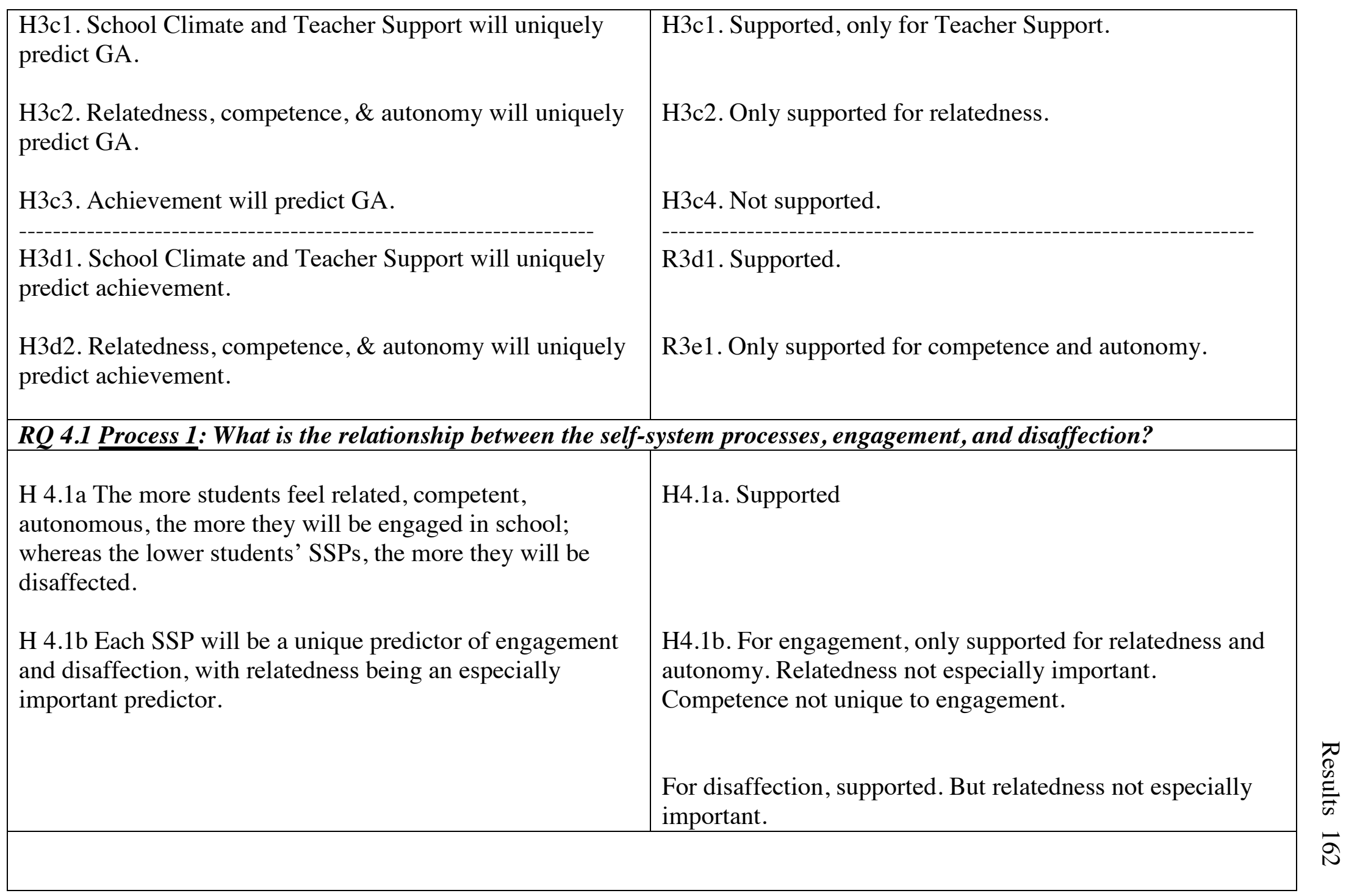




\section{RQ 4.2Process 2: What is the relationship between school climate, teacher support, engagement and disaffection?}

H 4.2a The more students experience a supportive school climate and teacher support, the more they will be engaged in school; whereas students who experience lower school and teacher support will be more disaffected.

$\mathrm{H}$ 4.2b School climate and teacher support will be unique predictors of engagement and disaffection.
H4.2a. Supported.

H4.2b. Supported.

$R Q 4.3$ Process 3. Is the relationship between overall school support and engagement mediated by self- system processes?

H4.3a. Each SSP will mediate the relationship between overall school support (OSS) and engagement.

H4.3b. Each SSP will mediate the relationship between overall school support (OSS) and disaffection.
H4.3a Supported only for autonomy. Autonomy partially mediated relationship between OSS and engagement. For relatedness and competence, OSS was found to be the mediator between each SSP and engagement.

With aggregated SSPs, supported for partial mediation.

H4.3b Not supported. For each mediation model each SSP and OSS uniquely contributed to disaffection. Predictors found to have direct negative effects on disaffection.

With aggregated SSPS, not supported. SSPs and OSS uniquely contributed to disaffection. Both predictors found to have direct negative effects on disaffection. 


\begin{tabular}{|c|c|}
\hline \multicolumn{2}{|c|}{$\begin{array}{l}\text { RQ } 4.4 \text { Process 4. Is the relationship between overall school support and each outcome mediated by engagement versus } \\
\text { disaffection? }\end{array}$} \\
\hline $\begin{array}{l}\text { H4.4. Engagement versus disaffection will mediate the } \\
\text { relationship between OSS and each outcome. }\end{array}$ & $\begin{array}{l}\text { H4.4: } \\
\text { For GI (NI relative to } G I) \text { : supported, OSS as mediator. } \\
\text { For GI (AR relative to } G I) \text { : supported, engagement versus } \\
\text { disaffection as mediator. } \\
\text { For GA: Supported, OSS as mediator. } \\
\text { For achievement: Supported, engagement versus disaffection } \\
\text { partially mediated the relationship between OSS and } \\
\text { achievement. }\end{array}$ \\
\hline \multicolumn{2}{|c|}{ RQ 4.5 Process 5. Is the relationship between the SSPs and each outcome mediated by engagement versus disaffection? } \\
\hline $\begin{array}{l}\text { H4.5. Engagement versus disaffection will mediate the } \\
\text { relationship between the SSPs and each outcome. }\end{array}$ & $\begin{array}{l}\text { H4.5: } \\
\text { For GI (NI relative to GI): Supported, engagement versus } \\
\text { disaffection fully mediates. } \\
\text { For GI (AR relative to GI): Supported, engagement versus } \\
\text { disaffection fully mediates. } \\
\text { For GA: not supported. } \\
\text { For achievement: Supported, engagement versus disaffection } \\
\text { partially mediates the relationship between the SSPs and } \\
\text { achievement. }\end{array}$ \\
\hline
\end{tabular}



a good account of achievement?

H5.1a1. The larger process model provides a good account of GI (Not Involved relative to Gang-Involved).

H5.1a2. The larger process model provides a good account of GI (At Risk relative to Gang-Involved).

H5.1b. The larger process model provides a good account of GA.

H5.1a. The larger process model provides a good account of achievement.

RQ 6. What motivational supports are provided to youth who are involved in gangs compared to those who are not?

H6.1a Students who are gang-involved will experience lower levels of teacher support and school climate, compared to students who are not gang-involved.

H6.1b Students who are attracted to gangs will experience lower levels of teacher support and school climate, compared to students who are not attracted to gangs.

H6.2a Students who are gang-involved will feel less related, competent, and autonomous than students who are not gang involved.
H5.1a1. Not Supported.

H5.1a2. Supported

H5.1b. Not Supported.

H5.1c. Supported

H6.1a. Supported.

H6.1b. Supported.

H6.2a. Supported for relatedness and competence, but not for autonomy. 
H6.2b Students who are attracted to gangs will feel less related, competent, and autonomous than students who are not attracted to gangs.

H6.3a Students who are gang-involved will be less engaged and more disaffected in school, compared to students who are not gang involved.

H6.3b Students who are attracted to gangs will be less engaged and more disaffected in school, compared to students who are not attracted to gangs.

H6.4a Students who are gang-involved will show lower levels of achievement than students who are not gang involved.

H6.4b Students who are attracted to gangs will show lower levels of achievement than students who are not attracted to gangs.
H6.2b. Supported for relatedness and competence, but not for autonomy.

H6.3a. Supported

H6.3b. Supported

H6.4a. Supported

H6.4b. Not supported. 


\section{Chapter VI}

Discussion 167

Discussion

Using a model of motivational development, the current study sought to conceptualize and examine a motivational model of gang involvement that has attraction to gangs as its central risk factor and identifies multiple personal and social motivational supports that should protect youth from becoming involved in gangs. The first goal of this study was to suggest a method for assessing risk for gang involvement that tapped into personal attraction to gangs as a motivational precursor to actually joining a gang. Second, the study sought to identify protective factors for gang involvement and hypothesized that school engagement would not only promote learning and achievement, but also protect students from being attracted to and involved in gangs. And, thirdly, the present study explored how contextual and personal factors may facilitate or undermine school engagement, which in turn would promote achievement and protect youth from being involved in and attracted to gangs. The selfsystem model of motivational development (SSMMD) was used to explain the interpersonal and psychological processes by which school engagement was promoted or undermined in a school setting.

\section{Summary of the Findings}

In what follows, the findings are summarized in five sections: (1) the usefulness of the Gang Attraction profile as a motivational indicator for future gang involvement, (2) demographic characteristics of GI and GA, (3) student comparisons in motivational supports across levels of GI, (4) student comparisons in motivational supports across levels of GA, and (5) achievement as motivational outcome. 
Gang Attraction as a Motivational Indicator for Future Gang Involvement

Discussion 168

The first goal of this study was to develop a motivational marker for future gang involvement different from the traditional method that identifies youth after they are already gang-involved. Traditional methods of identifying youth who are gang-involved have relied on self-nominations as well as peer involvement in gangs, which result in classification of youth into three groups: (1) students who are not gang-involved, (2) students who are at risk for gangs (because they or their peers belong to gangs), and (3) students who are -involved gangs (because both they and their peers belong to gangs) (Bjerregaard, 2002). The current study attempted to identify youth who were not yet gang-involved but who, nonetheless, found gangs attractive and alluring, which can be considered a motivational risk factor for future gang involvement. This study argued that, in a youth's trajectory toward gang membership, there may be a sensitive stage of gang attraction in which the youth slowly becomes closer to gang-involved youth because of the potential psychological benefits (i.e., protection, support, and belongingness) that gangs offer.

Preliminary evidence indicated that gang attraction is a distinct student profile that revealed a different distribution of students with differing levels of gang involvement than the traditional methods of self-reported gang membership. Chi-square analyses supported the notion that the student profile of gang attraction was structurally different and not redundant with the traditional methods. The Gang Attraction profile was sensitive in distinguishing youth of differing levels of gang attraction and gang involvement. Results indicated that the student profile of gang attraction was useful in (1) identifying students who were not yet involved in gangs but were attracted to them 
Discussion 169

$(n=5)$; (2) identifying students who were at risk for gangs, but were not attracted to them $(n=54)$; and (3) distinguished youth who were gang-involved but were not attracted to gangs $(n=23)$. For the two latter groups, these findings are significant because it suggested a group of students who were on the path toward becoming ganginvolved or were already gang-involved, but were not particularly attracted to gangs. For the at-risk group, this subgroup may be students who have friends or family who are gang-involved, and so may be expected to join gangs (Moore, 1978). For the ganginvolved/not attracted group, these findings suggest that a group of gang-involved students can be identified who may not be particularly interested in staying in the gang or participating in gang activities.

\section{Demographic Characteristics of Gang Involvement and Gang Attraction}

The second set of findings focused on describing youth who were involved and attracted to gangs based on their gender, grade, and ethnicity. Previous research has shown that boys, older children, and youth from certain ethnic backgrounds are more likely to be attracted to and involved in gangs. This study was especially interested in unpacking student ethnicity to consider immigration status and language use as potential risk factors for GA and GI.

Gender and grade differences. Counter to expectations, the levels of GI and GA did not differ by gender. Female students were just as attracted to and involved in gangs as their male counterparts. In fact, of the subsample of students who were attracted to gangs, $58 \%$ were girls. These results are important because research typically finds gender differences in gang membership, with boys being most at risk. 
Discussion 170

The levels of GI and GA did differ by grade. Results indicated that younger students were less attracted to and involved in gangs than older students. A surprising finding, however, was that approximately $25 \%$ of the potential GMs and $25 \%$ of the students attracted to gangs group were $6^{\text {th }}$ graders, which represents approximately $16 \%$ of the total $6^{\text {th }}$ grade sample. These findings corroborate current research that documents an increase in gang membership across grades (Dishion, Nelson, Yashi, 2005). In fact, the average age of gang joining is 13 (Lahey, Gordon, Loeber, Stouthamer-Loeber, \& Farrington, 1999; Thornberry, Krohn, Lizotte, \& ChardWierschem, 1993). Considering the results of the gang attraction profile, there is a sharp increase in gang attraction from $6^{\text {th }}$ to $7^{\text {th }}$ grade. This sharp increase provides supporting evidence for the trajectory of a youth to join gangs by age 13 .

Ethnicity differences. The Gang Attraction profile differentiated similar patterns of gang attraction across ethnicities. Specifically, ethnic differences were found between White, Latino, and Asian groups in levels of gang attraction. Follow up analyses were conducted to further examine the relationship between GA and ethnicity, taking into account students' immigrant status (USA born or immigrant) and English language proficiency (spoke native language or a mix of native languages and English at home). Findings indicated that across Latino, Russian/Ukrainian, and Asian immigrant students who spoke their native language at home (e.g., Spanish or Russian) or were bilingual (spoke native language and English at home) were more attracted to gangs. This pattern of findings would not have been discerned using the traditional methods of self-reported gang involvement. With the Gang Involvement profile, ethnic differences were only found between Latino and White ethnic groups, with Latino 
Discussion 171

students being overwhelmingly at a higher rate of being gang-involved than White students. Consistent with research, the Latino population has been identified at high risk for gang involvement. But the Gang Attraction profile demonstrated that it is not the culture of origin that likely predisposes a youth to GI, but the combination of immigration status and language use in addition to a host of other contextual, social, and personal factors. It is important to note that a student's immigrant status and home language alone does not lead to GA and GI. These personal risk factors in addition to micro-, meso-, exo- and macro-level risk factors in the youth's life compound the risk of the youth being vulnerable to becoming attracted to gangs. Student Profile (1): Gang-Involved (GI) vs. Not-Involved students and GI vs. At-Risk students

The next set of analyses focused on traditional markers of GI: students who were not involved in gangs (NI), students who were at risk for gangs (AR), and students who were gang-involved (GI). Findings are organized around two contrasts: (1) differences between youth were NI versus GI, and (2) differences between youth who were AR versus GI. Consistent with predictions, the motivational supports were closely related to a student's level of gang involvement. Students who experienced a supportive and caring school environment were more engaged in school and less gang- involved, whereas students who experienced a less supportive and caring school environment were more disaffected and more involved in gangs.

Engagement and disaffection. Analyses targeting the contributions of engagement and disaffection separately on gang involvement found that both predictors contributed to a student's level of gang involvement for both GI vs. Not-involved (NI) 
Discussion 172

students and GI vs. At-Risk (AR) students. That is, the more engaged students were in school, the less likely they were at risk for and involved in gangs. Conversely, the more disaffected students were in the learning process, the more likely they were at risk for and involved in gangs. However, when both predictors were entered into the model, analyses revealed a surprising distinction between GI vs. NI students and GI vs. AR students. For GI vs. NI students, engagement was the only unique predictor for decreasing gang involvement. However, for GI vs. AR students, disaffection was the only unique predictor differentiating students who were at risk for gangs from students who were gang-involved. These results indicate that, in the trajectory of a youth toward gang involvement, it is engagement in school that seems to first distinguish students who are not involved in gangs from students who are gang-involved, but later it is the level of disaffection from school that pushes students who are at risk for gangs toward becoming gang-involved. Disaffection distinguishes itself as a motivational state of frustration, boredom, and anger that blocks the student from participating in academic activities, which over time may increase the likelihood that the student will associate with similar disaffected peers (Kindermann, 2007) who may be gang-involved. These results provide preliminary evidence that engagement can protect students from becoming gang-involved. It also suggests that a student's level of disaffection from school may also act as a catalyst toward future gang involvement.

School climate and teacher support. As expected, both school climate and teacher support were negatively related to a student's level of gang involvement. However, when both predictors were entered into the model, teacher support distinguished itself as a strong unique predictor of gang involvement for GI vs. NI 
Discussion 173

students, but not for GI vs. AR students. In fact, for GI vs. AR students, neither

school climate nor teacher support were found to uniquely contribute to gang

involvement. However, for the GI vs. AR students, these results were likely the result of multicollinearity problems between the two variables as they were highly correlated with each other $(r=.61)$. This suggest that both variables should be combined to form a total score of overall school support, as both variables may be measuring the same underlying dimension.

Self-system processes. As predicted, students' self-system processes (SSP) were connected with their levels of gang involvement. Relatedness, competence, and autonomy all showed significant negative correlations with gang involvement. However, analyses targeting the unique contributions of each SSP on gang involvement revealed differences between GI vs. NI students and GI vs. AR students. Specifically, relatedness was found to be a strong predictor in distinguishing students who were not involved in gangs from those students who were gang-involved. Students, who felt they belonged, were valued and respected by their teachers, were less likely to be ganginvolved. A student's level of competence or autonomy did not uniquely contribute to a student's level of gang involvement over and above the contributions of relatedness. However, for GI vs. AR students, competence distinguished itself over and above the contributions of relatedness and autonomy in distinguishing students who were at risk for gang involvement relative to being gang-involved. Also, no significant differences were found in achievement scores between GI and AR students. Taken together, these results may suggest that any further losses in student academic competence may contribute to further pushing AR students toward becoming gang-involved. These 
Discussion 174

findings corroborate previous research that documents a history of school failure in gang-involved youth (Howell \& Egley, 2005), which may produce of sense of incompetence in academic activities.

Achievement. Achievement showed a significant negative relationship with gang involvement. Students who were higher achievers in school were significantly less likely to be gang-involved. However, analyses targeting the contribution of achievement on the differing levels of gang involvement demonstrated that the levels of achievement differentiated GI vs. NI students, but not GI vs. AR students. Mean level differences between the three levels of gang involvement revealed that GI students were scoring lower in achievement scores than NI students, but there were no significant differences between GI and AR and between AR and NI in achievement scores. These findings suggest that students who are at risk for gangs may be on a slippery slope towards gang involvement as their achievement in school decreases.

Process links. Guided by the SSMMD model, this study investigated whether motivational supports would promote achievement and protect students from gang involvement. Specifically, the SSMMD model predicted that supportive and caring school environments would be related to student feelings of belongingness, competence, and autonomy, which would fuel their engagement in learning activities and promote academic achievement. Results from the study found, however, that the process links for GI vs. NI students were different from the process links for GI vs. AR students. Specifically, the direction of effects was different than expected for GI vs. NI students. For GI vs. NI students, findings revealed positive self-system processes as a possible driver of student engagement versus disaffection from learning activities, which in turn 
Discussion 175

influenced teacher support, which were the proximal predictors of the likelihood of a student being gang-involved. In fact, the unique effects for each process link were more specific than expected. A student's sense of relatedness seemed to be the driver of their engagement, which in turn was related to higher teacher support and a lower likelihood of being gang-involved. In other words, students who were involved in gangs experienced as well as received less motivational supports than students who were not involved in gangs.

Considering the results that students who were attracted to gangs were overwhelmingly immigrants who spoke English as a second language, it follows that a student's lack of English language skills may influence how welcomed they feel in the school environment. It may be that a student's inability to effectively relate to and communicate with their teachers and classmates puts students at risk of a cascading negative spiral of disaffection from academic activities, which in turn may contribute to losses of teacher support, which over time may lead to future gang involvement. Figure 12 depicts one possible alternative of the SSMMD model of youth gang involvement.

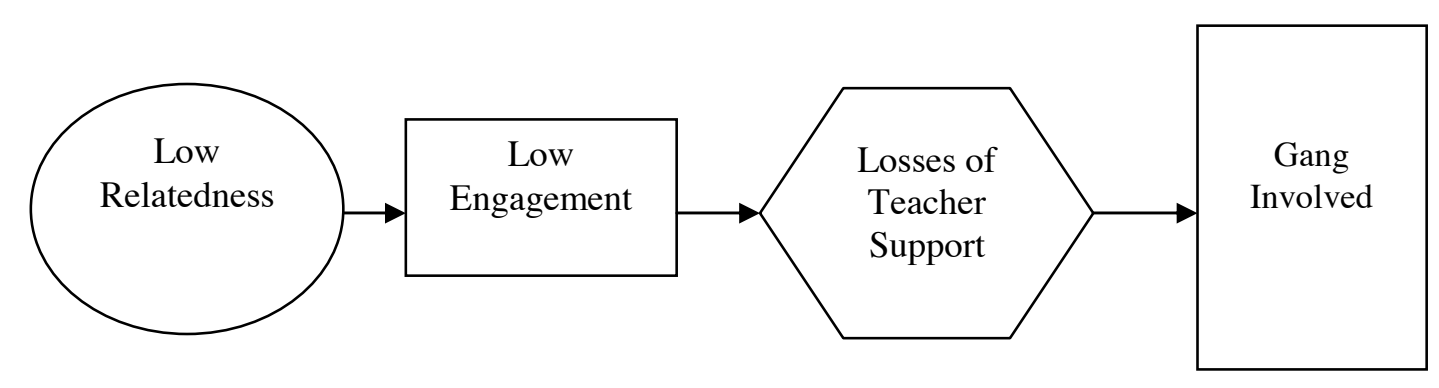

Figure 12. Alternative Motivational Model for Gang Involvement for Students 
who are Gang-Involved relative to Not-Involved in Gangs.

However, for GI vs. AR students, the model's process links were in the expected direction. That is, a supportive and caring school environment was the driver that influenced positive self perceptions, which in turn fueled student engagement versus disaffection, which in turn was related to the likelihood of a student being ganginvolved relative to being at risk for gangs. Similar to the model of GI vs. NI students, the unique effects were more specific than expected. A less supportive and caring school environment was related to lower student competence, which in turn feed their disaffection from learning activities, which in turn increased their likelihood of being gang-involved. One possible interpretation that could help explain why the process links may be different between GI vs. NI students and GI vs. AR students may be that, for GI vs. AR students, negligent contextual and interpersonal factors in the school may be more influential in undermining student competence that leads to increases in student disaffection, which over time contributes to the downward spiral into gang involvement. Student Profile (2): Levels of Gang Attraction

The next set of analyses focused on the motivational marker of Gang Attraction, which compared students who were attracted to gangs with students who were not attracted to gangs. In general, the motivational supports were in the expected direction for the Gang Attraction profile. That is, students who experienced a supportive and caring school environment were more engaged and less attracted to gangs, whereas students who experienced a less supportive and caring school environment were more 
disaffected from school and more attracted to gangs. The one exception was for the SSP of autonomy, which was not related to attraction to gangs.

Engagement and disaffection. Similar to the student profile (1): levels of gang involvement, both engagement and disaffection separately predicted gang attraction. That is, the more engaged students were in school, the less attracted they were to gangs, whereas the more disaffected they were in school, the more attracted they were to gangs. However, only disaffection was found to be a strong predictor for gang attraction over and above engagement. Similar to the traditional methods of self-reported gang involvement, disaffection distinguished itself as an important predictor for gang attraction. These results have important implications because prior research on ganginvolved students have typically portrayed students as disengaged from the classroom and school activities (Howell \& Egley, 2005; Reyes, 2006). This research demonstrates that disaffection is more than disengagement and reflects a maladaptive motivational state of frustration, anxiety, boredom, and anger that leads to withdrawal and passivity from participation in learning activities that over time can lead to poor grades and eventual school drop out as well as gang attraction and future gang involvement (Skinner, Furrer, Marchand, \& Kindermann, 2008).

School climate and teacher support. Both school climate and teacher support were negatively related to gang attraction. However, similar to student profile (1), only teacher support distinguished itself as a strong predictor of gang attraction over and above school climate. Students who experienced their teacher as highly involved, highly structured, and autonomy supportive, were less likely to be attracted to gangs. 
Discussion 178

Self-System Processes. Students' self-system processes of relatedness and competence showed significant negative correlations with gang attraction. However, similar to student profile (1), only relatedness was found to uniquely contribute to gang attraction over and above competence. Students who felt they belonged in school and felt valued and respected were significantly less attracted to gangs.

In understanding why autonomy was not related to gang attraction, potential explanations may consider measurement issues. It is possible that the way autonomy was measured did not capture the full spectrum of autonomy for this population of students. Only intrinsic and identified components of autonomy were used in the study. For example, student responded to items like "Why do you do your homework? Because it is fun, or Because I want to understand the subject." It is possible that for students at risk of school failure because of socio-economic factors and immigrant status, external components of autonomy would have been a better choice in measuring student autonomy. Items such as “Why do you do your homework? Because I'll get in trouble if I don't or because that's the rule may be explored as potential items that measure student autonomy. In addition, other measures of autonomy can be used such as a sense of ownership, value (e.g., items such as School is personally important to me), or amotivation (e.g., I don't do my homework) that may be a more psychological measurement of autonomy.

Achievement. Contrary to expectations, achievement was not found to be related to gang attraction. Similar to the at-risk students in the student profile (1) where no differences in achievement were found between not-involved and potential GM students, mean level differences in achievement were similar between students who 
Discussion 179

were attracted to gangs and students who were not attracted to gangs. It is possible that as students pass the stage of being merely attracted to gang to actually becoming a gang member, significant differences in achievement may be more detectable as students further become disaffected from school. However, in the interim of being attracted to and becoming further involved in gangs, students at risk do not distinguish themselves as lower achievers in school.

Process links. The SSMMD model predicted that caring and supportive school environments would be related to higher student experiences of relatedness, competence, and autonomy, which in turn would stimulate their engagement in school, in which in turn would promote achievement and protect students from becoming attracted to gangs. Similar to the student profile (1) that compared GI vs. NI students, the process links were not in the expected direction. That is, students' self-system processes were found to be the drivers that fueled student engagement, which in turn was related to supportive and caring school environments, which in turn were proximal predictors of lower attraction to gangs. In addition, the unique effects for each process link were more specific than hypothesized. A student's sense of relatedness was found to be the catalyst that sparked their engagement, which in turn was related to higher teacher support, which in turn lowered student attraction to gangs.

These findings add further support for the alternative model that was proposed for gang-involved vs. not-involved in gangs for student profile (1), in which similar process links were found. It is plausible that as students with English language barriers arrive at school, feelings of not belonging or feeling welcomed in school interfere with how much they can relate to and communicate with teachers and classmates, which over 
Discussion 180

time can erode their engagement and further disaffect them from academic

activities, which further alienates teachers and increases their attraction to gangs. In sum, students who were more attracted to gang experienced as well as received less motivational supports than students who were not attracted to gangs. Demographic characteristics such as immigrant status and speaking a language other than English at home may put students at a disadvantage for receiving motivational supports. Figure 13 depicts a possible alternative of the SSMMD for youth gang attraction.

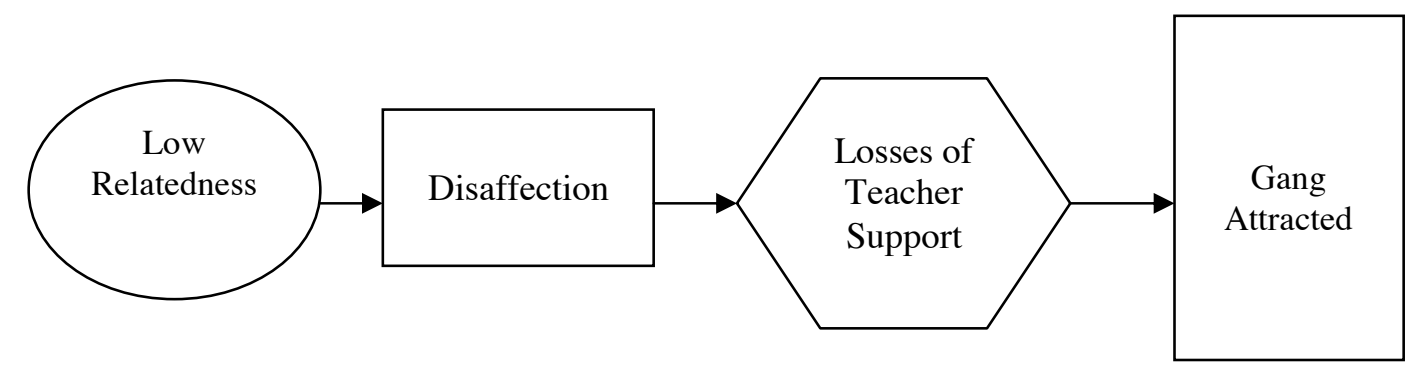

Figure 13. Alternative Motivational Model for Gang Involvement for Students who are Attracted to Gangs versus Not Attracted to Gangs.

\section{Achievement as a Motivational Outcome}

The third goal of the study was to test a general model of motivation, the selfsystem model of motivational development (SSMMD), on a heterogeneous group of youth who were socio-economically disadvantaged and ethnically/racially diverse. This study contended that the same motivational supports that promote achievement and positive youth development should also deflect risk for GI and GA. 
Discussion 181

Guided by the SSMMD model, the motivational supports were related to achievement in the expected direction. Supportive and caring school environments were related to higher student experiences of relatedness, competence, and autonomy, which in turn increased student engagement and promoted their achievement. Additionally, except for the self-system processes, each motivational support uniquely contributed to the prediction of achievement over and above other motivational supports. For the SSPs, however, only competence was found to uniquely contribute to achievement over and above the contributions of relatedness and autonomy. Relatedness and autonomy were not found to be unique predictors of achievement. These results are surprising given that research has generally found links between autonomy and better academic outcomes such as persistence, achievement, and learning (Grolnick \& Ryan, 1987; Miserandino, 1996; Patrick, Skinner, \& Connel, 1993; Vallerand, Fortier, Guay, 1997) and between relatedness and academic motivation and achievement (Garcia-Reid, Reid, \& Peterson, 2005; Goodenow, 1993; Midgley, Feldlaufer, \& Eccles, 1989; Roeser, Midley, \& Urban, 1996).

Summary. The study was located within the larger model of motivation and, in general, the pattern of findings supported its usefulness as a frame for understanding gang involvement (GI) and gang attraction (GA) in youth who are at risk based on their socio-economic, minority, and/or immigrant statuses. Youth self-reports of the major constructs in the model including experiences of teacher support and school climate, self-perceptions, and engagement all showed the expected concurrent connections. Students who experienced school environments as supportive and caring showed more engagement and achievement. Conversely, students who experienced school as 
Discussion 182

unsupportive and uncaring demonstrated more disaffection, lower levels of achievement, and more GI and GA.

Moreover, the motivational constructs seemed to connect to GI and GA in some illuminating ways. Engagement was found to be a unique predictor of GI in distinguishing youth who were gang-involved versus youth who were not involved in gangs. However, disaffection was found to be a unique predictor in distinguishing youth who were gang-involved versus youth who were at risk for gangs and for GA. Teacher support was also found to be a unique predictor of youth who were gang-involved versus youth who were not involved in gangs and GA. Evidence was also found that students' self perceptions of belongingness to the school played an important role in buffering youth from being involved in gangs as well as being attracted to gangs. Specifically, a student's sense of belonging in school was related to higher levels of school engagement and teacher support, and lower levels of gang involvement and gang attraction. Conversely, students who felt unwelcomed in school were more disaffected, had lower levels of teacher support, and were more gang-involved and attracted to gangs.

\section{Strengths and Limitations of the Study}

The results of this study should be considered in the context of its strengths and limitations. Both strengths and limitations are discussed in the following sections, including theory, measures, and the design of the study.

Theoretical model. This study proposed a motivational approach to understanding student attraction to gangs and tested an empirically supported and developmentally appropriate model of motivation on a heterogeneous high risk sample 
Discussion 183

of students. It attempted to identify and distinguish different factors that could be important to the trajectory of a youth towards gang attraction and gang involvement. By using a motivational perspective, predictors were identified that may help explain the mechanisms through which some students became attracted to and involved in gangs.

Previous research has commonly investigated the risk factors associated with youth gang involvement and the problem behaviors related to gang membership (e.g., delinquent behaviors, substance use, risky sexual behaviors, etc.) with little empirical work focusing on the day-to-day educational experiences of these students. This study expanded on previous work by including a motivational model that could help explain the mechanisms that may not only deflect youth from gang involvement, but also help promote their academic achievement and school success. Motivational components are key when thinking about how we can keep youth out of gangs while simultaneously offering a path towards greater school achievement and positive youth development.

Although it can be considered a strength that all study constructs, measures, and hypotheses (with the exception of GI and GA) were derived from a theoretically-driven model of motivational, this also presents limitations as the study did not consider other constructs not mentioned in the model. For example, incorporating constructs such as amotivation and a sense of ownership may help elucidate differences in self perceptions of autonomy in students at high risk for gang involvement and gang attraction.

Another weakness of the SSMMD model is the lack of consideration of higherorder contextual factors that may influence motivational outcomes. This study assumed that macro- level contextual risk factors for gang involvement were constant for all students because the school from which data were collected was located in a 
Discussion 184

predominantly lower working class community with a crime index 1.5 to 3 times

higher than the national average. However, no objective or subjective measure of neighborhood/community presence of gangs was used. It is plausible that there may be a higher percentage of particular ethnic gangs in the community (i.e., Latino), which could have biased results regarding gang involvement and gang attraction in certain ethnic students (i.e., Latino).

This study also assumed that students were homogeneous with respect to socioeconomic status (i.e., all students were lower working class), considering that the median family income was $\$ 41,267$ with an average family size of 3.22 persons. It is probable that there may be more variation in familial SES across students than initially assumed. These potential differences in familial SES could have influenced study results. It is plausible the students who were more attracted to and involved in gangs also came from more disadvantaged home backgrounds than their more affluent counterparts.

Measures. Although in general the assessments demonstrated satisfactory measurement properties, school climate had an internal consistency that was below satisfactory psychometric standards $(\alpha=.51)$ and two scales were barely adequate [i.e., engagement $(\alpha=.68)$ and competence $(\alpha=.69)$ ]. The low internal consistencies could have attenuated associations with these variables. For example, engagement was not found to be a proximal predictor of gang involvement (i.e., between gang-involved and at-risk students) and gang attraction. The low internal consistency of the engagement scale may have been an issue, contributing to the revision of the SSMMD model for gang-involved and at-risk students. 
Discussion 185

The primary drawback with assessments was that it relied on student selfreports. For certain constructs, such as the self-system processes, self- reports are appropriate because students are the best reporters of their own experiences of relatedness, competence, and autonomy in addition to the emotional components of engagement and disaffection in the classroom. However, including observable reports such as teacher reports on student engagement and disaffection would provide additional information on student behavior. In addition, observational methods could be used in order to add to the ecological validity of the present study.

Another limitation of the study is that there were no direct assessments of language difficulties. Students only reported on the primary languages that were spoken at home. This study found that any languages spoken at home other than English or in addition to English (i.e., bilingual households) increased the risk for youth gang involvement and gang attraction. However, it is plausible that not all students who spoke a language other than English at home had English language difficulties and, therefore, may have a lower risk for GA and GI than students with similar linguistic backgrounds but who have not yet mastered the English language.

And, finally, the levels of GI and GA did not differ across gender. Although the interactions between gender and GI and GA demonstrated that girls were fairing better than boys in certain motivational supports, it is plausible that these findings are specific to the students sampled for this study and may not reflect general patterns of GI and GA across boys and girls.

Design. A major drawback of the present study is its cross-sectional design. Although this study tested the process models of the SSMMD and revised the direction 
Discussion 186

of effects for some models, conclusions about student developmental trajectories

towards GA and GI cannot be made. Since only one time measurement was analyzed

for the present study, one cannot conclude anything about the direction of the

relationship between study constructs or process links of the model. For example, does

student disaffection lead to gang involvement or does increased gang involvement lead

to increases in student disaffection from school? A longitudinal design that includes

multiple time points would shed light on the nature and the direction of this relationship

as well as other motivational dynamics that may be related to student engagement and youth gang involvement.

A design that incorporates more frequent time measurements over the school year and across grades would be better suited to capture the dynamics as well as the developmental trajectories of students. This longitudinal design would potentially help capture and track a youth's trajectory toward gang involvement by identifying students who are (1) attracted to gangs, then (2) at-risk for gangs and, lastly, (3) gang-involved. Equally important, this design could capture the factors that buffered youth who were initially at risk for gangs, but were resilient from becoming gang-involved.

\section{Implications}

The present study has the potential to make important contributions to the literature. The first implication focuses on the utility of the study's framework for the design of prevention and intervention programs that target students at risk for GA and GI. The second topic is centered on the application and usefulness of the Gang Attraction profile to identify students who are attracted to gangs before they are actually gang-involved. And, lastly, the implications are discussed for capturing the complexity 
of the motivational processes that may be involved in deflecting risk for GA and GI while simultaneously promoting student achievement.

\section{Framework for Understanding Gang Attraction and Gang Involvement}

This study proposed a framework for understanding the attraction and motivation of youth to join gangs and argued that the benefits that gangs provide may fulfill fundamental psychological needs that may help explain why some youth join gangs. This framework suggested that youth who live in high risk environments may seek out gangs in order to satisfy basic psychological needs of protection, support, and belongingness that have not been met elsewhere. This framework considered gang membership as an adaptive response to the demands in a youth's environment. In other words, youth may seek out gangs for psychological security, a sense of belonging and support that is lacking in their lives. As such, gangs fulfill an important psychological role for these youth.

This framework has direct implications for the development and design of prevention and intervention programs that target youth at risk for joining gangs or who are already gang-involved. Specifically, prevention and intervention programs that subscribe to the study's framework should take into account the role of gangs in youths' lives by creating safe contexts that allow them to satisfy their basic psychological needs so that it will facilitate and promote their full engagement in the programs. These measures would help at-risk youth to form alternative constructive, meaningful, and stable relationships with school personnel that foster respect, belongingness, support, accountability, stability, and nurturance. 
Discussion 188

Many prevention and intervention programs have as a premise that gangs are a negative force in the lives of youth. Research has long demonstrated the negative consequences of gang involvement; however, a recent study has found the discrepancy between the expectations and reality of gang members' sense of security. Melde, Taylor, and Esbensen (2010) have documented that, although gang members' threat of actual victimization increases as a member of a gang, their anxiety associated with the threat of future victimization decreases. These findings highlight the apparent contradiction concerning the protective quality of a gang and self-reported victimization. However, these findings also reveal that although gang membership is not functional from an objective point of view, it serves as a protective function from an emotional point of view for these youth (Melde, Taylor, \& Esbensen, 2010). Therefore, if prevention and intervention programs begin with negative portrayals of gangs and its members (regardless of its truth), they may potentially threaten the values and experiences of at-risk youth and potentially lose their interest and attention and further alienate them from the programs. In addition, for those youth who have family or friends who are gang members, any negative portrayal of gangs could also threaten their values and further distance the students from benefiting from these programs.

The premise of prevention and intervention programs should include the acknowledgement that gangs may fulfill an important role in youth who live in high risk environments. These programs should be clear in delineating the benefits that gangs provide in the context of the youth's unique circumstances and acknowledge that friends and/or family of these youth may belong or have belonged to gangs. Once the benefits of belonging to a gang have been established, the costs of gang membership 
Discussion 189

should also be analyzed and examined in an interactive fashion. Students and staff should openingly discuss in a structured format the costs and benefits of gang membership from the student's point of view. By acknowledging the role of gangs in th lives of these youth without negatively portraying them sets a context of mutual respect between staff and students from which collaboration and openness to the programs' lessons and activities can begin. These programs should strive to provide a safe and neutral environment where students can come and feel respected and valued for who they are, regardless of their gang identity. These prevention and intervention programs should also implement strict behavioral and dress codes for the safety of staff and students, especially in programs where potential rival gangs may be present.

\section{Gang Attraction Profile}

This study developed a potential method for identifying youth who are attracted to gangs before they are actually gang-involved. This motivational precursor to future gang involvement may hold promise for use as an indicator for prevention purposes. Identifying youth who may be attracted to gangs before they actually become ganginvolved provides critical information because it reveals a sensitive stage that may be an important window for prevention strategies that may have greater success of avoiding the gang joining process. In addition, the Gang Attraction profile is an improvement to traditional methods of assessing risk for GI as it was able to detect important demographic characteristics in youth who were attracted to gangs that traditional methods would have overlooked. These findings have important implications for research. 
Discussion 190

Student classification. It can be argued that youth who join gangs may be divided into three types: (1) youth who are forced to join gangs through coercive methods (Johnstone, 1983), (2) youth who are expected to join gangs due to family or friend induction (Moore, 1978), and (3) youth who are voluntarily join gangs for particular needs fulfillment. Identifying this latter group was the primary goal of this study. The Gang Attraction profile not only identified students who were attracted to gangs, but also identified a group of students who were (1) at risk for gangs (i.e., students who either spent time or had friends who spent time with a gang) and were also attracted to gangs, (2) at risk for gangs, but were not attracted to gangs, (3) ganginvolved, but were not attracted to gangs, and (4) gang-involved and attracted to gangs. This classification revealed two interesting and surprising findings: (a) youth who were at risk but were not attracted to gangs and (b) youth who were gang-involved but not attracted to gangs. Youth who were identified as at risk/not attracted may be youth who have friends or family who are gang-involved and may be expected to join gangs. Although future gang involvement may be likely for this group, prevention and intervention strategies for this group may perhaps focus on lowering the youth's engagement in gang activities. In addition, youth who were identified as ganginvolved/not attracted may be youth who have become disaffected from the gang and/or its activities. This group may be searching for a way to get out of gangs and may be optimal candidates for intervention efforts.

These student classifications also provide information about the potential progression of a student towards GI that takes into account their attraction to gangs. According to this progression, a student's attraction to gangs provides a stepping stone 
Discussion 191

towards seeking out, associating, and later befriending peers who are GI, which

further increases their attraction to gangs, which over time leads to future GI. As can be seen from Table 6.1, a student progresses from being initially attracted to gangs (Step 1) to seeking out and associating with gang peers (Steps 2-5) to later becoming ganginvolved (Step 6). Students who are not attracted to gangs and do not have peers who are GI are considered to the "safe" from future GI. Students who are gang-involved, but are not attracted to gangs are considered as disaffected from the gang and may benefit from intervention strategies tailored from these youth.

Table 6.1

Attraction to Gangs as a Pathway to Gang Involvement

\begin{tabular}{|c|c|c|c|c|c|}
\hline & \multicolumn{5}{|c|}{ Levels of Gang Involvement } \\
\hline \multirow{3}{*}{$\begin{array}{l}\text { Attraction to } \\
\text { Gangs }\end{array}$} & & $\begin{array}{c}\text { No Self/No } \\
\text { Peer }\end{array}$ & $\begin{array}{c}\text { No Self/Yes } \\
\text { Peer }\end{array}$ & $\begin{array}{c}\text { Yes Self/No } \\
\text { Peer }\end{array}$ & $\begin{array}{c}\text { Yes Self/ Yes } \\
\text { Peers }\end{array}$ \\
\hline & $\mathrm{NO}$ & SAFE & STEP 2 & STEP 4 & $\begin{array}{l}\text { Youth who are } \\
\text { disaffected } \\
\text { from the gang }\end{array}$ \\
\hline & YES & STEP 1 & STEP 3 & STEP 5 & $\begin{array}{c}\text { STEP 6= Gang } \\
\text { Involved }\end{array}$ \\
\hline
\end{tabular}

Note. $*$ Self $=$ student associates with a Gang; Peers = student's friends associate with a gang.

Demographic characteristics. This study found that girls were as attracted to and involved in gangs as their males counterparts. Although research has documented an increase in female gangs (Snethen, 2010) and investigated the reasons that influenced girls to join gangs (National Youth Gang Center, 2007; Archer \& Grascia, 2006), research has normatively found higher levels of gang membership in boys than girls (Freng \& Esbensen, 2007; Howell \& Egley, 2005). These findings highlight that prevention and intervention programs should not only be designed to meet the needs of 
Discussion 192

youth who are GA and GI, but also offer programs that are gender-specific so that each gender can have a safe zone that discourages entrance to gangs through increased participation in school or other extra-curricular activities where individual talents may flourish.

The Gang Attraction profile also detected important demographic characteristics that were related to the likelihood that an ethnic minority student would be attracted to gangs. Minority students who were immigrants and spoke a language at home other than English were found to be more attracted to gangs. These findings are important for two reasons. First, the Gang Attraction profile was able to detect demographic characteristics (i.e., immigrant status and language spoken at home) that were related to a youth being attracted to gangs that were similar across all ethnic groups. The Gang Attraction profile appeared to be a sensitive indicator that was able to detect demographic similarities across ethnicities that may predispose youth to be attracted to gangs. Students who may not speak English proficiently may feel less welcomed in school, less able to relate and communicate with their teachers and classmates, and may be restricted in their ability to choose appropriate peer groups. Over time, these students may begin to associate with peers who have similar linguistic and cultural backgrounds who may happen to be gang-involved. These findings also highlight that the lack of adequate English language skills may be considered a risk factor for gang membership.

However, these findings should not be considered in isolation. That is, a minority student who is an immigrant and who speaks a language other than English at home is not necessarily at an increased risk for GA and GI. Rather, these findings are to be considered in context with the multiple risk factor framework of the study. This 
Discussion 193

study attempted to understand GA and GI utilizing the work of Howell and Egley (2005) where multiple risk factors across developmental domains were present and conceptually held constant in order to further examine the personal and social risk factors that distinguish youth who are involved in gangs from youth who are not. As such, students who are immigrants and who may speak a foreign language at home in addition to experiencing low school engagement, low school belonging, low teacher support, low achievement, and in addition to having micro- level (e.g., low parental attachment, low parental monitoring and supervision), exo- level (e.g., dangerous neighborhood with high gang presence), and macro-level risk factors (e.g., inadequate funding for extra-curricular activities, community centers for at-risk youth, etc.) have a compounding risk that increases their vulnerability of becoming attracted to and potentially involved in gangs.

Secondly, the sensitivity of the Gang Attraction profile to detect demographic similarities across ethnicities that may predispose a youth to join a gang calls into question the stereotype that links gang membership to particular ethnic minorities (i.e., Latino youth). For example, it has been suggested that the cultural values characteristic of the Hispanic/Latino culture (i.e., familismo) may explain the high rates of Latino youth who are gang-involved (Soriano, 1994). In fact, some researchers have asserted that although familismo may be a protective factor, this cultural value may also draw Latino youth to gangs (Soriano, 1994). Although evidence is preliminary, the Gang Attraction profile has discredited this assumption. By detecting a pattern of demographic characteristics across ethnicities, it brings attention to individual characteristics that, in conjunction with a host of micro- and macro-level risk factors 
Discussion 194

(i.e., dangerous neighborhood with gang presence, low parental attachment, etc.),

may have an additive and multiplicative influence in increasing the vulnerability of a youth to join a gang (Howell \& Egley, 2005). As such, a youth's immigrant status and language spoken at home may be considered additional risk factors for gang attraction and future gang involvement across ethnic groups, including white students.

Motivational Processes that Deflect Risk for GI and GA and Promote Positive Youth Development

The present study examined school engagement as a protective factor for students at risk for GI and GA and incorporated a motivational model that may explain the mechanisms through which students could potentially become increasingly disaffected from school and have a higher likelihood of becoming attracted to and involved in gangs. In testing the model of motivation, the results of this study suggest that relatedness to teachers and other school staff made a difference in students' attraction to and involvement in gangs. Moreover, a supportive school environment facilitated the process of increasing a student's sense of relatedness to school which in turn made in difference in their engagement and their levels of GI and GA. From this perspective, feeling connected to and valued by teachers and school staff plays an integral role in engaging students in school and potentially protecting them from becoming involved in gangs.

The priority of schools should be building strong relationships with students, especially with students who may be more vulnerable to feeling and becoming alienated from school. Prevention and intervention programs that target strengthening the quality of the relationship between teachers (and other school staff) and students is critical in 
Discussion 195

establishing a welcoming school environment in which students, especially

immigrant students, may develop a strong sense of belonging to the school, as well as a sense that they are a valuable contributor to the school spirit and mission. Some efforts may include matching students who are English Language Learners with peers who are bilingual to mentor and help them learn language skills easier and faster to facilitate their path of integration and participation in class activities. Teacher and educational assistants who are bilingual and bicultural can also help in these preventative efforts. These efforts make a difference in how students feel about themselves which in turn influences their engagement in school activities. In designing prevention and intervention programs, it is important to note that the same efforts that promote the quality of relationships between school staff and students not only reduces negative outcomes such as GA and GI, but also promotes academic goals and positive youth development.

However, schools and particularly teachers should not be alone in addressing the needs of at-risk students. Schools are embedded in larger social systems that should work together to enhance community inclusion, connectedness, and cohesion. Community partnerships with schools that link students and families with appropriate cultural competent social services should be an imperative in order to address cultural and linguistic needs that may influence healthy integration and connection to wider social networks. These efforts should embrace multiculturalism and celebrate multilingualism and avoid stigmatizing bilingualism. Being bilingual is correlated with contemporary and cosmopolitan identities and has long-term economic benefits as it improves student chances of success in the global jobs market (Creese et al., 2007). 


\section{Future Studies}

Discussion 196

The limitations and implications of the current study provide avenues for expanding research involving motivational processes and youth gang involvement.

First, additional research is needed to replicate the Gang Attraction student profile that identifies students who are not yet involved in gangs, but who nonetheless find gangs attractive. This research is imperative before implementing the use of the Gang Attraction profile in prevention efforts. These studies should incorporate longitudinal designs that help capture developmental trajectories in youth GI that takes into account personal attraction to gangs. In addition, studies could also investigative student characteristics that make them attractive to gangs as potential recruits. It could be that certain competencies (or the lack of) may increase a potential recruit's attractiveness to gangs as well as their attraction to gangs. These studies would help elucidate the dynamics that carry students at risk for GI and GA from one developmental step to the next. It is important to consider that there may be multiple pathways to GI. These studies would help tease out differential developmental trajectories towards GI that takes into account family, school, and peer factors. Considering that this study found a portion of $6^{\text {th }}$ graders were already attracted to and involved in gangs, future studies should also sample younger students, preferably in elementary school, to potentially capture the age when attraction to gangs begins.

Secondly, the finding that immigrant students who are not native English speakers were more attracted to gangs needs more study. Specifically, it would be interesting to compare whether students who are not native English speakers and are not attracted to gangs score higher in relatedness to their teachers than students who are not 
Discussion 197

native English speakers, but are attracted to gangs. This research would inform prevention efforts that may use a student's level of engagement versus disaffection as diagnostic of the state of their relatedness to their teachers. If relatedness is found to be low, teachers may be able to provide additional motivational supports that could encourage a greater sense of feeling welcomed and belonging. Such compensatory efforts by teachers may be one avenue that sparks student engagement and promotes learning and achievement as well as protects students from being attracted to and becoming involved in gangs.

Third, future research should incorporate objective and subjective measures of neighborhood safety and gang presence in the community. In addition, familial SES should also be examined. This study assumed all students were subjected to macro-level risk factors of gang involvement due to SES and crime index information of the community from which school data were collected. It is possible that within the low average SES status of each student, there were students whose families were higher SES than others, which could have influenced results. For example, it would be interesting to examine whether students who were attracted to and involved in gangs came from predominantly lower SES groups than their more SES affluent counterparts. Research has found that gang members are more likely to come from predominantly single parent female-headed households (Johnstone, 1983). Therefore, future studies should also examine additional family factors (e.g., family composition) to investigate whether different familial characteristics are related to gang attraction and involvement. And, lastly, this research appears promising as a source of insight in the contextual and interpersonal factors that may protect youth from joining gangs. In 
Discussion 198

testing the SSMMD, many of the process links were found to be supported in a

reverse order. Although the process links need replication for the highest risk students for gang attraction and gang involvement, the general direction seems to suggest that a student's sense of relatedness with teachers and other school staff may be more influential in the path towards gang membership. Longitudinal studies can investigate whether teachers and school staff may play a pivotal role in diminishing and perhaps even reversing the negative spirals of disaffection that can contribute to future gang attraction and involvement by creating classroom communities where all students feel welcomed and are part of a larger mission. Extra supports (e.g., bilingual teachers, extra classes in English as a Second Language, and tutoring) for students who are not native English speakers should be provided to increase their sense of belongingness to the school. Future studies focusing on these and other motivational supports may further provide information about the protective role of school engagement in preventing youth from joining gangs.

\section{Conclusion}

Incorporating a motivational model, this dissertation explores contextual and personal factors that may protect youth from being attracted to and involved in gangs. Further, this study offers an innovative method of identifying youth who are attracted to gangs before they are actually gang-involved. Taking a motivational and developmental perspective in examining youth gang involvement allows for a more comprehensive picture in distinguishing the potential stepping stones in a youth's trajectory towards gang involvement as well as how the school context can influence this trajectory. 


\section{References}

Ainsworth, M. D. S. (1979). Infant-mother attachment. American Psychologist, 34, 932- 937.

Ainsworth, M.D.S. (1991). Attachments and other affectional bonds across the life cycle. In: C. M. Parkes, J. Stevenson-Hinde \& P. Marris (eds.), Attachment across the life cycle. New York: Routledge. Pp. 33-51.

Ainsworth, U.W. (2002). Why does it take a village? The mediation of neighborhood effects on educational achievement. Social Forces, 81, 117-152.

Aisenberg, E., \& Mennen, F.E. (2000). Children exposed to community violence: Issues for assessment and treatment. Child \& adolescent Social Work Journal, 17, 341360 .

Allen, J. P. \& Land, D. (1999). Attachment in adolescence. J. Cassidy \& P. R. Shaver (Eds.), Handbook of attachment theory and research, New York: Guilford.

Archer, L., \& Grascia, A.M. (2006). Girls, gangs, and crime: Profile of the young female offender. Journal of gang Research, 13, 37-49.

Arfaniarromo, A. (2001). Toward a psychological and sociocultural understanding of achievement motivation among Latino gang members in U.S. schools. Journal of Instructional Psychology, 28, 123-136.

Baron, R.M., \& Kenny, D.A. (1986). The moderator-mediator variable distinction in social psychological research: Conceptual, strategic, and statistical considerations. Journal of Personality and Social Psychology, 51, 1173-1182.

Battistich, V., Schaps, E., Watson, M., \& Solomon, D. (1996). Prevention effects of the child development project: Early findings from an on-going multi-site demonstration trail. Journal of Adolescent Research, 11, 6-11.

Baumeister, R.F., \& Leary, M.R. (1995). The need to belong: Desire for interpersonal attachments as a fundamental human motivation. Psychological Bulletin, 117, 497- 529.

Belitz, J., \& Valdez, D. (1994). Clinical issues in the treatment of Chicano male gang youth. Hispanic Journal of Behavioral Sciences, 16, 57-74.

Bjerregaard, B. (2002). Self-definitions of gang membership and involvement in delinquent activities. Youth \& Society, 34, 31-54. 
References 200

Bjerregaard, B., \& Smith, C. (1993). Gender differences in gang participation, delinquency, and substance use. Journal of Quantitative Criminology, 9, 329355.

Bowlby, J. (1969). Attachment and Loss. Vol. 1. Attachment. New York: Basic Books.

Brewster, A.B., \& Bowen, G.L. (2004). Teacher support and the school engagement of Latino middle and high school students at risk of school failure. Child and Adolescence Social Work, 21, 47- 67.

Bowen, N.K., \& Bowen, G.L. (1999). Effects of crime and violence in neighborhoods and schools on school performance of adolescents. Journal of Adolescent Research, 14, 319-342.

Bowen, G.L., \& Chapman, M.V. (1996). Poverty, neighborhood danger, social support, and the individual adaptationamong at-risk youth in urban settings. Journal of Family Issues, 17, 641-666.

Bronfenbrenner, U. (1979). The ecology of human development: Experiments by nature and design. Cambridge, M.A.: Harvard University Press.

Bronfenbrenner, U., \& Morris, P.A. (1998). The ecology of developmental processes. In W. Damon (Ed.), Handbook of Child Psychology, $5^{\text {th }}$ edition (pp. 993-1028). New York: John Wiley \& Sons, Inc.

Calabrese, R. L., \& Noboa, J. (1995). The choice of gang membership by MexicanAmerican adolescents. The High School Journal, 78, 226-235.

Ceballo, R., Dahl, T.A., Aretakis, M.T., \& Ramirez, C. (2001). Inner-city children's exposure to community violence: How much do parents know? Journal of Marriage and Family, 63, 927-940.

Connell, J. P. (1990). Context, self, and action: A motivational analysis of self-system processes across the lifespan. In D. Ciccechetti (Ed.), The self in transition:

From infancy to childhood (pp. 61-97). Chicago: University of Chicago Press.

Connell, J. P. \& Wellborn, J. G. (1991). Competence, autonomy, and relatedness: A motivational analysis of self- system processes. In M. R. Gunnar \& L. A. Sroufe (Eds. ), Self processes in development: Minnesota symposium on child psychology (Vol. 23, pp. 43-77). Hillsdale, NJ: Erlbaum.

Connell, J. P., Halpern-Felsher, B. L., Clifford, E., Crichlow, W., \& Usinger, P. (1995). Hanging in there: Behavioral, psychological, and contextual factors affecting 
References 201

whether African-American adolescents stay in high school. Journal of Adolescent Research, 10, 41-63.

Connell, J. P., Spencer, M. B., \& Aber, J. L. (1994). Educational risk and resilience in African American Youth: Context, self, and action outcomes in school. Child Development, 65, 493-506.

Creese, A., T. Bhatt, B., Blackledge, A., Hamid, S., Li, W., Lytra, V., Martin, P., Wu, C.J., \& Yağcıŏglu-Ali, D. Forthcoming 2007. Investigating Multilingualism in Complementary Schools in Four Communities. Final Report. RES-000-23-1180. University of Birmingham.

Daly, B.P., Shin, R.Q., Thakral, C, Selders, M., \& Vera, E. (2009). School engagement among urban adolescents of color: Does perception of social support and neighborhood safety really matter? Journal of Youth Adolescence, 38, 63-74.

Deci, E. L. \& Ryan, R. M. (1985). Intrinsic motivation and self-determination in human behavior. New York: Plenum Press.

De Bruyn, E.H., Dekovic, M., \& Meijnen, G.W. (2003). Parenting, goal orientations, classroom behavior, and school success in early adolescence. Applied Developmental Psychology, 24, 393-412.

Dishion, T. J., Nelson, S.E., \& Yasui, M. (2005). Predicting early adolescent gang involvement from middle school adaptation. Journal of Clinical Child and Adolescent Psychology, 34, 62-73.

Dukes, R.L., \& Stein, J.A. (2003). Gender and gang membership: A contrast of rural and urban youth on attitudes and behavior. Youth \& Society, 34, 415-440.

Eccles, J. S., \& Roeser, R. W. (2003). Schools as developmental Contexts. In G. R. Adams \& M.D. Berzonsky (Eds.). Blackwell Handbook of Adolescence. Oxford, UK. Blackwell Publishing.

Egley, A., Jr., Howell, J.C., and Major, A. K. 2006. National Youth Gang Survey: 19992001. Washington, DC: U.S. Department of Justice, Office of Juvenile Justice and delinquency Prevention.

Esbensen, F.A.,Winfree, L.T., He, N., \& Taylor, T.J. (2001). Youth gangs and definitional issues: When is a gang a gang, and why does it matter? Crime and Delinquency, 47, 105-130.

Escribano, L. M. (2007). Why are adolescents attracted to and motivated to join gangs? An examination of proximal processes underlying gang membership in Latino youth. Unpublished master's thesis, Portland State University, Portland. 
Fredricks, J.A., Blumenfeld, P.C., \& Paris, A.H. (2004). School engagement: Potential of the concept, state of the evidence. Review of Educational Research, 74, 59-109.

Freng, A., \& Esbensen, F. (2007). Race and gang affiliation: An examination of multiple marginality. Justice Quarterly, 24, 600-628.

Furlong, M.J., Whipple, A.D., St. Jean, G., Simental, J., Soliz, A., \& Punthuna, S. (2003). Multiple contexts of school engagement: Moving toward a unifying framework for educational research and practice. The California School Psychologist, 8, 99- 113.

Gabarino, J. (2001). An ecological perspective on the effects of violence on children. Journal of Community Psychology, 29, 361-378.

Garcia-Reid, P., Reid, R, \& Peterson, N. (2005). School engagement among Latino youth in an urban middle school context: Valuing the role of social support. Education and Urban Society, 37, 257-275.

Gibson, M.A., \& Bejinez, L.F. (2002). Dropout prevention: How migrant education supports Mexican youth. Journal of Latinos and Education, 3, 155-175.

Goldstein, A.P. (1991). Delinquent Gangs: A Psychological Perspective. Research Press, Champaign.

Goodenow, C. (1993). The psychological sense of school membership among adolescents: Scale development and educational correlates. Psychology in the Schools, 30, 79-90.

Gorski, J.D., \& Pilotto, L. (1993). Interpersonal violence among youth: A challenge for school personnel. Educational Psychology Reviews, 5, 35-61.

Gottfredson, G. D., and Gottfredson D. C. October 2001. Gang Problems and Gang Programs in a National Sample of Schools. Ellicott City, MD: Gottfredson Associates, Inc. http://www.gottfredson.com/gang.htm

Gurin, Patricia. "The Compelling Need for Diversity in Education," January 1999. Expert report prepared for the lawsuits Gratz and Hamacher v Bollinger, Duderstadt, the University of Michigan, and the University of Michigan College of $L S \& A$, U.S. District Court, Eastern District of Michigan, Civil Action No. 9775231; and Grutter v Bollinger, Lehman, Shields, the University of Michigan and the University of Michigan Law School, U.S. District Court, Eastern District of Michigan, Civil Action No. 97-75928. [On-line]. Available: http://www.umich.edu/ urel/admissions/legal/expert/gurintoc.html 
References 203

Hamre, B.K., \& Pianta, R. C. (2001). Early teacher-child relationships and the trajectory of children's school outcomes through eighth grade. Child Development, 72, 625-638.

Hawkins, J.D., Catalano, R.F., and Miller, J. Y . (1992). Risk and protective factors for alcohol and other drug problems in adolescence and early childhood: Implications for substance abuse prevention. Psychological Bulletin, 112, 64105.

Hazan, C., \& Zeifman, D. (1994). Sex and the psychological tether. Advances in Personal Relationships, 5, 151-177.

Hill, K.G., Howell, J.C., Hawkins, J.D., \& Battin-Pearson, S.R. (1999). Childhood risk factors for adolescent gang membership: Results from the Seattle Social Development Project. Journal of Research in Crime and Delinquency, 36, 300322.

Hirsto, L. (2001). Children in their learning environment: Theoretical perspectives. Unpublished doctoral dissertation, University of Helsinki, Helsinki, Finland.

Hoffman, J., \& Xu, J. (2002). School activities, community service, and delinquency. Crime \& Delinquency, 48, 568-592.

Houchhaus, C., \& Sousa, F. (1987). Why children belong to gangs: a comparison of expectations and reality. The High School Journal, 71, 74-77.

Howell, J. C. (2004). Youth gangs: Prevention and intervention. In P. Allen-Meares \& M.W. Fraser (Eds.), Intervention with children and adolescents: An interdisciplinary perspective (pp. 493- 514). Boston: Allyn \& Bacon.

Howell, J. C. (2006). The impact of gangs on communities. NYGC Bulletin No. 2. Tallahassee, FL: National Youth Gang Center.

Howell, J. C., \& Egley, A. (2005). Moving risk factors into developmental theories of gang membership. Youth Violence and Juvenile Justice, 3, 334-354.

Howell, J. C., \& Lynch, J. (2000). Youth gangs in schools. Juvenile Justice Bulletin. U.S. Department of Justice. Washington, D.C

Howell, J. C., Egley, A., Jr., and Gleason, D. K. (2002). Modern Day Youth Gangs. Bulletin. Youth Gang Series. Washington, DC: U.S. Department of Justice, Office of Juvenile Justice and Delinquency Prevention. 
References 204

Huff, C.R. (1992). The New York Gangs: Social Policy and Malignant Neglect. In Schwartz, I.M. (Eds.). Juvenile Justice and Public Policy: Toward a National Agenda, Lexington Books, New York, pp. 20-44.

Johnstone, J.W.C. (1983). Recruitment of a youth gang. Youth \& Society, 14, 281-300.

Kindermann, T. A. (1993). Natural peer groups as contexts for individual development: The case of children's motivation in school. Developmental Psychology, 29, 970-977.

Kindermann, T. A. (2007). Effects of naturally-existing peer groups on changes in academic engagement in a cohort of sixth graders. Child Development, 78, 1186-1203.

Laney, B.B., Gordon, R.A., Loeber, R., Stouthamer-Loeber, M., \& Farrington, D.P. (1999). Boys who join gangs: A prospective study of predictors of first gang entry. Journal of Abnormal Child Psychology, 27, 261-276.

Lawrence-Lightfoot, S. (1983). The good high school: Portraits of character and culture. New York: Basic Books.

Loeber, R., \& Farrington, D.P. (Eds.). (1998). Serious and violent juvenile justice offenders: Risk factors and successful interventions. Thousand Oaks, CA: Sage.

Loeber, R., \& Farrington, D.P. (Eds.). (2001). Child delinquents: Development, intervention, and service needs. Thousand Oaks, CA: Sage.

Loeber, R., Wung, P., Keenan, K., Giroux, B., Stouthamer-Loeber, M., Van Kammen, W. B., \& Maughan, B. (1993). Developmental pathways in disruptive child behavior. Development and Psychopathology, 5, 103-133.

Lopez, D.A., \& O’ Donnell Brummett, P. (2003). Gang membership and acculturation: ARSMA-II and choloization. Crime \& Delinquency, 49 (4), $627-$ 642.

Maddox, S., \& Prinz, R. J. (2003). School bonding in children and adolescents: conceptualization, assessment, and associated variables. Clinical Child and Family Psychology Review, 6, 31-49.

Marchard, G., \& Skinner, E. (2007). Motivational dynamics of children's academic help-seeking and concealment. Journal of Educational Psychology, 99, 6582. 
References 205

Melde, C., Taylor, T., Esbensen, F. (2009). "I got your back": An examination of the protective function of gang membership in adolescence. Criminology, 47, 565594.

Miller, W.B. (2001).The Growth of Youth Gang Problems in the United States: 19701999 Report. Washington, D.C: U.S. Department of Justice, Office of Justice Problems, Office of Juvenile Justice and Delinquency Prevention. Retrieved November 10, 2003, from the Institute for Intergovernmental Research Web site: http://www.iir.com/nygc/faq.htm\#miller2001.

Moore, J.W. (1978). Homeboys: Gangs, Drugs and Prison in the Barrios of Los Angeles. Philadelphia, PA: Temple University Press.

Morrison, G.M., Robertson, L., Laurie, B., \& Kelly, J. (2002). Protective factors related to antisocial behavior trajectories. Journal of Clinical Psychology, 58, 277-290.

Osborne, J.W . (1997). Race and academic disidentification. Journal of Educational Psychology, 89, 728-735.

National Center for Educational Statistics. (2002). The condition of education 2002 (NCES 2002-025). Washington, DC: U.S. Department of Education, Office of Educational Research and Improvement.

National Youth Gang Survey Analysis. (2007). Retrieved 2/12/2010 from http://www.iir.com/nygc/nygsa/.

Parks, C. (1995). Gang behavior in the schools: reality or myth? Educational Psychology Review, 7, 41- 68.

Peacock, M.J., McClure, F., \& Agars, M.D. (2003). Predictors of delinquent behaviors among Latino youth. The Urban Review, 35, 59- 72.

Reyes III, R. (2006). Cholo to 'Me': From peripherality to practicing student success for a Chicano former gang member. The Urban Review, 38, 165- 186.

Roderick, M. (2003). What's happening to the boys? Early high school experiences and school outcome among African American male adolescents in Chicago. Urban Review, 38, 538-607.

Roeser, R. W., Urban, T. C., \& Stephens, J. M. (2008). School as a context of student motivation and achievement. In Wentzel, K. and Wigfield, A., (Eds.). Handbook on Motivation at School. 
Schafer, J. L. \& Graham, J. W. (2002). Missing data: Our view of the state of the art. Psychological Methods, 7, 147-177.

Snethen, G. (2010). Preventing female gang involvement: Development of the JointInterest Core and Balance Model of mother/daughter leisure functioning. Aggressive and Violent Behavior, 15, 42-48.

Stanton-Salazar, R.D. (1997). A social capital framework for understanding the socialization of racial minority children and youth. Harvard Educational Review, 67, 1-40.

Stanton-Salazar, R.D., Chavez, L.F., \& Tai, R.H. (2001). The help seeking orientations of Latino and non- Latino urban high school students: A critical-sociological investigation. Social Psychology of Education, 5, 49-82.

Saltzman, W.R., Pynoos, R.S., Layne, C.M., Steinberg, A.M., \& Aisenberg, E. (2001). Trauma and grief focused intervention for adolescents exposed to community violence: Results of a school-based screening and group treatment protocol. Group Dynamics, 5, 291-303.

Schultz, G.F. (1993). Socioeconomic advantage and achievement motivation: Important mediators of academic performance in minority children in urban schools. Urban Reviews, 25, 221-232.

Shernoff, D.J., \& Schmidt, J.A. (2008). Further evidence of an engagementachievement paradox among U.S. high school students. Journal of Youth Adolescence, 37, 564-580.

Sirin, S.R. (2005). Socioeconomic status and academic achievement: A meta-analytic review of research 1991- 2000. Review of Educational Research, 75, 417-453.

Skinner, E. A. \& Belmont, M. J. (1993). Motivation in the classroom: Reciprocal effects of teacher behavior and student engagement across the school year. Journal of Educational Psychology, 85, 571-581.

Skinner, E. A. \& Edge, K. (2002). Parenting, motivation, and the development of coping. In L. J. Crockett (Ed.), The Nebraska Symposium on Motivation: Motivation, agency, and the life course (pp. 77-143). Lincoln, NB: University of Nebraska Press.

Skinner, E. A., Furrer, C., Marchand, G., \& Kindermann, T. (2008). Engagement and disaffection in teh classroom: Part of a larger motivational dynamic? Journal of Educational Psychology, 100, 765-781. 
References 207

Skinner, E. A. \& Wellborn, J. B. (1994). Coping during childhood and adolescence: A motivational perspective. In D. Featherman, R. Lerner, \& M. Perlmutter (Eds.), Life-span development and behavior (Vol. 12, pp. 91-133). Hillsdale, NJ: Erlbaum.

Skinner, E. A. \& Wellborn, J. B. (1997). Children's coping in the academic domain. In S. A. Wolchik \& I. N. Sandler (Eds.), Handbook of children's coping with common stressors: Linking theory and intervention (pp. 387-422). New York: Plenum Press.

Skinner, E.A., Wellborn, J.G., \& Connell, J. P. (1990). What it takes to do well in school and whether I've got it: A process model of perceived control and children's engagement and achievement in school. Journal of Educational Psychology, 82, 22-32.

Skinner, E.A., Wellborn, J.G., \& Regan, C. (1986). The "Parents as Social Context Questionnaire (PASCQ): Parent-and child-reports of parent involvement, structure, and autonomy support. (Tech Rep.). Rochester, NY: University of Rochester.

Soriano, F. (1994). U.S. Latinos. In L. Eron, J. Gentry, P. Schlegel (Eds.), Reason to hope: A psycho-social perspective on violence and youth. Washington DC: American Psychological Association.

Spencer, M.B. (2006). Phenomenology and ecological systems theory: Development of diverse groups (Chapter 15). In W. Damon, \& R. Lerner (Eds.), Handbook of child psychology, vol. 1 (R. Lerner, Ed.): Theoretical models of human development (6th ed.), (pp. 829-893). New York: Wiley.

Spergel, I.A., Chance, R.L., \& Curry, G.D. (1990). National Youth Gang Suppression and Intervention Program (NIJ Report No. 222), Office of Juvenile Justice and Delinquency Prevention. Washington, D.C.

Thompson, R. (2005). Multiple relationships multiply considered. Human Development, 48, 102-107.

Thornberry, T. P. (1987). Toward an interactional theory of delinquency. Criminology, $25,863-891$.

Thornberry, T. P., Huizinga, D., and Loeber, R. (2004). "The Causes and Correlates Studies: Findings and Policy Implications," Juvenile Justice, 10(1), 3-19.

Thornberry, T. P., Krohn, M. D., Lizotte, A. J., \& Chard-Wierschem, D. (1993). The role of juvenile gangs in facilitating delinquent behavior. Journal of Research in Crime and Delinquency, 30, 55-87. 
Thornberry, T. P., Krohn, M. D., Lizotte, A. J., Smith, C. A., and Tobin, K. (2003). Gangs and Delinquency in Developmental Perspective, New York, NY: Cambridge University Press.

Thornberry, T.P., \& Krohn, M.D. (2001). The development of delinquency: An interactional perspective. In S. O. White (Eds.), Handbook of youth and justice (pp. 289-305). New York: Plenum.

Tucker, C.M., Zayco, R. A., Herman, K.C., Reinke, W.M., Trujillo, M., Carraway, K., Wallack, C., Ivery, P. (2002). Teacher and child variables as predictors of academic engagement among low-income African American children. Psychology in the Schools, 39, 477- 488.

U.S. Department of Education, National Center for Education Statistics. (2008). The Condition of Education 2008 (NCES 2008-031), Retrieved January 13, 2009 from http://nces.ed.gov/FastFacts/display.asp?id=16.

Vigil, J.D. (1988). Group processes and street identity: Adolescent Chicano gang members. Ethos, 16, 421-445.

Vigil, J.D. (1999). Street and schools: how educators can help Chicano marginalized gang youth. Harvard Educational Review, 69, 270-288.

Walker-Barnes, C. J., \& Mason, C.A. (2001). Ethnic differences in the effect of parenting on gang involvement and gang delinquency: A longitudinal, hierarchical linear modeling perspective. Child Development, 72, 1814-1831.

Wallace, L. H., \& May, D. C. (2005). The impact of parental attachment and feelings of isolation on adolescent fear of crime at school. Adolescence, 40, 457-475.

Wellborn, J.G., Connell, J.P., Skinner, E.A., \& Kindermann, T. A motivational perspective on engagement and disaffection: Conceptualization and assessment of children's behavioral and emotional involvement in academic activities in the classroom. In preparation.

Wentzel, K.R. (1999). Socio-motivational processes and interpersonal relationships: Implications for understanding motivation at school. Journal of Educational Psychology, 91, 76-97.

Wigfield, A., Eccles, J. S., Schiefele, U., Roeser, R., \& Davis-Kean, P. (2006). Development of achievement motivation. In W. Damon (Series Ed.) \& N. Eisenberg (Volume Ed.), Handbook of Child Psychology, 6th Ed. Vol.3. Social, emotional, and personality development (pp. 933-1002). New York: John Wiley. 
References 209

Wooley, M.E., Bowen, G.L. (2007). In the context of risk: Supportive adults and the school engagement of middle school students. Family Relations, 56, 92-104.

Wyrick, P. A. (2000). Vietnamese youth gang involvement (Fact Sheet 2000-01).

Washington, DC: Office of Juvenile Justice and Delinquency Prevention.

Yoder, K.A., Whitbeck. L.B., \& Hoyt, D.R. (2003). Gang involvement and membership among homeless and runaway youth. Youth \& Society, 34, 44146.

Zeldin, S. (2004). Preventing youth violence through the promotion of community engagement and membership. Journal of Community Psychology, 32, 623-641. 